\title{
Aproximación a la obra científica del Comandante médico Fidel Pagés Miravé
}

\author{
Velázquez Rivera I. ${ }^{1}$
}

Sanid. mil. 2011; 67 Suplemento (1): 131-134; ISSN: 1887-8571

\begin{abstract}
RESUMEN:
A. Faulconer en su libro «Foundations of Anesthesiology» refiriéndose a Pagés afirma: «No se encuentran apenas datos sobre la vida de este importante cirujano español». Esta concluyente afirmación unida a imperdonables omisiones de la figura de Pagés por historiógrafos de la anestesia o de la cirugía, y a graves errores en datos sobre su vida u obra, nos movió a realizar una aproximación, lo más exacta posible, a la obra científica del Comandante Médico Fidel Pagés Miravé. Escasas han sido las figuras españolas que hayan aportado alguna interesante novedad al mundo de la anestesia. Pero ninguna tan injustamente tratada y olvidada como la de Pagés, verdadero pionero de la anestesia epidural, que él denominaría Anestesia Metamérica en su artículo publicado en el mes de marzo de 1921 en la Revista Española de Cirugía, por él fundada. Años después, en 1931, Dogliotti, Profesor de Cirugía de Modena publicó sus experiencias sobre la anestesia epidural, a la que llamó Anestesia Peridural Segmentaria, ignorando el trabajo de Pagés publicado diez años antes. El trabajo de Dogliotti fue rápidamente reconocido, asumiendo todos los méritos de la paternidad de la técnica epidural, quedando Pagés relegado a un olvido injusto que con este trabajo tratamos de reparar. En la necesidad de ubicar a Pagés en el entorno en el que desarrolló su obra científica, tratamos de realizar una visión de las principales aportaciones quirúrgicas y anestésicas de aquellos cirujanos que fueron coetáneos con nuestro personaje. Con especial abundamiento, profundizamos en los precedentes históricos de las técnicas de anestesia intradural o caudal, así como las descripciones posteriores a Pagés sobre el abordaje lumbar de la vía epidural. A su vez realizamos un análisis comparativo del trabajo de Pagés sobre la anestesia metamérica, en relación con la actual vigencia que puedan tener sus observaciones, descripciones, indicaciones y contraindicaciones. La idea central del trabajo versará sobre el reconocimiento de Pagés como verdadero promotor del abordaje epidural con fines quirúrgicos. Así como valorar una obra que, aunque corta, bien pudiera incluirse entre los mejores cirujanos españoles de principio de siglo. Nos centramos, para la recopilación de datos, en sus expedientes académicos (Zaragoza y Madrid), en su hoja de servicios como Médico Militar y en las publicaciones sobre Historia de la Anestesia, Historia de la Cirugía y de la Sanidad Militar. Para mejor conocer al Personaje hemos localizado a su familia y revisamos los diarios oficiales del Ministerio de la Guerra las colecciones completas de la principal prensa de la época, especialmente las de Madrid y Melilla.
\end{abstract}

PALABRAS CLAVE: Cirujano, Militar, Anestesia, Metamérica, Pionero.

\section{Approach to the scientific work of medical Commander Fidel Pagés Miravé SUMMARY:}

A. Faulconer in his book «Foundations of Anesthesiology», referring to Pagés says: «There are little data on the life of this important Spanish surgeon». This conclusive statement attached to unforgivable omissions to the figure of Pagés by historians of anesthesia or surgery, and to serious errors in facts about his life or work, led us to make an approximation as accurate as possible, to the scientific work of the Medical commander Fidel Pagés Miravé. Few figures have been the Spanish who have made some interesting news to the world of anesthesia. But none so wronged and forgotten like Pagés, a true pioneer of epidural anesthesia, that he would call Metameric Anesthesia in his article published in the month of March, 1921, in the Spanish Journal of Surgery, founded by him. Years later, in 1931, Dogliotti, Professor of Surgery in Modena published his experiences on the epidural, which he called Segmental Epidural Anesthesia, ignoring the work published ten years earlier by Pagés. Dogliotti's work was quickly recognized, assuming all the merits of the paternity of the epidural technique, being Pagés relegated to an unfair oblivion that this work is trying to repair. Feeling the need to locate Pagés on the environment in which he developed his scientific work, we try to realize a vision of the main surgical and anesthetic contributions of surgeons who were contemporaries with Pagés. With special sake, we delve into the historical precedents of spinal or caudal anesthesia techniques, as well as Pagés later descriptions on the lumbar approach of the epidural route. At the same time, we conducted a comparative analysis of the work of Pagés on metameric anesthesia in relation to the current force that may have their comments, descriptions, indications and contraindications. The central idea of the work will focus on the recognition of Pagés as a true promoter of the epidural approach with surgical aims. And to evaluate a work which, though short, may well be included among the best spanish surgeons in the beginning of the century. We focus for the collection of data on their records (Zaragoza and Madrid), on his records as a military doctor and on publications about the History of Anesthesia, history of Surgery and of the Military Health. To better know his character we have located his family and review the official journals of the Ministry of War, the complete collections of the main newspapers of the time, especially in Madrid and Melilla.

KEY WORDS: Surgeon, Military, Anesthesia, Metamerism, Pioneer.

${ }^{1}$ Cte. Médico (Excedencia). Hospital de Alta Resolución de Guadix. Servicio de Anestesia.

Dirección para correspondencia: ignave150@hotmail.com

Recibido: 28 de junio de 2010

Aceptado: 17 de febrero de 2011 


\section{INTRODUCCIÓN}

El objetivo de este estudio no es otro que el de clarificar y resaltar el papel que le corresponde al malogrado cirujano Pagés dentro de la Historia de la Medicina. Creemos que se trata de uno de los personajes más injustamente tratados por los distintos historiadores y biógrafos de la Medicina. Probablemente su temprano fallecimiento y una insuficiente difusión de sus escritos entre sus coetáneos, hayan contribuido decisivamente a este olvido. Hoy, incluso, no existe ninguna biografía o estudio monográfico completo y exhaustivo sobre su obra.

En los libros, publicaciones, o, cuando no, artículos que recogen algunos aspectos suyos, su imagen queda, en algunos casos, tergiversada, falseada o recortada. A veces se trata de importantes errores biográficos científicos, en otras ocasiones son graves omisiones. Omisiones que podemos esperar de algunos historiadores foráneos, pero que difícilmente se comprende cuando son historiadores hispanos.

La obra médico-científica, en lo que respecta a las aportaciones en el campo de la Anestesia de Pagés, se encuentra a la altura de otros pioneros españoles como Basilio San Martín (que describió a la perfección y por primera vez las alteraciones que presentaban a la Anestesia los pacientes alcoholizados), González Olivares (que en su cátedra de Santiago exponía las ventajas del éter como anestésico de elección), Suárez de Mendoza (creador de un original sistema anestésico conocido como «Método Español» consistente en una mezcla de oxigeno y cloroformo), Alejandro San Martin (que incorporó al método español un sofisticado aparato para su administración) o como el Ginecólogo Fargas o Eulogio Corvera.(1) del mismo modo, los trabajos y publicaciones quirúrgicas y traumatológicas que realizó, no desmerecen tampoco de las efectuadas por las grandes figuras de la Cirugía Española de la época.

Entre éstas destacan: Diego de Argumosa y Obregón, Víctor Escribano, Federico Rubio y Gali, Federico Oloriz y su gran amigo José Ribera y Sans, el cual en el Congreso Internacional de Cirugía celebrado en Bruselas durante 1908, expuso diversos procedimientos quirúrgicos llevados a cabo en España. Finalizada la exposición exclamó asombrado el Profesor de Cirugía de Freiburgo, Vicent Czerney «no teníamos ni idea de nada de esto» (2).

El olvido, y en algunas ocasiones ignorancia, hacia la medicina española era la nota dominante en el final del siglo XIX y principios del XX. La desgarradora frase que el Dr. Víctor Escribano incluye en su discurso leído con motivo de la solemne inauguración del Curso Académico 1916-1917, en la Universidad de Granada al afirmar: «Ninguno de los grandes adelantos de la cirugía y anestesia han nacido en España durante el siglo XIX», (2) es un índice de la necesidad que tenía la cirugía hispana por encontrar innovadores que realzaran el nivel científico y la propia autoestimación.

Por estas razones aludidas no comprendemos cómo una figura auténticamente original e introductor de técnicas nuevas, como Pagés, no consigue llamar la atención, primero de sus contemporáneos y posteriormente de los investigadores de la historia. Pocas veces nos encontraremos un médico que consiga aportar importantes novedades en diversos campos de la medicina y a la vez se le reconozca tan poco.
Se puede entender que el nombre de Pagés no quede reflejado en los grandes tratados de Historia de la Medicina, como los escritos por los españoles Sánchez Guisande, Granjel, Barquín o Laín Entralgo $(3,4,5,6)$; pero es absolutamente imperdonable las omisiones habidas en publicaciones más específicas como el «Libro de homenaje a Goyanes» (7.). En el capítulo dedicado a los progresos de la anestesia, hace referencia a los descritos por Cathelin (inyección de sustancias anestésicas en el espacio epidural a través del hiato sacro), Kappis (difusión de anestésicos desde los espacios paravertebrales por los agujeros de conducción), o por el propio Goyanes, que de forma magistral define la anestesia intraarterial, auténtica técnica original.

Como decíamos, en este capítulo se relatan estas innovaciones, pero es realmente injusto que no haga ninguna referencia a las aportaciones de Pagés a este campo.

Estimamos que el homenaje a Goyanes no hubiera desmerecido un ápice si se llega a reconocer los méritos de otros pioneros españoles en la misma materia.

Continuando con las graves omisiones de la figura de Pagés, una que resulta especialmente curiosa, es la de Álvarez Sierra en su libro «Historia de la cirugía española» (8) o la de García del Real en sus artículos aparecidos en Medicamenta $(9,10)$ con motivo del centenario del descubrimiento de la anestesia quirúrgica.

También la ignorancia del nombre de Pagés es la nota dominante de las últimas revisiones de historia de la anestesia, efectuadas por distintas revistas médicas como: Revista Española de Anestesiología y Reanimación, Gaceta Médica Mejicana y Gaceta Médica de Bilbao $(13,14,15,16)$ no apareciendo Pagés entre los innovadores o aportadores de nuevas técnicas.

Existen a su vez, amplios estudios históricos sobre Sanidad Militar. Pagés desarrolló gran parte de su vida profesional dedicado a la institución castrense, pero en ninguno de esos estudios históricos se refleja adecuadamente la importante labor que llevó a efecto. En algunos trabajos científicos sobre esta materia queda patente el olvido $(17,18,19,20,21,22,23)$.

Pagés intervino también de forma muy activa en otras importantes instituciones sanitarias como Beneficencia y realizó un elevado número de intervenciones quirúrgicas en el Hospital General. Sobre estos centros se ha escrito de forma prolífica, pero en ninguno se considera la figura de nuestro personaje $(24,25,26,27)$.

Hasta ahora hemos relatado las ausencias acaecidas en libros o artículos referentes a la historia de la medicina española o escrita por historiadores españoles. En lo concerniente a historiadores extranjeros, son así mismo amplias las omisiones.

Podemos considerar como razonable y lógico que no se recoja ningún dato sobre Pagés en los grandes tratados de Historia de la Medicina Universal. ( 28, 29, 30, 31, 32, 33, 34, 35, 36, 37, $38,39,40,41)$ Pero de nuevo tenemos que volver a insistir en nuestra extrañeza al comprobar cómo en revistas o publicaciones específicas sobre la historia de la anestesia, no se hace la menor referencia a los artículos de Pagés. Incomprensibles son por tanto los olvidos de Bobbio, $(42,43,44)$ y los de otros autores (45, $46,47,48,49,50,51,52,53,54,55,56,57)$ Más extraño resulta entender que Lund $(58,59)$, en sus artículos dedicados a la historia de la anestesia epidural, no mencione el trabajo de Pagés «La anestesia metamérica» como uno de los pioneros en la materia, no incluyéndolo tampoco entre la bibliografía consultada. Un escritor francés, Picard, tiene un interesante artículo dedicado a 
la evolución de la anestesia para empleo militar (60) en el que comete la injusticia de no constatar los resultados y experiencias aportadas por Pagés durante la campaña de África de 1921.

Como hemos podido comprobar hasta el momento, el nombre y la obra científico-médica de Pagés han sido ignorados por un gran número de historiadores. Pero no solamente este injusto olvido nos ha movido a dedicarle este trabajo a Pagés. También nos ha impulsado la cantidad de errores e inexactitudes que han cometido otros autores al hacer referencia a su obra.

Así Álvarez Sierra en su «Diccionario de cirujanos españoles, hispanoamericanos y filipinos» (61), ubica su nacimiento en la ciudad de Zaragoza. Dato falso, pues por documentos oficiales se comprueba que su ciudad natal fue Huesca un 28 de enero de $1886^{1}$.

El mismo autor sigue afirmando, en la sucinta biografía que le dedica (situándolo entre Fray Pabón Alonso y Palacios Olmedo) que la muerte le sobrevino en un accidente de automóvil cuando regresaba de un Congreso de Pediatría celebrado en San Sebastián por esas fechas, en el que supuestamente habría presentado «Interesantes Ponencias». Ciertamente en esos días, concretamente el 9 de septiembre de 1923 se inauguró en la ciudad donostiarra el Congreso Nacional de Pediatría, clausurándose el 16 del mismo mes. El acto de clausura contó con la presencia del ministro de Instrucción Sr. Salvatella ${ }^{2}$. A este Congreso no se tiene constancia cierta de que asistiera Pagés y mucho menos que presentara ponencia alguna.

El motivo real de su viaje al País Vasco fue el de descansar con su familia durante el período estival en Cestona ${ }^{3}$, no teniendo intención ninguna por tanto de asistir a ningún Congreso. Probablemente la coincidencia de fechas es lo que ha inducido al error.

Tampoco hemos podido confirmar, al contrario sólo hemos constatado opiniones encontradas ${ }^{4}$, que Pagés fuera médico de la Casa Real por oposición, como continúa afirmando Álvarez Sierra en su mencionado libro.

Parece más verosímil pensar que fue médico personal de algunos miembros de la Casa Real como consecuencia de la amistad que le dispensaba la Reina Madre María Cristina ${ }^{(4)}$. Otras de las afirmaciones que efectúa Álvarez Sierra es que Pagés fue Catedrático Auxiliar de la Facultad de Medicina de la Universidad Central de Madrid en la rama de Cirugía. Creemos que esto tampoco se ajusta enteramente a la realidad. No hemos obtenido ningún dato que confirme dicha aseveración ${ }^{5}$.

Por último Álvarez Sierra enumera algunos de los importantes artículos legados por Pagés, entre ellos menciona: «El Shock Traumático», «Arteritis de la arteria Subclavia»y «Las infecciones difusa de la mano». Ninguno de estos escritos ha aparecido

\footnotetext{
${ }^{1}$ Los documentos oficiales consultados han sido la Hoja de Servicio Militar, facilitada por el Archivo General Militar de Segovia. Otro documento es el expediente académico, facilitado por la Universidad de Zaragoza. ${ }^{2}$ Información recogida del Diario ABC de Madrid con fecha 21 de septiembre de 1923.

${ }^{3}$ En su Hoja de Servicios se recoge la petición formulada para disfrutar 28 días de permiso en la localidad de Cestona. La fecha de petición es la del 8 de agosto, efectuándose la salida desde Madrid el 28 del mismo mes. ${ }^{4}$ Tanto la información de la amistad de Pagés con la Reina Madre como el hecho de que no acudió al Congreso de San Sebastián han sido facilitados y corroboradas por su hija Concepción.

${ }^{5}$ Para confirmar esta información recabamos datos de la Facultad de Medicina de Madrid, careciendo dicha Facultad de su expediente personal y desconociendo en absoluto que Pagés hubiera pertenecido a su cuerpo docente.
}

publicado en las revistas donde habitualmente colaboraba Pagés como la Revista de Sanidad Militar o la Revista Española de Cirugía. Al no indicar Álvarez Sierra donde fueron publicados los mencionados artículos y el no haber podido hallar documentación que confirmara su existencia, podemos dudar de la autenticidad o al menos de que no pertenecen a la obra de Pagés ${ }^{6}$.

De cualquier forma creemos que el grave error de Álvarez Sierra en esa reducida biografía, es el no haber sabido recoger y resaltar los trabajos más importantes de Pagés y cuál fue el legado que dejó en la medicina.

Estimamos que una biografía destinada a Pagés, por pequeña que sea no debe faltar una referencia a artículos suyos como el dedicado a la Anestesia Metamérica (62) en el que por primera vez se describe la técnica de punción epidural lumbar con fines quirúrgicos y los resultados obtenidos.

Este hecho de recoger lo primordial de la obra de Pagés es resaltado por algunos autores extranjeros, Bonica, Killian, Morisot. $(63,64,65)$ Este último llega a considerar al referido tratado de Pagés sobre la Anestesia Metamérica, como «Un trabajo que aún hoy nos parece comparable en más de un aspecto a los mejores que se han escrito sobre el tema y puede afirmarse que en él está todo descrito, las bases anatómicas, las características de la analgesia y la parálisis motora; la técnica; los signos y las complicaciones y contraindicaciones».

Morisot es de los pocos autores (quizás el único) que concede a Pagés la paternidad y originalidad del método de anestesia epidural por vía lumbar. Defiende abiertamente esta tesis, aunque tenemos que oponerle dos objeciones. En primer lugar achaca al trabajo de Pagés un débil conocimiento de los trabajos franceses sobre esta técnica. No podemos estar de acuerdo con esta imputación pues ya Pagés en su artículo (62) hace referencia al artículo de Cathelin (66) y el consiguiente de Sicard (67), así como menciona a otros autores galos que habían comunicado sus experiencias, tales con Tuffier, Reclus o el mismo Le Filliatre entusiasta defensor de la anestesia espinal completa y que en el Congreso Médico Internacional de Londres de 1913 expuso sus resultados con 2.837 casos.

Pero además de estas referencias, Pagés da muestra de un casi completo conocimiento de las técnicas de anestesia más avanzadas en Europa merced a los comentarios y colaboraciones que realiza en la revista Española de Cirugía a diversos trabajos de autores extranjeros ${ }^{7}$.

\footnotetext{
${ }^{6}$ Su familia desconocía también que existieran artículos inéditos, o publicados en otras revistas. El único artículo inédito que nos mostró fue «Tratamiento de las fracturas diafisarias de los huesos largos de las extremidades producidas por proyectiles de armas de fuego», de cuya existencia conocíamos a través de su Hoja de Servicios en la que se le concede una mención especial por el trabajo.

7 )En la Revista Española de Cirugía de agosto de 1919 comenta el artículo de V. Riche aparecido en Presse Medicale titulado «La raquianestesia general con novocaína por vía lumbar». En la misma revista de marzo de 1920, comenta el trabajo de Johonesco (Edit. Masson Paris 1919) «La raquianestesia general». En el número de marzo de 1923 comenta la comunicación de M. Fornesco realizada en el XXXI Congreso de Cirugía de Paris (3 de octubre de 1922) «Nueva técnica para la raquianestesia general». A. Roussel le comenta su artículo «Estudio crítico de los procedimientos de anestesia utilizados en cirugía gastrica» («Journal de Chirugique» tomo 17 número 5) y que apareció en el mes de abril -mayo de 1920.
} 
Como puede desprenderse de la lectura detallada de los artículos y comentarios de Pagés, éste disponía de un vasto conocimiento no sólo de los trabajos publicados por los franceses, sino también de los centroeuropeos. En especial los escritos por los alemanes. ( $\mathrm{Su}$ dominio del idioma alemán le permitió asistir como cirujano a los campos de concentración del Imperio Austro-Húngaro, durante la I Guerra Mundial) ${ }^{8}$.

La segunda objeción que debemos reprocharle a Morisot es, una vez más, desconocer o al menos no profundizar en la auténtica biografía de Pagés, de esta manera llega a afirmar que el fallecimiento sobrevino como consecuencia de una enfermedad pulmonar aguda, abandonado y olvidado de todos.

Nada más incierto. Cierto es que cuando falleció todavía nadie le consideraba como descubridor de algo nuevo, pero es conveniente recordar que la muerte le llegó a la temprana edad de 37 años, con toda una vida profesional por delante y cuando su fama como cirujano iba en aumento día a día 9 .

Evidentemente Pagés no falleció tampoco a consecuencia de ninguna patología pulmonar sino a consecuencia de un desafortunado accidente automovilístico acaecido en las proximidades de la ciudad de Burgos cuando regresaba de pasar sus vacaciones en Cestona ${ }^{10}$

De nuevo otro autor, Alfred Lee (68) reconoce la paternidad de Pagés en describir por primera vez la localización del espacio epidural a nivel lumbar, pero una vez más, pone una serie de reparos con los que por supuesto no podemos estar de acuerdo.

Acusa a Pagés de ser incapaz de comunicar a sus colegas la utilidad del método, haciendo recaer sobre Dogliotti el mérito de haberle dado a la técnica la posibilidad de su uso clínico. No entendemos como puede acusar a Pagés de falta de difusión de sus experiencias cuando llegó a publicarlas en dos revistas distintas $(62,69)$.

Quizás la situación sanitaria española a principios de siglo, como comentábamos al principio, no era todo lo prestigiosa que cabría desear como para que los autores foráneos estudiaran o al menos leyeran las investigaciones y experiencias clínicas que se realizaban en España.

Es indudable que el mérito de Dogliotti al comunicar sus resultados (70) es la gran difusión que consigue en el mundo entero, con toda seguridad un factor que le ayudó sobremanera a aumentar su difusión fue el publicar pronto su artículo en inglés y en una revista norteamericana (71). Pagés no será traducido a ese idioma hasta el año 1961 (72).

\footnotetext{
${ }^{8}$ Realizó un curso de lengua alemana en la Escuela de Comercio de Zaragoza durante su época de estudiante de medicina en esa Facultad. Se puede comprobar por su expediente académico. La estancia en los campos de concentración austro-húngaros se refleja en su hoja de servicios. ${ }^{9}$ La fama de Pagés era indudable. En vida se le hicieron diversos homenajes como es el que recoge la foto celebrado en Tornié. Tras su muerte las muestras de afecto se multiplicaron y en el Blanco y Negro del 28 de octubre de 1923 S.M. Dña. María Cristina con su hermano el Archiduque Eugenio y los generales Arzadún y Moltó descubren una lápida en el Hospital Militar de San Sebastián en su conmemoración. también se descubre otra en el Hospital General de Madrid (foto). Finalmente su muerte se recoge ampliamente en los diarios ABC (26 de septiembre) El Globo (1 de octubre). El Telegrama del Riff 25 de septiembre y 30 del mismo mes.

${ }^{10} \mathrm{ABC}$ del 26 de septiembre.(fotos) La noticia de la muerte se ve confirmada por el telegrama enviado por el general gobernador militar de Burgos al general subsecretario del Ministerio de la Guerra, cuya fotocopia se conserva en la hoja de servicios.
}

Evidentemente su mayor aportación la reporta en el campo de la anestesia y así es reconocido por un amplio número de autores $(63,64,65,68,74,75,77,78,79)$ aunque el resto de su obra, sin llegar a ser tan innovadora, presenta interesantes aportaciones.

Sus dos grandes problemas fueron su precoz muerte, que le impidió completar una de las mejores y más prometedoras carreras dentro del ámbito de la cirugía de principios de siglo. Otro serio inconveniente que presentó su obra, fue la falta de difusión no exclusivamente imputable a él, sino en mayor medida a un no disimulado menosprecio que por aquella época, presentaba la medicina francesa y alemana hacia la española. Esta indiferencia impidió que muchísimas investigaciones y experiencias realizadas en España, traspasaran nuestra frontera.

Pagés, por tanto, representa la imagen de un cirujano de su época, polivalente, inquieto y preocupado por el amplio campo de la medicina que se abre en esos momentos.

Las razones antes expuestas no son suficientes para explicar el largo olvido en el que los historiadores españoles han dejado a este hombre. En otros países, especialmente los anglosajones, se resalta rápida e inmediatamente cualquier personalidad descollante (79) dedicándole amplias monografías.

El reconocimiento a su labor llega de forma vaga tras su fallecimiento. Lo demuestran los homenajes y discursos a su figura $(80,81,82,83,84,85,86,87)$ o el entrañable artículo de Gómez Ulla publicado en El Telegrama del Riff el 25 de septiembre de 1923, o el homenaje celebrado en el Hospital del Docker ${ }^{11}$.

Dos últimos hechos se van a sumar a la lista de homenajes. Aunque estos dos supongan para su figura un mayor reconocimiento y satisfacción póstuma. Uno sucede en el año 1926, el Hospital Docker de Melilla cambia su nombre y se le otorga la nueva denominación de Hospital Militar Pagés en honor del cirujano que tantas intervenciones practicó entre aquellas paredes ${ }^{12}$.

El otro suceso es más reciente, data de 1957, en el que por acuerdo de la Asamblea General de la Sociedad Española de Anestesiología y Reanimación se crea el premio Pagés de temas libres para cualquier aspecto experimental o clínico relacionados con anestesia y o reanimación. Fue otorgado por primera vez en el año 1959 en Valencia, durante la celebración del IV Congreso Nacional de Anestesiología, recayendo el galardón al Dr. F. Cantero Gómez por su trabajo «los procesos de oxido-reducción en Anestesia» ${ }^{13}$

Desde la instauración de este prestigioso premio la Revista Española de Anestesiología y Reanimación ha visto cómo en sus páginas aparecía algún recordatorio hacia la figura de Pagés (88), pero es, definitivamente, en la década de los noventas, con motivo del CL

\footnotetext{
${ }^{11}$ Este homenaje lo recoge El Telegrama del Rif el 30 de septiembre y ambos reportajes lo reproducimos textualmente.

${ }^{12}$ La fecha del cambio de nombre la transcribimos por información de la familia y al coincidir con la facilitada por el Comandante de Intendencia Francisco Gandarillas, versado historiador de la guerra de Africa y Presidente de la Asociación de Estudios Melillenses. No hemos podidos confirmar la fecha a través del Diario oficial en la que se ordena el cambio de nombre, pero damos como buena la fecha por ser la fuente de toda solvencia. Actualmente dicho Hospital continúa con la misma denominación. (Foto lápida).

${ }^{13}$ El premio Pagés lleva 30 años de existencia y a él acuden los más prestigiosos anestesiólogos de España. En el apédice reproducimos la convocatoria. Datos obtenidos del Boletín de la Asociación Revista Española de Anestiología 1960: 7: 116-124.
} 
Aniversario del nacimiento de la Anestesiología y del LXXV de la publicación del original «Anestesia Metamérica», cuando la imagen, biografía y obra científica de Pagés se reconocen y divulgan en diversas publicaciones y artículos $(89,90,91,92,93)$ Es posible que si este tardío, pero justo y merecido, reconocimiento por parte de los historiógrafos españoles se hubiera producido con cierta antelación muy probablemente A. Faulconer en su obra Foundations of Anesthesiology no hubiera escrito sobre Pagés: «No se encuentran apenas datos sobre la vida de este importante cirujano español» (94).

\section{MATERIAL Y MÉTODO}

La mayor dificultad con la que nos hemos encontrado a la hora de recopilar datos e información sobre nuestro personaje, ha radicado precisamente en la ausencia de suficiente bibliografía en la que basarnos. La no existencia de monografías, las biografías incompletas y erróneas y la falta de referencias en la mayoría de publicaciones, han sido los obstáculos más importantes que hemos tenido que solventar.

Las primeras fuentes de información a la que acudimos fueron aquellas que nos pudieron ofrecer una idea general y continuada de las actividades profesionales de Pagés. Con este fin acudimos al Archivo General Militar de Segovia solicitando su Hoja de Servicios completa, en la que se narra minuciosamente diversos e interesantes episodios de su vida y obra científica. Otra importante fuente fue el expediente Académico Universitario y el de bachiller, obtenido por medio de la Secretaría de la Facultad de Medicina de Zaragoza.

El reconocimiento a su labor llega de forma vaga tras su fallecimiento. Lo demuestran los homenajes y discursos a su figura (80, $81,82,83,84,85,86,87)$ o el entrañable artículo de Gómez Ulla publicado en El Telegrama del Riff el 25 de septiembre de 1923, o el homenaje celebrado en el Hospital del Docker ${ }^{14}$.

Dos últimos hechos se van a sumar a la lista de homenajes. Aunque estos dos supongan para su figura un mayor reconocimiento y satisfacción póstuma. Uno sucede en el año 1926, el Hospital Docker de Melilla cambia su nombre y se le otorga la nueva denominación de Hospital Militar Pagés en honor del cirujano que tantas intervenciones practicó entre aquellas paredes ${ }^{15}$.

La localización de su familia nos sirvió para conocer aún mejor a Pagés y para confirmar una serie de datos que pudieron que pudieron generar dudas. En especial nos fue de gran interés las aportaciones de su hija Concepción (residente en Madrid y domiciliada en la última vivienda que habitó Pagés, Infanta, 13) y las de su hijo Fidel. (Médico inspector de la seguridad Social, fallecido y que residió en Barcelona, Casanova, 164).

Gracias a la información facilitada por su familia pudimos conocer la totalidad de sus trabajos, tanto inéditos como publica-

\footnotetext{
${ }^{14}$ Este homenaje lo recoge El Telegrama del Rif el 30 de septiembre y ambos reportajes lo reproducimos textualmente.

${ }^{15} \mathrm{La}$ fecha del cambio de nombre la transcribimos por información de la familia y al coincidir con la facilitada por el Comandante de Intendencia Francisco Gandarillas, versado historiador de la guerra de Africa y Presidente de la Asociación de Estudios Melillenses. No hemos podidos confirmar la fecha a través del Diario oficial en la que se ordena el cambio de nombre, pero damos como buena la fecha por ser la fuente de toda solvencia. Actualmente dicho Hospital continúa con la misma denominación. (Foto lápida).
}

dos. Estos se ciñeron a dos revistas, la Revista de Sanidad Militar y la Revista Española de Cirugía de la que además es fundador.

Para centrar a Pagés en su tiempo y valorar su obra en relación a los trabajos de sus contemporáneos, realizamos un amplio escrutinio bibliográfico. Este abanico bibliográfico lo centramos alrededor de las tres facetas principales en las que pudo descollar nuestro personaje:

1.- Publicaciones sobre la historia de la anestesia

2.- Publicaciones sobre la historia de la cirugía.

3.- Publicaciones referentes a la historia de la Sanidad Militar.

Otras fuentes consultadas y que nos han servido para conocer datos o anécdotas importantes, fueron los diarios oficiales del Ministerio de la Guerra desde 1909 a 1923, y las colecciones completas del «El Globo», «ABC»y «Blanco y Negro» referente a los años 1921, 1922 y 1923. «El Telegrama del Rif»fue a su vez revisado desde 1909 a 1923.

Los artículos que hacen referencia a Pagés, se localizaron en el Science Citation Index y algunos se consiguieron en los servicios de documentación que actualmente tienen algunos laboratorios de especialidades médicas.

\section{BIOGRAFÍA}

La vida y obra de Pagés, no llegan a entenderse si no se realiza una lectura pormenorizada de los distintos avatares por los que atraviesa su singladura militar. Su obra científica, en gran parte, va a estar condicionada y unida íntimamente a los destinos y ciudades que visita durante su vida castrense. Por otra parte uno de los puntos más sobresalientes de su personalidad como médico se la dedica a la Sanidad Militar. Por estas razones estimo que es conveniente realizar una sinopsis de su biografía antes de entrar de lleno en su obra científica.

Fidel Pagés Miravé nació en Huesca el 26 de enero de 1886, de familia acomodada compuesta por Juan Pagés Marqué y Concepción Miravé Sesé. Su padre fallece cuando Fidel cuenta con siete años de edad y su madre vuelve a contraer matrimonio ${ }^{16}$.

Sus primeros estudios los cursa en el Instituto de Huesca, donde ingresa en 1896. Alcanza el grado de Bachiller tras superar los últimos exámenes realizados los día 15 y 17 de junio de 1901. En ese mismo año inicia los estudios de Medicina en la Universidad de Zaragoza, de la que es Rector D. Mariano Ripollés.

Durante el año académico 1899-1900 realiza un curso de lengua francesa que aprueba con la calificación de notable.

Los estudios de bachillerato de Pagés coinciden con un período histórico convulso para España. Son años marcados por el desastre del 98 y las pérdidas de las últimas colonias de ultramar.

Obtiene el título de medicina el 12 de junio de 1908, después de siete años de estudios en los que consigue once matrículas de honor, doce sobresalientes y cuatro notables. Cinco días más tarde recibe la calificación de sobresaliente en los ejercicios de la licenciatura. Durante estos años de carrera realizó un curso de lengua alemana en la Escuela de Comercio Zaragozana.

\footnotetext{
${ }^{16}$ Información facilitada por su familia y parte constatada por la Hoja de Servicios.
} 
Mediante oposición, el 27 de septiembre de 1908, obtiene el «Premio Extraordinario de la Licenciatura de Medicina».El $25 \mathrm{de}$ febrero de 1909 el Ministerio de Instrucción Pública y Bellas Artes le expide el correspondiente título ${ }^{17}$.

Recién terminada la carrera, prepara las oposiciones al Cuerpo de Sanidad Militar, cuerpo en el que ingresa el 30 de septiembre de 1908 con el número tres de su promoción. Jura bandera ante el Regimiento de Asturias $n^{0} 31$ el uno de noviembre del mismo año, siendo destinado al Hospital Militar de Carabanchel con el grado de Médico Segundo al año siguiente, después de haber superado los estudios en la Academia Especial de Sanidad.

Durante su estancia en la Academia, cursó los cuatro cursos del doctorado, en las facultades de Medicina, Farmacia y Ciencias de la Universidad Central de Madrid, obteniendo un sobresaliente en Análisis Químico, dos notables en Historia de la Medicina y Antropología y un aprobado en Psicología Experimental (18).

En este su primer destino no permanece mucho tiempo, pues a principio de agosto es comisionado al Hospital Militar de Melilla, donde comienza a ejercer como ayudante de cirugía (Pagés ya tenía cierta experiencia en cirugía pues fue alumno interno de esa cátedra en la Facultad de Zaragoza, así lo recordaba el telegrama del entonces Rector de la Universidad de esa ciudad Sr. Royo Villanova enviado a su homenaje póstumo).

No obstante, al finalizar el mes de diciembre de ese mismo año, se le comisiona a la sección de tropas de la Compañía de Sanidad, por necesidades del servicio. A pesar de ser un trabajo poco gratificante y excesivamente alejado de su vocación quirúrgica, Pagés lo desempeña dignamente y mantiene alto el espíritu de colaboración y trabajo en la tropa a su mando. Como recompensa a esta abnegada labor y a la desempeñada en el Hospital Militar se le concede la Cruz de Primera Clase del Mérito Militar con distintivo rojo y pensionalidad ${ }^{18}$.

El 28 de enero de 1910 es destinado de nuevo al Hospital Militar de Carabanchel. Marcha a Madrid con la experiencia de haber intervenido por primera vez en su vida a heridos en combate y con la decisión de completar sus estudios con el doctorado ${ }^{19}$.

Los reveses que sufre constantemente el ejército Español en el norte de África frente a las cábilas rifeñas, van a provocar el envío de nuevos contingentes de hombres a esa zona. Entre los oficiales que vuelven se encuentra Pagés.

Es destinado al Regimiento de Infantería de San Fernando mandado por el teniente coronel Santaló y con sede en la proximidades de Melilla, en un lugar conocido con el nombre del Hipódromo, donde estaba destacado, pues este Regimiento tenía su ubicación habitual en la Octava Región Militar, más concretamente en Lugo.

Su función en el segundo batallón de este Regimiento es asistencial, efectuando las primeras curas de los heridos cuando su

\footnotetext{
${ }^{17}$ Expediente Académico. Durante los años que cursa sus estudios en la Facultad de Medicina de Zaragoza, imparte clases de Patología Quirúrgica D. Ricardo Lozano Monzón, instructor y entusiasta propagandista de la aplicación de la raquicocainización en España. En 1902, en la Revista La Clínica Moderna publicó ochenta casos y con posterioridad en el 1903, en el XIV Congreso Internacional de Medicina celebrado en Madrid, comunicó 152 nuevos casos ( Vaca Miguel J.M.. Orígenes de la Raquicocainización en España. Rev. Esp. Anestesiol. 1991; 38:38-40.

${ }^{18}$ Diario Oficial No 112 de 1910 del 25 de mayo.

${ }^{19}$ Información facilitada por su familia.
}

unidad se incorpora la frente y realizando las medidas propias de la medicina preventiva militar ${ }^{20}$.

Vuelve a cambiar de destino por orden del Diario Oficial $n^{\circ} 25$ incorporándose a la Compañía de Sanidad como instructor de reclutas el 31 de enero de 1911. Asciende a Médico Primero el 7 de julio del mismo año con antigüedad de 30 de junio. Toda esta larga sucesión de destinos obliga a Pagés a posponer sus estudios de doctorado y afianzar su irrenunciable vocación de cirujano ${ }^{21}$.

Cuando el territorio queda parcialmente pacificado, se reembarca para la Península un elevado número de tropa y oficiales. Con ellos regresa Pagés destinado al Primer Batallón del Regimiento de Infantería Almansa $\mathrm{n}^{\circ} 18$ con sede en Tarragona. Aunque durante algún tiempo queda agregado al Primer Grupo de Hospitales de Melilla por orden expresa del inspector accidental del territorio. Esta medida se toma para atender convenientemente al gran contingente de heridos que quedan en Melilla al finalizar las hostilidades.

Por fin sale de Melilla el 3 de agosto de 1911 con destino a Tarragona. Tampoco en esta Ciudad catalana va a permanecer por un largo período de tiempo. El día 6 de octubre se va a incorporar a su nuevo destino en el Colegio de Huérfanos de María Cristina, sección de varones en Toledo ${ }^{22}$.

En agosto de 1912 publica su primer artículo. Lo hace en la Revista de Sanidad Militar y lleva el título «La lucha en campaña contra de las enfermedades infecciosas» (94). En él pone de relieve la importancia de las medidas profilácticas para evitar la contaminación de las enfermedades contagiosas en grandes colectivos con especial insistencia en el medio militar y en períodos bélicos. Resalta la necesidad de efectuar una desinfección del material, tropas y enseres así como del propio individuo potencialmente infectado. La desinfección en estos se realizará antes «que los microbios hayan atravesado las barreras epiteliales de defensa del cuerpo humano». Comenta la imposibilidad de conseguir una efectiva acción bactericida cuando los microorganismos radiquen en el interior del organismo pues. «de composición similar la célula del organismo y poseyendo parecidas propiedades vitales a las de los microbios toda acción bactericida resultaría histolítica al mismo tiempo».

En el mismo artículo pone de relieve, a su vez la importante labor que en este sentido desempeñó la Sanidad Militar japonesa en la Guerra Ruso-Japonesa de 1904 con la instalación de lazaretos como los de Hiroshima, Dairir, Wadanomisaki, Aomori y Muroran.

Hace hincapié en lo beneficioso que resulta la ubicación de estos lazaretos en las islas o zonas costeras con posibilidad de instalación de dos puertos, uno de desembarco o infectados y otro de embarque o limpios.

Todas estas medidas higiénico-profilácticas, Pagés había tenido oportunidad de ponerlas en práctica durante su estancia en la Campaña Africana.

En enero de 1912 es agregado al Ministerio de la Guerra y se le comisiona al servicio de eventualidades de la Primera Región Militar en agosto del mismo año. Allí permanece hasta el

\footnotetext{
${ }^{20}$ Hoja de Servicios página 4. También refiere que marchó destacado a la posición de Hardui a las órdenes del teniente coronel José Lecheva. Por Real Orden de 22 de junio se le concede a él y a todas las fuerzas que tomaron parte en los combates del 2 de octubre, un voto de gracia. Diario Oficial ${ }^{\circ} 158$.

${ }^{21}$ Afirmaciones de familia.

${ }^{22}$ Hoja de Servicios página 5.
} 
28 de marzo de 1913, en la que se le destina al Regimiento de Zapadores-Minadores de Madrid, de donde es comisionado en varias ocasiones a la zona de reclutamiento de Ciudad Real ${ }^{23}$

El 24 de junio de 1912 alcanza el grado de Doctor en Medicina con la calificación de sobresaliente, defendiendo su memoria titulada «Patogenia de las Bradicardias», compuesta por cientoveintitres páginas ${ }^{24}$.

En agosto de 1913 contrae matrimonio con una madrileña, Berta Concepción Bergenman Quirós hija de padre alemán Wilhem Bergenmann y madre española Asunción Quirós y Romero. Se casan en la Iglesia de San Ildefonso y establecen el primer domicilio en la calle Fuencarral ${ }^{25}$.

Antes de finalizar el año publica en la Revista de Sanidad Militar su segundo trabajo. En esta ocasión no se trata de un trabajo original, es la traducción del alemán de un discurso pronunciado en el Congreso de Naturalista de Munster por el profesor Vicent Czerney y publicado en el Muncherer Medicinishe con el título «El tratamiento incruento de los tumores» ${ }^{26}$.

En pleno año 1914 (pocas fechas después del atentado de Sarajevo contra el archiduque Francisco Fernando de Austria), Pagés es removido de su destino y enviado a Mahón al Batallón del regimiento de Infantería de Menorca. Durante este verano y por Real Orden del 21 de agosto se le concede una mención honorífica por su trabajo «Tratamiento de las fracturas diafisarias de los huesos largos de las extremidades producidas por proyectiles de armas de fuego» ${ }^{27}$.

En este trabajo, inédito aún, se exponen las ideas y experiencias de los cirujanos alemanes en este tipo de heridas. También recoge como los equipos quirúrgicos españoles que intervinieron la Guerra del Rif de 1909, llevaron a cabo estos tratamientos ${ }^{28}$.

El 26 de febrero de 1915 consigue cambiar de destino en Mahón al Hospital Militar de Alicante, al realizar una permuta. Regresa por fin a Madrid para ser destinado al Gabinete Militar del Ministerio de la Guerra el 19 de mayo, no sin antes quedar retenido en Alicante hasta la llegada del relevo ${ }^{29}$.

Al llegar a la capital vuelve a habitar la misma residencia en la calle Fuencarral, donde tiene el primer hijo en este mismo año al que bautiza con el nombre de Adolfo. (Posteriormente seguirá los pasos de su padre y ejercerá como médico $)^{30}$.

Comienza de nuevo su corta pero brillante carrera como cirujano. En este mismo año 1915 obtiene el número uno en la oposición para cirujano de la beneficencia (61). Comienza a operar con asi-

\footnotetext{
${ }^{23}$ Hoja de Servicios Pag. 5.

${ }^{24}$ Expediente Académico.

${ }^{25}$ Información de la familia.

${ }^{26}$ Vicent Czerney (1842-1916), nacido en Trautenau, Bohemia. Ayudante de T. Billroth en Wien. profesor de cirugía en Freiburg y Heidelberg donde falleció. Entre sus contribuciones a la cirugía están las técnicas en la operación radical de la hernia, ser el primero en describir la histerectomía por vía vaginal y modificaciones a las técnicas de Billroth en operaciones de laringe, esófago, riñones y cirugía digestiva. (García del Real E.1946, Garrison F.).

${ }^{27}$ El Diario Oficial en que se le concede la mención es el número 185 de 1914.

${ }^{28}$ De este trabajo inédito pude ver una copia que me facilitó su hija Concepción.

${ }^{29}$ La permuta realizada con el médico primero Fortunato García Gómez, el cual marcha de forma voluntaria a Mahón. Hoja de Servicios. Pag. 6.

${ }^{30}$ Información de la Familia.
}

duidad en el Hospital General. Junto con el doctor Segovia destacan especialmente las nuevas técnicas quirúrgicas que emplean en el tratamiento de las heridas por asta de toro, siendo uno de los cirujanos pioneros en las plazas de toros ${ }^{31}$.

El 25 de enero de 1916 cambia nuevamente de destino aunque permanece en Madrid, pasa al Estado Mayor del Ejército ${ }^{32}$. La estancia continuada en la capital hace que su fama como cirujano aumente. Buena muestra de ello es que se convierte en médico personal de la Reina María Cristina, con la que le une una amistad que durará hasta su trágico fallecimiento ${ }^{33}$.

$\mathrm{Al}$ año siguiente y debido al amplio conocimiento del idioma alemán, se le comisiona para realizar un servicio por tiempo indefinido en el Imperio Austro-Húngaro, con el fin de cooperar en concepto de Delegado del Embajador de España en Viena para inspeccionar los campamentos de los prisioneros de guerra allí instalados. Pagés no solamente visitó los campamentos sino que en Viena se le asignó el Hospital Militar $\mathrm{n}^{\circ} 2$ como cirujano.

Realiza un elevado índice de intervenciones por lo que es felicitado por su colaboración y entrega. A pesar del corto período de tiempo que está en la comisión (11 de abril al 8 de septiembre), se vuelve a España con una amplia experiencia de intervenciones en heridos de guerra y poli traumatizados ${ }^{34}$.

De regreso a Madrid, cambia su residencia habitual por otra vivienda algo más moderna y confortable en la calle Antonio Maura donde nace su segundo hijo, una niña a la que bautizan con el nombre de Concepción ${ }^{35}$. Reanuda sus actividades en el Hospital General y comienza a relacionarse con las primeras figuras de la cirugía de la época. (Ramírez de la Mata, Víctor Nogueras, Bastos y Ansard, Gómez Ulla...). Especialmente con éste último traba una sólida amistad que se verá fortalecida con posterioridad después del trabajo que desempeñan conjuntamente en el Hospital Militar de Melilla durante la campaña de 1921. Muestra de ésta amistad son las palabras que le dedica en un homenaje póstumo celebrado en el Hospital de Carabanchel (80).

Queda encargado como secretario de la redacción de la Revista de Sanidad Militar, sucediendo al Médico primero Silvano Escribano García, en 1918. En el mismo año y en el mes de septiembre pública «La teoría y la práctica del injerto óseo» (96). En este artículo realiza una revisión de las técnicas, en aquellas época actuales, sobre injertos óseos. Continúa exponiendo el método empleado por él en el Hospital Provincial de Madrid para este tipo de operaciones, y lo finaliza haciendo una exposición de algunos casos con sus resultados y complicaciones. Recomienda

\footnotetext{
${ }^{31}$ Datos extraidos de una entrevista realizada al Doctor Mariano Fernández Zumel a la revista Jano del 3 al 9 de febrero de 1984, nº 602 en las Pags. 87-92. Pagés en uno de sus artículos (Pagés F.1921) hace referencia al tratamiento que somete a un novillero herido por un rejón en la región antecubital con desgarro de la primera arteria radial, solucionado con tubulación arterial de la fascia muscular.

${ }^{32}$ Diario Oficial n ${ }^{\circ} .20$ del 20 al 25 de enero de 1916.

${ }^{33} \mathrm{La}$ amistad con la Reina Madre me fue comentada por la familia. Como muestra relatamos que al fallecer Pagés, la Reina palió de alguna manera las necesidades de la familia al admitir en el Colegio de Doncellas Nobles de Toledo a las dos hijas del fallecido, donde realizaron los estudios de forma gratuita.

${ }^{34}$ Hoja de Servicos Pag. 6.

${ }^{35}$ Esta información, de nuevo, fue facilitada por la familia. Dentro de la familia presisamente su hija Concepción, junto con la ya anciana ama de llaves fueron las que más datos aportaron.
} 
la utilización de isquemia en las intervenciones sobre miembros, mediante la aplicación de la venda de $\mathrm{Esmarch}^{36}$.

Dentro de su trabajo en el Estado Mayor del Ejército, recibe una nota del Estado Mayor en la que se hace constar sus dotes de inteligencia y alto interés en el cumplimiento de sus obligaciones.

Esta nota se produce por su colaboración con el Estado Mayor en la elaboración del plan de reorganización del Ejército ${ }^{37}$.

El año de 1919 va a ser uno de los más importantes en la vida de Pagés. Funda con el doctor Ramírez de la Mata la Revista Española de Cirugía, siendo a la vez de fundadores, directores, colaboradores y críticos.

El primer número aparece en el mes de enero y lleva un artículo de Pagés: «Sobre un caso de estrangulación retrógada de epiplón». (97) Este artículo se publicará unos meses más tarde en la Revista de Sanidad Militar en el número del mes de mayo. En él, Pagés expone un caso clínico de una paciente que operó por estrangulación retrógada de epiplón. Comenta la rareza de esta dolencia, descrita por Maydl por primera vez en 1895 y Walter Wendel en 1913 recopila 78 casos de intestino delgado y 20 de otras vísceras. Probablemente se trate del primer caso que se publica en revistas españolas.

En este primer número de la Revista Española de Cirugía, Pagés realiza diversos comentarios y críticas a otros tantos artículos.

La experiencia de la revista tiene éxito y continúa publicando en ella. En el mes de mayo publica «Contribución al estudio de la cirugía plástica de la mejilla», reproducido posteriormente en la Revista de Sanidad Militar (98). Comunicación que había presentado al Congreso Nacional de Medicina celebrado en Madrid entre los días 20 al 25 del mes de abril. En el artículo Pagés expone sus resultados y opiniones sobre las diversas técnicas quirúrgicas de injertos para la mejilla. Insiste que aunque este tipo de intervención es de aplicación en caso de tumores malignos, es a su vez efectiva para cuando se trate de lesiones extensas provocadas por armas de fuego. Describe minuciosamente las técnicas descritas por Lerda, Gersuny, Tiersch, Reverdin y Krause ${ }^{38}$.

Algo que conviene remarcar convenientemente de este artículo es la importancia que Pagés le concede a la técnica anes-

\footnotetext{
${ }^{36}$ J. Friedrich A. Von Esmarch (1823-1908). Nacido en Toning. Ayudante de C. Langenbech y G. F. Stromeyer. Afamado cirujano militar forjado en las guerras que tuvo Prusia entre 1840 y 1870. Como cirujano fue conservador prefirió la resección a la amputación. Introdujo el paquete de cura individual del soldado y el vendaje elástico para operar los miembros con isquemia. Creó el cuerpo de enfermeras militares: «Samaritenwesens». (García del Real E.1934, Garrison F.).

${ }^{37}$ El plan de reorganización del Ejército se plasmó en la Ley del 29 de junio de 1918. Diario Oficial núm. 149. Por esta Ley los Oficiales dejan la antigua denominación de oficiales primeros o segundos para recibir el empleo de tenientes, capitanes, comandantes...

${ }^{38}$ Robert Gersuny nació en Teplitz-Schonau (Bohemia) y se considera uno de los primeros especialistas en cirugía Plástica. Thiersch Fedor Krause aparte de sus innovaciones a los injertos cutáneos, en 1839 realizó la escisión del ganglio de Gasser. J. L. Reverdin nación en Fontenex (Ginebra) en 1842. Posee diversos métodos de aplicación de injertos. Diseñó una técnica para la extirpación total y parcial del Tiroides, señalando las consecuencias de la ablación como el miedema. Murió en 1929. Carl Thiersch (1822-1895) nació en Munich. Fue cirujano militar y profesor de cirugía en Erlangen y Leipzig. Fue pionero en aplicar injertos cutáneos y mantuvo la histogénesis epitelial del cáncer en contra de la opinión de R. Virchow. (García del Real E.1934, Garrison F.).
}

tésica. Opina que el «Anestesiador» (Sic) debe preservar las mismas medidas de asepsia que el resto del personal quirúrgico «poniéndose blusa, guantes y gorro esterilizados y en realidad, aun cuando sea una práctica poco seguida, en materia de asepsia no cabe la palabra exageración».

Por otra parte muestra claramente su preocupación por todo lo que rodea a la anestesia, cuando trata de indicar el método anestésico ideal para esta modalidad quirúrgica.

Habla de la anestesia intratraqueal de Meltzer Auer, el aparato de Ombredanne, la cánula de Trendelenburg, la anestesia intrarrectal de Víctor Horsley, la anestesia intravenosa con hedonal (introducida en España por Olivares) y la anestesia espinal completa de Le Filliatre.

En el número de agosto aparece un nuevo artículo suyo: «Tratamiento de las fracturas del olécranon por el enclavijamiento y la extensión continua» (99). Presenta un caso clínico de un joven con fractura de olécranon al que se le trata con el sistema de tracción continua de Steinman. Se inclina hacia esta forma de tratamiento abstencionista frente a la actitud intervencionista de otros autores. La razón que le lleva a inclinarse por la extensión continua es el alto índice de supuraciones que traen consigo las suturas metálicas del olécranon ${ }^{39}$.

En este mismo número siguen sus comentarios a otros artículos aparecidos en otras revistas. Entre los autores sobre los que realiza sus comentarios se encuentran: Le Fort, Hutchinson, Beck, Labat, e incluso Gregorio Marañón al que le comenta un artículo publicado en la Revista Española de Medicina y Cirugía, titulado «Un síntoma muy constante en el hipertiroidismo».

El interés y la preocupación que siente Pagés por el tema de la anestesia es notorio. En la Revista Española de Cirugía van sucediéndose continuamente los comentarios a otros artículos publicados sobre el tema:

Rev. Española de Cirugía. Marzo de 1919. Pol. Coryllos. Bull et Mem. Soc. Chir. París. «La anestesia raquidiana alta y baja por la novocaína como procedimiento de anestesia general».

Abril de 1919; M. Gómez Ulla. «Inconvenientes reales y contraindicaciones de la anestesia medular».

Mayo de 1919; Fernando de la Sierra Durán. «Toxicidad de los anestésicos locales más usados, como: novocaína, cocaína, apilina, estovaina, querocaína, amethocaína y athoxicaína».

Mayo de 1919; J. de Sard y P. Sáez. «Anestesia en Cirugía de guerra».

Mayo de 1919; Vicente Soldevilla (Zaragoza). «Valor actual de la anestesia raquídea por la novocaína».

junio de 1919; Harries. Indian. Med. Gog. «Masaje cardíaco en la intoxicación por cloroformo».

Agosto de 1919; V. Riche. Presse. Med. «La raquianestesia con novocaína por vía lumbar».

Marzo de 1920; Johonesco. Edit. Masson. París. «La raquianestesia general».

\footnotetext{
${ }^{39}$ Uno de los principales cirujanos que defienden la tesis de intervencionismo en la fractura del olécranon, es el parisiense Theodore Tuffier, pionero también en las intervenciones del pulmón con insuflación endotraqueal. Gran parte de su trabajo lo realizó en el Hospital de Hartford British de París. Se le concedió el título de Caballero del Imperio Británico por su actuación en la $1^{\text {a }}$ Guerra Mundial. Propulsó la raquinestesia quirúrgica y publicó monografías sobre cirugía abdominal. Fue cirujano de la Pitié, Lariboisiere y Beaujun. Nacido en 1857, murió en 1929 (Garrison F.).
} 
Marzo de 1920; Manuel Altuna. Rev. Med: Cubana. «Principales métodos que se practican en USA para obtener la anestesia».

Enero de 1921; J.R. Eastman. J. Of. Ann. Med. Ass. «Ventajas de la anestesia local en las operaciones del tiroides».

Abril-mayo de 1921; Roussiel. Journal de Chirurgie tomo 17 nº5 «Estudio crítico de los procedimientos de anestesia utilizados en la cirugía gástrica» ${ }^{40}$.

Pagés en este año 1919 tiene su tercer hijo al que llaman Juan ${ }^{41}$. $\mathrm{Al}$ año siguiente pasa destinado como cirujano al Hospital Militar de Carabanchel. Al llegar con la aureola de buen organizador por su participación en la elaboración de la Ley del 29 de junio, se le encarga para la formación de una Junta que prepare un cuadro de lesiones e inutilidades de los combatientes. Este cuadro será el embrión del actual Cuadro de exclusiones del Ejército. En el año anterior y por una Real Orden del 14 de junio se le concede portar en el uniforme la Medalla de segunda clase de la Cruz Roja ${ }^{42}$.

En mayo de 1920 publica en la Revista Española de Cirugía «Sobre algunos casos de utilización de las fascias en cirugía». (Este artículo fue posteriormente reproducido en el número de enero de 1921 en la revista de Sanidad Militar) (100). En él describe detalladamente las distintas utilidades de las fascias musculares en cirugía y su experiencia en algunos casos. Entre los usos de las fascias menciona: la tubulación de nervios para su regeneración, sustitución de pared costal resecada por tumuración amplia según la técnica de Neuhof, reparación de la duramadre según las directrices del doctor Olivares, ineficacia de las fascias en su aplicación libre al tubo digestivo por el peligro evidente de oclusión intestinal. Sienta la principal indicación de las fascias en las lesiones arteriales con gran hemorragia, siguiendo las directrices de Horsley ${ }^{43}$.

Abre el artículo indicando que el camino en la utilización de las fascias en cirugía se inicia gracias a los estudios de Kirschner en 1909.

Se le concede la Cruz de Primera Clase del Mérito Militar con distintivo blanco por la labor desarrollada durante los cuatro años que permaneció en el disuelto Gabinete Militar y Estado Mayor Central ${ }^{44}$. Comienza una nueva faceta en su vida profesional. Inicia una etapa docente al ser nombrado profesor de enfermeras militares del Hospital de Urgencias. Imparte la docencia en diversas materias: cuidados posoperatorios, primeros auxilios, nociones elementales de cirugía de urgencias, prácticas de preparación y esterilización de toda clase de material de ur-

\footnotetext{
${ }^{40}$ Las referencias a los artículos originales son incompletas en algunas ocasiones, pero de esta forma vienen recogidas en la revista Española de Cirugía de esos años.

${ }^{41}$ Cuando nace el tercer hijo, Juan, la familia Pagés ya habita en la que actualmente sigue siendo la residencia de la familia. El viejo caserón de la calle Infantas $n^{\circ} 13$. Al año siguiente nace el cuarto hijo del matrimonio, Ascensión. Juan falleció después de ejercer como abogado y Ascensión vive con su hermana Concepción.

${ }^{42}$ Hoja de Servicios, Página, 7.

${ }^{43}$ Victor Horsley nacido en Kensintong en 1857 y fallecido en 1916, estudió las propiedades hemostáticas de los tejidos llegando a la conclusión que el músculo es el que mejor cumple esa función por sus cualidades tromboquinéticas y su facilidad para la adherencia. Fue pionero en la extirpación de un tumor extramedular. Diseñó la técnica para la resecar el ganglio de Gasser en la neuralgia del trigémino (Garrison F.).

${ }^{44}$ Real Orden de 22 de enero Diario Oficial no 19 de 1921.
}

gencias y anestesia local y general, con lo que abunda en el conocimiento de esta materia ${ }^{45}$.

En marzo de 1921 publica en la revista Española de Cirugía el que sin duda va a ser el trabajo más importante de su vida, «Anestesia metamérica». Reproducido posteriormente en la Revista de Sanidad Militar. $(62,69)$ Como dice Morisot (Morisot P.) «este artículo es el primero en que no sólo el principio de la anestesia epidural, sino también sus aplicaciones prácticas están codificadas perfectamente. En tal aspecto, Pagés puede ser considerado como el verdadero promotor del método». Efectivamente Pagés realiza una descripción pormenorizada de la técnica y de los «po$\cos$ datos históricos» que presenta el original método. Comienza explicando el por qué del nombre de metamérica: «por la posibilidad que nos proporciona de privar de sensibilidad a un segmento del cuerpo, dejando con ella a las porciones que están por encima y por debajo del segmento medular de donde proceden las raíces bloqueadas». En el recuento histórico conoce perfectamente los trabajos de Cathelin (66.), Sicard (67), Tuffier (101) y los de Reclus $^{46}$, sin duda los autores que con más interés ahondaron en la búsqueda de realizar anestesia localizando el espacio epidural. Sus resultados no fueron muy alentadores pues la introducción del anestésico la efectuaban a través del hiato sacro sin conseguir un nivel metamérico adecuado para intervenciones abdominales.

Es determinante cuando se refiere a la utilidad quirúrgica de la anestesia metamérica: «El bloqueo de las raíces nerviosas con substancias anestésicas en el espacio epidural, es susceptible de producir analgesia utilizable en intervenciones quirúrgica».

La descripción que hace para la localización del espacio epidural por vía lumbar, demuestra un conocimiento perfecto de la anatomía al realizarlo solo con la percepción de las estructuras anatómicas. Tal como lo relata hoy en día cualquier anestesista puede aprender con su lectura: «Los dos chasquidos que se producen al paso del instrumento por el ligamento amarillo y por la duramadre son tan perceptibles, que pueden oírse por las personas que están en la más inmediata proximidad del enfermo. Los internos que nos auxilian en la sala de operaciones los perciben con frecuencia, y el operador, que asocia su impresión auditiva a la táctil, siempre está en condiciones de localizar con la punta del instrumento las mencionadas estructuras».

$\mathrm{Su}$ larga experiencia en practicar raquianestesia (confiesa haber hecho más de 1.500) le ha ayudado a comprender y exponer mejor la técnica: «Esta seguridad la tendremos al inyectar el líquido que penetra en la cavidad epidural con la misma suavidad que en la subaracnoidea y en cambio hay que apretar mucho el émbolo y hacer presión para vencer la resistencia tanto de los ligamentos como del tríceps»».

En el artículo llega incluso a insinuar la posibilidad de conseguir anestesia selectiva exclusivamente de una parte del cuerpo: «Nosotros generalmente, cuando la operación ha de recaer en un sólo lado del cuerpo, elegimos el mismo lado para hacer la punción, porque hemos observado que casi siempre se presenta la anestesia en la mitad del cuerpo en la que recayó la inyección de un modo más precoz y más extenso; pero no hay inconveniente

\footnotetext{
${ }^{45}$ Hoja de Servicios Página, 7.

${ }^{46}$ Paul Reclus (1847-1914) tenía amplios conocimientos sobre la técnica de anestesia local, llegando a publicar su experiencia sobre 7.000 casos en «L' anaesthesie localiseé par la cocaine» ( Killian H.).
} 
ninguno en practicarla en el lado contrario». La forma en que se inicia la anestesia está detallada en todos los extremos, lo que indica un minucioso y protocolizado estudio de los casos. "Al poco tiempo de inyectar, a los cinco o seis minutos, empieza a aparecer una zona de hipoestasia en un segmento del cuerpo correspondiente a las raíces bañadas por la mezcla anestésica; esta zona es bilateral pero al principio algo más extensa en la mitad del cuerpo correspondiente al lado de la inyección. La motilidad permanece en un principio inalterada, así como las reacciones vasomotoras. La sensibilidad se va haciendo más obtusa a medida que pasa el tiempo y se extiende en el lado no inyectado, hasta alcanzar los límites del otro. Desaparece en primer término, la sensibilidad al dolor y casi paralelamente la térmica; de modo que al cabo de quince minutos y a veces antes la anestesia es completa en las metámeras inervadas por las raíces que sufrieron el bloqueo. La sensibilidad táctil persiste casi siempre».

Comenta también la poca afectación de la motilidad con este tipo de anestesia en comparación con la intrarraquídea clásica, la paresia vasomotriz como consecuencia de la afectación del simpático, lo molesto que resulta, en ocasiones, las tracciones del peritoneo parietal o el mesentérico, los posibles accidentes que pueden producirse llegando a relatar un caso clínico en el que por error consiguieron una anestesia completa excepto de las zonas inervadas por los pares craneales.

Es conveniente insistir que la descripción que realiza Pagés de la técnica, así como de sus indicaciones, contraindicaciones y complicaciones sigue gozando en la actualidad de plena vigencia.

En el verano de 1921 sobreviene el desastre de Annual con la muerte del general Silvestre y la de miles de soldados del Ejército Español, como consecuencia de la sublevación de los rifeños encabezados por Abd el-Krim. El lamentable incidente conlleva el envío urgente de tropas a Melilla asediada por los insurgentes. Entre los refuerzos enviados al Norte de África llegan insignes figuras de la cirugía española. Entre ellas se encuentran Bastos, Nogueras, Gómez Ulla y Pagés. Éste es destinado el 5 de septiembre como cirujano jefe de equipo al segundo grupo de Hospitales de Melilla, en particular al Hospital Docker ${ }^{47}$ (llamado así por estar formado por barracones de origen germano procedentes de la I Guerra Mundial).

Por esta fecha se nombra alto comisario de España en Marruecos y general jefe del Ejército de Operaciones a don Dámaso Berenguer Fuste (102). Este nombra jefe de Sanidad del Territorio a don Francisco Triviño, coronel médico. Con posterioridad le sucederá en el mando el inspector médico de Sanidad don Federico Urquidi Allbiño ${ }^{48}$.

Mediante una orden particular de la Plaza con fecha 11 de septiembre, se organizan 18 equipos de cirugía. Cada uno de ellos estará compuesto por: un cirujano jefe, un ayudante, un anestesista médico o practicante y dos enfermeros o sanitarios. Como director de los servicios de cirugía se nombra al Comandante Médico don Mariano Gómez Ulla ${ }^{49}$.

Debido a la ferocidad y virulencia de los combates aumenta enormemente el número de bajas, por lo que se decide acondicionar

\footnotetext{
${ }^{47}$ Hoja de Servicios Pag. 7.

${ }^{48}$ Información recogida del periódico «El Telegrama del Rif» del 10 de noviembre de 1921

${ }^{49}$ Información recogida de El Telegrama del Rif del 28 de septiembre.
}

diversos establecimientos militares como hospitales. De esta forma se clasifican los hospitales en cuatro grupos, cada uno de ellos con sus mandos naturales bajo la dirección del inspector médico del Territorio. El primer grupo estaba compuesto por el Cuartel Alfonso XIII y el Pabellón Mixto de Artillería mandado por el coronel médico Victoriano Delgado Piris. El segundo grupo compuesto por el Hospital Docker, por el Centro Hispano-Marroquí y por el Casino Militar estaba mandado por el coronel médico García Julián. El tercer grupo compuesto por el cuartel de Santiago, Hospital de Cruz Roja y el grupo Escolar, mandado por Francisco Alverico Almagro. Y el cuarto grupo compuesto por el Hospital Gómez Jordana, por el Hospital Central y por la Enfermería de Indígenas mandado por el Comandante Médico Roldán ${ }^{50}$.

Pagés se incorpora a su destino el 18 de septiembre. Recién incorporado se recupera de nuevo la ciudad de Nador. Con motivo de este combate se produce una enorme cantidad de heridos que afluye a los hospitales, entre los heridos se encuentra el famoso teniente coronel González Tablas y el teniente coronel legionario Millán Astray, al que opera el día $20^{51}$.

El trabajo de Pagés en el Hospital Docker es continuo e incesante, especialmente cuando suceden los combates de Tizza el 2 de octubre, el de Atlaten y Segangan los días 10 y 11 del mismo mes o el de Tizza librado el 2 de noviembre. En estos días llegó a permanecer hasta 24 horas seguidas en quirófano. Por su comportamiento es felicitado por el jefe de Sanidad del Territorio en oficio fechado el 10 de diciembre ${ }^{52}$. Pagés no solamente espera en el Hospital la llegada de heridos, sino que cuando acontece el avance de las tropas españolas se incorpora con su equipo quirúrgico a las zonas de combate. Estableció puestos quirúrgicos en Batel, Dar Drius, y Tistutin. Como comentó posteriormente el coronel médico Isidro García Julián: «...considerando Pagés que la suerte de los heridos de cerebro, vientre y hemorragia depende de ser prontamente intervenidos, se adelanta con su equipo». (García Julián J.) Con el hecho de incorporar los equipos quirúrgicos a la misma línea de combate, Pagés se adelanta treinta años a las modernas instalaciones de los equipos Quirúrgicos avanzados de la Sanidad de Campaña.

Hay muchos testimonios de los enfermos que fueron operados por Pagés o de aquellos que mostraban la esperanza, tras caer heridos, de que fuera él quien los tratara ${ }^{53}$.



${ }^{51}$ Estas noticias aparecen en El Telegrama del Rif del 20 de septiembre.

${ }^{52}$ Hoja de Servicios, página 8 . El oficio puntualiza que se le concede la felicitación «por haberse distinguido con gran celo, inteligencia y actividad en los servicios encomendados y curas de enfermos».

${ }^{53}$ En el libro diario de una Bandera del Comandante de Infantería Francisco Franco Bahamonde, contiene un párrafo que reza; «La noche es triste en Ambar; el Comandante Fontanes está muy grave, y todos saben lo que significa una herida de vientre con el hospital tan lejos. El doctor Pagés es toda la preocupación del herido; él podría salvarle. En la Legión se siente admiración por este notable cirujano, que ha librado a tantos legionarios de la muerte». La familia relata un último testimonio que por su curiosidad merece la pena anotarlo. En 1936 la viuda de Pagés, Berta Bergenman, contrajo segundas nupcias con un inspector de policía llamado Corrales Guerrero. Al inicio de la Guerra Civil detuvieron a toda la familia, fusilando al inspector Corrales en los primeros día de agosto. Doña Berta temiendo por la vida de sus hijos, encarcelados con ella en la «Checa» en que se convirtió el cine Europa, consiguió hablar con el Comisario Político responsable de su seguridad. Al explicarle que los hijos que ella tenía no eran de 
Otros consiguieron sobrevivir a pesar de lo grave de sus lesiones; el teniente Alafont de Zapadores con el cráneo atravesado por un proyectil, el Capellán López del Batallón de la Princesa con herida explosiva de hígado, el teniente Montero del Tercio con fractura de vértebra con compresión medular o el teniente Urzáiz con una bala que le destrozó la vejiga. (Gómez Ulla M.). Como complemento a la estructura sanitaria de Melilla durante los combates, se organizó un tren hospital entre esta Ciudad y Nador. Para ello se aprovechó el mismo que se utilizaba en el transporte de los minerales procedente de la Mina del Rif.

Para la evacuación de heridos a la Península se habilitó el buque de transporte Levante como barco-hospital. Hay que recordar el elevado contingente de tropas que había en Melilla en el año 1921.

El número de hombres era de unos 70.000, consiguiendo disponerse de 5.000 camas hospitalarias con una ocupación máxima de $4.714^{54}$.

Con la conquista de Nador, Seganga, y Monte Arruit, el Protectorado se pacifica parcialmente y es repatriado un gran número de tropas y oficiales. Pagés regresa de nuevo a su destino en el Hospital de Urgencias de Madrid, incorporándose el 24 de diciembre ${ }^{55}$.

Vuelve a iniciar su andadura como cirujano en Madrid trabajando en el Hospital General. En el tiempo que ha permanecido en Melilla un nuevo artículo suyo ha sido publicado en la Revista Española de Cirugía y en su número de diciembre; «Sobre la existencia de un espacio paravertebral hipersonoro en los pneumotórax de tensión» (103). En este artículo expone la observación que ha realizado en varios casos clínicos con pneumotórax a tensión provocado por proyectiles. Describe un signo constatado en todos los casos con gran pneumotórax, consistente en la presencia de una zona de hipersonoridad en el lado contralateral donde se produjo la lesión. Lo compara al triángulo paravertebral de Grocco, presente en las pleuresías, describiéndolo de la siguiente forma: «La zona hipersonora descrita tiene la forma de un triángulo aproximadamente isósceles, cuya base longitudinal se extiende entre las vértebras $4^{\mathrm{a}}$ y $9^{\mathrm{a}}$ dorsales y el vértice; en el caso descrito, está situada a 10 centímetros (cinco traveses de dedo) en la línea horizontal trazada desde el vértice de la apófisis espinosa de la $7^{\mathrm{a}}$ dorsal».

Como él bien reconoce, no se trata de un signo constante en todos los pneumotórax a presión. «No sé si en todos los casos de pneumotórax de tensión será comprobable la existencia del signo descrito, pero hay que suponer que su presencia estará condicionada por la cantidad de aire intrapleural y la tensión alcanzada por el mismo. La pleura distendida por la presión gaseosa tiende a tomar forma esférica y desplaza los órganos que la envuelven en una proporción que está en razón inversa de sus medios de fijeza».

En enero de 1922 se publica otro artículo: «La gastroenterostomía con collar epiplóico» (104). Quizás este trabajo deba recibir la denominación más propia de Nota Técnica, pues se ajusta más a su contenido.

Expone la técnica seguida por él para evitar las úlceras de boca anastomóticas que se producen en las gastroenterostomías y la con-

su actual matrimonio sino de su anterior marido el doctor Pagés, el Comisario Político ordenó la inmediata puesta en libertad de toda la familia. Pagés había sido el cirujano que le curó las graves heridas que sufriera en la Guerra de Africa de 1921.

${ }^{54}$ Información del El Telegrama del Rif del 27 de noviembre de 1921.

${ }^{55}$ Hoja de servicios. Pág. 8. siguiente peritonitis; «Si se considera que por lo menos un 2 por ciento de los gastroenterostomizados sufre de úlcera yeyunal y que en la mitad de los casos la localización es de boca anastomótica y si recordamos la tendencia perforativa de este ulcus hacia la cavidad libre del peritoneo, hacia la transcavidad epiplóica o en los órganos vecinos, colon transverso principalmente, encontraremos justificada toda protección de la boca anastomótica que atenúe los peligros de la perforación. Con este objeto he utilizado recientemente un refuerzo epiplóico de la línea externa de sutura, que me parece de utilidad tanto para evitar la peritonitis primitiva como el peligro de perforación de ulcus gastroyeyunal».

En agosto de 1922 asciende al empleo de comandante continuando en el Hospital Militar de urgencias desempeñando su función de cirujano.

A finales del mismo año publica en la Revista Española de Cirugía un trabajo que sin duda es uno de los mejores de sus artículos. «Heridas abdominales de guerra, mi experiencia personal» (105). Y desde el punto de vista quirúrgico es su mejor trabajo. En él se compendia toda su experiencia como cirujano en los Hospitales de Melilla, con heridos en abdomen por arma de fuego. Inicia el artículo intentando dejar clara su actitud frente a este tipo de heridos, teniendo en cuenta que durante la Gran Guerra las posiciones de los cirujanos se dividían en intervencionistas y abstencionistas. Pagés cree que lo indicado es la intervención inmediata de las heridas abdominales ${ }^{56}$

Critica a Bergman ${ }^{57}$ por su abstencionismo: «La frase de Bergman "yo no opero moribundos", hizo un proselitismo que seguramente ha acarreado más perjuicios que ventajas". También hace referencia a Delorme y a MacCormac ${ }^{58} ;$ «...el último conflicto mundial era tan contrario a la terapéutica-quirúrgica, activa en esta clase de heridas, que MacCormac pudo difundir como una verdad admitida, como axiomática su célebre frase "a herida de vientre abstención" y Delorme, en una comunicación titulada: "Consejos a los cirujanos", presentada a la Academia de Ciencias de París el 10 de agosto de 1914, insistía en la necesidad de someter a los penetrados de vientre al tratamiento incruento como más favorable para los heridos».

La razón principal que aducían los abstencionistas era la dificultad de practicar una intervención a un paciente en franco shock (106,

\footnotetext{
${ }^{56}$ De la misma forma opinaba Carl Gussenbauer (1842-1903), Sucesor de Billroth en la cátedra de Wien. Cuando una vez le preguntó a un colega porqué no sajaba un abceso, le contestó que se inclinaba por el planteamiento conservador, a lo que Gussembauer respondió: «son pacientes los que debes conservar, no los abcesos». También demostró la posibilidad de gastrotomía con técnicas asépticas en perros y relató la técnica de resección completa de laringe (Haeger K, Guerra F.).

${ }^{57}$ Ernst Von Bergmann (1836-1907) natural de Riga. fue cirujano del ejército Prusiano en 1866 y ayudante de R. Volkmann y T. Billroth y sucesor de B. Langen en la clínica de Berlín. Se interesó por el embolismo graso, la cirugía de las articulaciones, ligadura de la vena femoral, tratamiento quirúrgico de las enfermedades de las glándulas linfáticas y diseñó la operación radical de mastoides y la cirugía cerebral. Su gran aportación a la cirugía fue el paso del concepto de la antisepsia listeriana a la de la asepsia, estableciendo la limpieza preoperatoria del cirujano y sus ayudantes, paciente y la esterilización al vapor de los instrumentos. (Haeger K., Guerra F., Riera J.).

${ }^{58}$ Edmond Delorme (1847-1929) natural de Luneville. Médico Militar. Introdujo la decorticación del pulmón en el enfermo crónico. William M. MacCormac (1830-1901). de Belfast. Participó en las guerras Franco-Prusiana (1870) y Turco-Serbia (1876) donde aplicó los métodos antisépticos. Se centró en la cirugía abdominal y articular. (Gar.ía del Real E.1934., Haeger K., Guerra F.).
} 
107, 108). Pagés no solamente niega este razonamiento, sino que incluso indica soluciones para sacar al paciente del shock. Lo que hoy en día llamaríamos reanimación preoperatoria. «El calentamiento general, el suero y los tónicos cardíacos, no deben desecharse, pero no pretendamos con ellos reparar definitivamente el estado creado por la lesión de un vaso aislado o de un parénquima vascular que continuara sangrando a pesar de la aplicación de aquellas medidas; así pues por lo que al shock por hemorragia se refiere, de ninguna manera puede motivar aplazamiento en una intervención».

Para reafirmar su actitud intervencionista presenta su propia estadística: «En resumen: cuatro abstenciones impuestas, cuatro muertos».

Es curioso que la estadística que presenta en los puestos quirúrgicos avanzados es superior a la que obtiene en el propio Hospital Docquer, teóricamente mejor dotado, un $70 \%$ frente a un $52 \%$. Probablemente esta diferencia se deba a la celeridad con que se operaban los heridos que eran evacuados a los puestos avanzados, mientras que transcurrían horas si la evacuación se efectuaba sobre el Hospital. También por que como decía Pagés: «...soy un convencido de que con buena voluntad y personal auxiliar entrenado puede llevarse la asepsia a todas partes y no otra cosa hace falta para laparotomizar a un herido de guerra».

Pagés llega a afirmar que, en gran parte, la actitud abstencionista de muchos cirujanos se debía al miedo de enfrentarse con una estadística elevada de mortalidad.

El trata de huir de esas posturas y por ello dice: «Hemos operado casos desesperados, en los que por anticipado podía hacerse el pronóstico fatal, por tanto; pero era necesario buscar la pequeña posibilidad de curación con el bisturí en la mano y con la mente alejada de los resultados estadísticos».

Para finalizar esta discusión entre abstencionistas e intervencionista concluye: «...así es que las discusiones que sostenían los cirujanos de ambos bandos beligerantes al comienzo de la pasada guerra mundial, no tienen en la actualidad más que un interés histórico».

Desaconseja la práctica de incisiones complejas como las de Murphy-Sprengel, Jaboulay ${ }^{59}$, etc. «En la actualidad cualquier cirujano elegiría la laparotomía longitudinal ante heridas abdominales».

Aunque se trata de un trabajo puramente quirúrgico, Pagés deja entrever la gran importancia que concede a la anestesia y los amplios conocimientos que posee sobre la misma. Ya hemos comentado anteriormente como combate el shock y no lo considera contraindicación para la intervención, llegando incluso a la administración de suero si la situación clínica del paciente lo precisase.

Como método anestésico elige la raquianestesia dorsolumbar. Prefiere este método pues le reporta una relajación intestinal mejor que con la anestesia inhalatoria, aparte de un silencio abdominal muy conveniente. El único inconveniente que le encuentra es el corto espacio de tiempo que concede la raquianestesia, apenas una hora $\mathrm{u}$ hora y cuarto. No obstante considera

\footnotetext{
${ }_{59}$ John Benjamín Murphy (1857-1916) nacido en Appleton, Wisconsin. Fue profesor de cirugía en Chicago y en la North Western University. Preocupado por las peritonitis resolvió la dificultad de anastomosis intestinales mediante un empalme que lleva su nombre. También realizó la sutura boca a boca de vasos sanguíneos mediante invaginación. Mathieu Jaboulay (1860-1913). fue el primero en realizar la simpatectomía en las enfermedades vasculares e introdujo la gastro-duodenostomía (Guerra F.).
}

que en cirugía de guerra es un tiempo suficiente para hacer una laparotomía.

Demuestra conocer el efecto de simpatectomía con vasoplejía e hipotensión que acompaña a la raquianestesia, cuando escribe: «La raquianestesia alta produce con frecuencia una hipotensión acentuada que, unida a lo que acompaña el shock inicial es causa de fenómenos alarmantes en algunas ocasiones pero que, afortunadamente, nunca hemos visto terminar de un modo fatal».

Durante el año transcurrido Pagés recibe numerosos homenajes en reconocimiento a la labor desempeñada en la pasada guerra africana. En este año también nace Fidel, quinto hijo del matrimonio ${ }^{60}$.

Sus publicaciones continúan, en 1923 y en la Revista Española de Cirugía aparece: «Drenaje transcerebral» (109).

Artículo en el que resume en un principio los distintos tratamientos más usados por los cirujanos de la época. «Las opiniones han estado muy divididas desde que Von Bergmann aconsejaba alejar el peligro de infección cerebral por la reunión inmediata de las partes blandas del pericráneo» ${ }^{61}$.

Posteriormente incluye su experiencia personal y las variantes que realiza a la técnica de drenaje transcerebral original de Sedlicka y puesta en práctica en 1917 en el Hospital austríaco de Dorna Raudrey. «El empleo repetido de una técnica nos lleva de una manera insensible al lógico perfeccionamiento de la misma, y de ahí algunas modificaciones al proceder de Sedlicka, corrigiendo pequeños detalles, con los cuales tuvimos que tropezar y resolver. Las principales modificaciones introducidas fueron: $1^{\text {a }}$; sustituir el clamp o pinzas corrientes por una de Pita para extracción de cuerpos de uretra, ventaja indiscutible tanto por la disminución del grosor como por la comodidad del manejo. $2^{\text {a }}$; aplicación de inyecciones frecuentes de agua oxigenada (12 y diluidas a la mitad) por los extremos del dren cada tres horas para impedir la coagulación de la sangre dentro del tubo y mantener cierto grado de humedad y limpieza en el foco; y $3^{\mathrm{a}}$; continuar al drenaje de caucho el de un manojo de crines al objeto de evitar los fenómenos exvacuo engendrados al retirar el tubo»».

Finaliza el escrito insistiendo en los beneficios indudables que reporta el método siempre que se utilice en los casos que verdaderamente lo requieran: «La impresión que hemos sacado del empleo del drenaje transcerebral es francamente favorable, ya que lo hemos reservado para casos sumamente graves, con grandes destrozos craneales y extensas lesiones de centros nerviosos, casos que abandonados a la evolución espontánea o sometidos a la precaria terapéutica de la toillete focal, hubieran fallecido con seguridad».

En agosto de este año solicita permiso para marchar de vacaciones a Cestona. Sale de Madrid con toda su familia el 24 de agosto, dejando en imprenta el que sería su póstumo trabajo «Aspectos quirúrgico del estreñimiento». (110). El artículo se imprime en el número de agosto de la Revista Española de Cirugía, aunque su distribución debió de producirse después de su muerte (21 de septiembre), pues en la portada debajo del título se incluye la leyenda: «Trabajo póstumo». En este último trabajo

\footnotetext{
${ }^{60}$ Información que nos facilita la familia. La foto corresponde al homenaje celebrado en un restaurante madrileño; Tournié. Fidel haría con posterioridad la carrera de medicina.

${ }^{61}$ A Bergmann se deben los principales adelantos del siglo XIX en las técnicas de cirugía craneal. (Guerra F., Riera J.)
} 
hace un repaso de la fisiopatología de las apendicitis crónicas, en el que incluye sus observaciones. «Además, según he podido observar es muy frecuente la existencia de ciego móvil y apendicitis crónica hasta el punto que cuando diagnosticamos la primera afección podemos suponer que existe la segunda. El ciego móvil no constituye una enfermedad por su disposición anatómica, sino por la ectasia cecal y la tiflitis catarral que en él se desarrollan. Se comprende fácilmente que el apéndice tiene que ser tributario del proceso inflamatorio de la mucosa cecal y de las alteraciones circulatorias de esta primera porción del intestino grueso».

«En todos los ciegos móviles operados por nosotros había apéndices alargados, engrosados, con bastante exudación en su contenido y a veces coprolitos».

En las últimas hojas de su trabajo hace una curiosa y acertada indicación acerca del shock que sufrían los pacientes al traccionar de los mesos; este efecto aún hoy ante una anestesia no excesivamente profundizada podemos comprobar trastornos hemodinámicos cuando el cirujano realiza dicha maniobra. De esta forma lo relata Pagés: «Cuando los mesos son largos la operación se practica con facilidad y no es preciso para exteriorizar las vísceras tracción sobre ellas que tanto favorecen la aparición del shock».

Antes de partir para Cestona, Pagés entrega en el Ministerio de la Guerra una instancia solicitando su pase a la situación de supernumerario dentro del Ejército; esto le sería concedido el 20 de septiembre $^{62}$. Según su amigo Gómez Ulla, a Pagés ya le habían sugerido con anterioridad la posibilidad de abandonar el Ejército y dedicarse por entero a su clientela, pero hasta la fecha se había resistido e incluso acudió voluntario a la guerra de África (85).

El viernes 21 de septiembre Pagés decide regresar a Madrid con toda la familia. Emprende la marcha a primeras horas de la mañana con el fin de llegar en el día a su destino ${ }^{63}$.

A 15 kilómetros de Burgos, en el término municipal de Quintanapalla, en la llamada cuesta de «la brújula», el vehículo derrapa y tras dar varias vueltas de campana choca contra un árbol. Como consecuencia del golpe, una hija de Pagés, Ascensión, sufre la amputación casi completa de la mano izquierda, el joven Teodomiro se fractura una clavícula y Pagés fallece, al parecer, en el acto ${ }^{64}$.

Los restos son trasladados a Madrid el día 23 por ferrocarril hasta la estación del Norte, desde allí son trasladados entre una gran multitud hasta el Cementerio de San Lorenzo donde es enterrado ${ }^{65}$.

La muerte de Pagés deja inacabada su obra científica y por desarrollar una prometedora carrera de cirujano ${ }^{66}$.

\footnotetext{
$\overline{{ }^{62} \text { Diario Oficial }} n^{\circ} 209$ del 20 de septiembre.

${ }^{63}$ Según su hija Concepción, en el vehículo viajaban los cinco hijos, una sirvienta de la familia, Pagés y su esposa y un joven llamado Teodomiro Díaz que actuaba de conductor. No obstante, en el momento de producirse el accidente, el vehículo iba conducido por Pagés, siempre en versión de su hija, que lo llevaba desde Vitoria.

${ }^{64}$ Información recogida de ABC de Madrid del 26 de septiembre de 1923. Cuenta a su vez que debido a la escasez de tráfico por la carretera el cuerpo de Pagés y los heridos permanecen sin poder ser atendidos desde las tres de la tarde hasta las cinco en que un vehículo matrícula de Granada conducido por Francisco Martín y cuyo dueño era Angel Rodrigo, lleva a los accidentados hasta la Casa de Socorro de Burgos, donde se certifica la muerte de Pagés y a la pequeña Ascensión se le amputa la mano a la altura de la muñeca.

${ }^{65}$ Información del diario ABC del 26 de septiembre de 1923.

${ }^{66}$ En diversos periódicos se recoge la información sobre la muerte de Pagés. En el Globo con fecha 1 de octubre se transcribe un artículo de
} Gómez Ulla dedicado a Pagés y publicado en El Telegrama del Rif del

\section{ANÁLISIS DE SU OBRA: DISCUSIÓN}

Para un mejor conocimiento y estudio de lo que significa Pagés en la historia de la medicina es conveniente realizar una parcelación de su obra, con todos los riesgos que lleva consigo el dividir de manera artificial la obra de un autor, la cual hay que entenderla siempre dentro de un contexto general, tanto en lo concerniente a los aspectos globales de su existencia vital, como al entorno social y político en el que desarrolla su labor y, especialmente, resulta imprescindible relacionarlo con el desarrollo científico de la era de la medicina que le tocó vivir.

Pero, quizás, esta artificiosa disección de cualquier obra se nos antoja más penosa con Pagés, si tenemos en cuenta las características y peculiaridades que definen su trabajo, compendiado y sintetizado en muy pocos años. Los escasos catorce que duró su trayectoria profesional.

Pagés nace en un incierto período de la historia decimonónica de España. Su nacimiento se encastra a horcajadas entre el sorprendente fallecimiento de Alfonso XII (25 de noviembre de 1885) y el renacer de la esperanza monárquica con la llegada al mundo de Alfonso XIII (17 de mayo de 1886). La regencia de María Cristina, el pacto del Pardo entre liberales y conservadores, la dimisión de Antonio Cánovas del Castillo y la llegada al Gobierno de Práxedes Mateo Sagasta $^{67}$, no fueron suficientes bálsamos tranquilizadores para apaciguar una sociedad española tan acostumbrada a la inestabilidad golpista de la época, a la alternancia precipitada de partidos en el poder y al caciquismo como norma en las elecciones.( El propio Sagasta, tras los comicios de 1884 que dieron el triunfo a los conservadores dijo: «Las futuras Cortes están deshonradas antes que nacidas») (111).

Fruto de esa inestabilidad política, dieciséis días antes del nacimiento de Pagés, el 10 de enero de 1886, se produce en Cartagena una nueva y violenta intentona golpista que acabará con la muerte del leal general Fajardo y la huida de los insurgentes a Orán(111).

En este ambiente de incertidumbre y convulsión ve la luz nuestro personaje. Características socio-políticas que le acompañarán, desafortunadamente, a lo largo de su corta vida.

Este es el mundo político que rodea a Pagés en su nacimiento. En lo concerniente a la vida social, diversos acontecimientos se suceden a lo largo de este año. En España, se estrena la Zarzuela «La Gran Vía» con libreto de Felipe Pérez y música del maestro Federico Chueca.

La escritora Emilia Pardo Bazán publica su novela «Los Pazos de Ulloa». Del mismo modo, el ilustre y genial Benito Pérez Galdós da a conocer su novela «Fortunata y Jacinta», fiel reflejo

25 de septiembre, en este diario también se hace eco de una reunión de médicos militares con el fin de elevar un escrito al Ministro de la Guerra Sr. La Cierva, solicitando que sus hijos cobren la paga íntegra. En el mismo sentido se dirigió Gómez Ulla a la Reina Madre María Cristina en el póstumo homenaje celebrado en el Hospital de Carabanchel. (Gómez Ulla M.1924). En Blanco y Negro del 28 de octubre, homenaje en el Hospital Militar de San Sebastián. Descubrimiento de una lápida en el Hospital Militar de Melilla, en el Telegrama del Rif del 30 de septiembre.

${ }^{67}$ El Gobierno tomó posesión el 27 de noviembre de 1886. Junto a Sagasta, que ostentaba el cargo de Presidente del Consejo, juraron ante la Reina Regente Doña María : Morete como Ministro de Estado, Montero Rios en Fomento, Berenguer en Marina, Jovellar en Guerra, Gamazo en Ultramar, Camacho en Hacienda y Venancio González en Gobernación. 
de la sociedad de final de siglo. Se inician las obras de uno de los proyectos tan originales como malogrado en el ámbito del urbanismo: el arquitecto Arturo Soria ejecuta la primera, y única, fase de «Su ciudad lineal». Por otra parte, en el resto del mundo destacan diversos acontecimientos como la inauguración de la Estatua de la Libertad, instalada en el puerto de Nueva York, por el presidente Stephen Grover Cleveland. También en los Estados Unidos se inician las luchas sindicales por la reivindicación de la jornada laboral de ocho horas. Mientras, en Rusia, se aprueban leyes declarando ilegales las huelgas y en Francia se manda al exilio a los pretendientes al trono. Como dato final anecdótico, en este año se da a conocer una bebida refrescante; el Doctor Pemberton un boticario de Atlanta, pone en circulación una bebida dulzona y tonificante: la Coca-Cola (112).

La guerra de Margallo en Melilla (1893), las insurrecciones Cubana y Filipina (1897), el asesinato de Cánovas el 8 de agosto del mismo año por el anarquista Angiolillo, la declaración de Guerra del presidente norteamericano McKinley a España, el 23 de abril de 1898, los desastres navales de Cavite y Santiago (mayo y julio del 98), y la Paz de Paris del 12 de agosto, abocaron a España y su sociedad a un ambiente de desánimo y de desilusión. En este ámbito de angustia y desesperanza, Pagés cursó sus estudios de bachillerato en el Instituto de Huesca (111).

En el mundo de la Medicina y su contexto, Pagés nace en pleno período del positivismo-naturalista. En palabras del Profesor Laín Entralgo, este vasto período abarca desde 1848 (generalización del uso de la anestesia) hasta 1914 (inicio del primer gran conflicto mundial). Afirma D. Pedro: «En pocos momentos de su historia ha alcanzado tan alto nivel como en este el cultivo de las ciencias de la naturaleza; en ninguno tanto prestigio. El hombre de 1880 espera de la ciencia natural todo lo que sólo en esperanza puede conseguirse sobre el planeta: Felicidad perfecta, paz definitiva, plenitud de espíritu» (113).

En el terreno de la cirugía, toda una serie de novedades técnicas: anestesia, hemostasia, transfusión sanguínea, antisepsia, asepsia, perfección creciente del instrumental; van a transformar rápidamente el cariz y las perspectivas del acto quirúrgico, disminuyendo la elevada mortalidad del 50 por ciento que hasta entonces se mantenía en las salas de cirugía de los hospitales $(106,107,108,113)$.

Pagés nace dentro de este período. Período de espléndido desarrollo de la cirugía. Un período en el que pueden ser diferenciados tres etapas: en la primera (1848-1867) se difunde y perfecciona la anestesia y son introducidas nuevas técnicas operatorias. En la segunda (1867- hasta el último decenio del siglo XIX), ocurre otro tanto con la antisepsia. El cirujano apoyado en las ventajas anestésicas y en los nuevos conceptos de antisepsia y asepsia, aborda regiones y métodos que para él venían constituyendo un «Noli me tangere». En la tercera, se hace patente la transformación de una cirugía exerética o, a lo sumo, conservadora, en otra de índole restauradora y funcional (113).

Es un período en que el estudio clínico ordenado, basado en métodos exploratorios, consigue determinar la localización anatómica de afecciones susceptibles de tratamiento quirúrgico, generando una patología quirúrgica nueva. Este gran momento de la cirugía positivista germinó y floreció en los hospitales parisinos y tuvo carácter universal en breve tiempo por haber acudido a las aulas y hospitales parisinos médicos de todo el mundo $(107,108)$.
La cirugía española de este período se vio afectada por la tardía aceptación del método antiséptico, y si bien la anestesia por inhalación se aceptó inmediatamente después de su descubrimiento ${ }^{68}$, fue lenta también la adopción en la cirugía electiva de los métodos anatomoclínicos de exploración, el recurso a las pruebas diagnósticas de laboratorio y a los exámenes histo-patológicos, así como la ejecución de los grandes intervenciones cavitarias según normas asépticas regladas (106). Los progresos experimentados en la segunda mitad del siglo XIX, a pesar de lo expuesto, se debió al esfuerzo personal de un número determinado de cirujanos españoles que con su contacto directo con figuras de otros países, trajeron la renovación doctrinal y técnica precisa ${ }^{69}$. Tampoco es despreciable el esfuerzo modernizador de la cirugía española llevado a efecto por las escuelas médico-quirúrgicas, distintas de las universitarias, como la Escuela libre de Medicina y Cirugía de Sevilla y la Escuela Práctica libre de Medicina y Cirugía de Madrid (107, 113).

Por tanto, cuando Pagés nace ya se habían alcanzados los más importantes logros quirúrgicos del siglo XIX. La anestesia por inhalación era una práctica común en todos los hospitales del mundo. Después de la anestesia etérea de Morton y Jackson (1846) y la anestesia clorofórmica de Simpson (1847), Bigelow (1816-1890) en Estados Unidos, Robert Liston en Inglaterra, Jobert de Lamballe (1799-1867) y J.F. Malgaigne (1800-1865) en Francia ${ }^{70}$, N.I. Pirogov (1810-1881) en Rusia, F. Schuch (1804-1865) en Austria y J.N. Von Nussbaum (1829-1890) en Alemania $^{71}$ se habían convertido en fervorosos propagandistas

${ }^{68}$ El primero en utilizar éter como anestésico en España fue Diego Argumosa y Obregón (1792-1865) el 13 de enero de 1847. Desde el 13 al 26 de enero, Argumosa realizó once ensayos con el éter, con resultados más o menos satisfactorios, utilizando el inhalador de William Harapath. Los ensayos de Argumosa tuvieron rápido eco en la prensa médica y en diarios de Madrid. El 24 de enero el periódico Anales de Cirugía daba la noticia del descubrimiento de la anestesia y de los ensayos de Argumosa .El periódico La Facultad informaba también de lo mismo el 28 de enero. Si tenemos en cuenta que William T.G. Morton introdujo el éter como anestésico por primera vez el 16 de octubre de 1846, y en Europa realizó la primera demostración Robert Liston el 21 de diciembre de 1846 en el University College Hospital de Londres, podemos afirmar la pronta aceptación de la anestesia inhalatoria en nuestro país (Franco A.1996).

${ }^{69}$ Uno de estos médicos pioneros fue Federico Rubio y Gali (1827-1902) natural del Puerto de Santa María. Por sus ideas liberales se vió obligado a marchar a Londres en 1860 donde trabajó con W. Fergusson, visitó Montpellier y Paris donde colaboró con Broca, Velpeau y A. Nelatón. También recorrió Estados Unidos donde mejoró la excelente formación anatómica y quirúrgica que ya había adquirido. Fundó a su regreso a España en 1868 con la Primera República, la Escuela Libre de Medicina y Cirugía y el Instituto Terapéutico en Madrid. Practicó la disección de los ganglios linfáticos en el cáncer de mama antes que Kocher y Halsted. Hizo nefrectomías, histerectomías y laringectomías. (Guerra F., Laín Entralgo P.1963).

${ }^{70}$ Un estudiante Norteamericano residente en Paris llamado Francis Wi1lis Fischer recibió noticias por carta desde Boston, en diciembre de 1846, del uso del éter como anestésico. Después de haberlo autoexperimentado propuso a Alfred A.L. M.Velpeau (1795-1867) ensayarlo en su clínica de la Charité.A lo que el cirujano francés se negó por parecerle la práctica peligrosa y por mantener su conocido aforismo: «Evitar el dolor en las operaciones quirúrgicas es una quimera». El joven estudiante sí convenció a Lamballe. (Haeger K.,Franco A.1996).

${ }^{71}$ En Alemania es preciso también destacar la aportación de Friedrich Trendelenburg (1844-1924) introductor de la anestesia endotraqueal en 1870. (Guerra F.). 
del nuevo método). En el campo de la anestesia local, Albert Niemann (1834-1861) de Göttiengen sintetizó la cocaína a partir de las hojas de coca en $1858^{72}$, en 1873 Alexander H. Bennett (1848-1901) demostró las propiedades analgésicas de la cocaína. En 1878 V. K. Anrep la empleó como analgésico local, pero su uso no se generalizó hasta que Karl Koller (1857-1944) comunicó su trabajo sobre los efectos anestésicos de la cocaína sobre la conjuntiva en el Congreso de oftalmólogos alemanes celebrado en Heidelberg en septiembre de $1884^{73}$ (106, 107, 108, 113, 114, 115).

En 1885 William Steward Halsted (1852-1922) describió la anestesia de conducción, siete años antes que Karl Ludwig Schleich (1859-1922) expusiera en el Congreso de Cirugía celebrado en abril en Berlín su aportación sobre la anestesia por infiltración.(106, 107, 108). En España, como ya hemos apuntado, pronto Diego Argumosa y Obregón utilizó el éter por inhalación, otros, como el dentista americano residente en Madrid, Oliverio Machechan (114), A. Mendoza Rueda (107) y González Olivares (116) generalizaron su uso.

En lo concerniente a la anestesia local, el oftalmólogo catalán Luis Carreras Aragó (1853-1907) publica el 10 de diciembre de 1884 sus experiencias personales con la cocaína, posteriormente, Juan Ristol Canellas; médico militar, en 1885 publicó un trabajo recopilatorio del uso de la cocaína aportando experiencias personales (115). También en diciembre de 1884, Rodolfo del Castillo (Del 117) y en enero de 1885 Cayetano del Toro (118) se encargaron de difundir el método de Koller.

También el método antiséptico de Lister iba ganando adeptos desde la primera descripción completa que en 1867 hizo el Barón de la antisepsia de su tratamiento en la revista Lancet (106). Carl Thiersch (1822-1895), Richard Von Volkman (1830-1889) y J.N. Von Nussbaum en Alemania, Billroth (1829-1894) en Suiza, Bassini (1847-1924) en Italia, M. Saxtorph (1822-1900) en Dinamarca, Just M. Lucas-Championniere (1843-1913) en Francia y Salvador Cardenal (1852-1927) en España ${ }^{74}$ se encargaron de hacer extensivo y divulgar el «listerismo», imponiéndose definitivamente a la teoría del «Pus bonum et laudabile» ${ }^{75}$.

La hemostasia, a su vez, experimentó en esta parte del siglo XIX notables perfeccionamientos, entre ellos la primera pinza hemostática introducida en 1872 por Spencer Wells, las pinzas compresoras de Vernuil y Pean, la venda elástica de Esmarch, el aplastamiento lineal de Chassaignac, la acupresión de Simpson y la transfixión de los tejidos de Halsted $^{76}(108,113)$.

La incorporación a la práctica quirúrgica de la anestesia, antisepsia asepsia y hemostasia, permite a los cirujanos empezar a penetrar sin temor en las cavidades internas y articulaciones.

Así aparecen destacados cirujanos en Europa y Estados Unidos que van incorporando nuevas técnicas quirúrgicas. En Francia Paul Reclus (1847-1914) describe intervenciones intestinales y ginecológicas, A. Nelaton (1807-1873) ejecuta la ovariectomía y describe el hematocele retrouterino (1851), Jules Guerin (1805-1886) realiza numerosos trabajos sobre cirugía ortopédica, Pierre Paul Broca (1824-1880) inicia la cirugía cerebral, siendo el primero en trepanar un absceso cerebral (1861), Tuffier, Delorme, Jaboulay, Pean, Farabeuf... Son otros de los destacados especialistas. En Suiza, Jacques L. Reverdin (1842-1929) inició la técnica de injertos de piel libre (1870), Theodor Koller (1841-1917) describió en 1870 la técnica para reducir las subluxación de la articulación del hombro y en 1878 apuntó el mixedema que se produce en el 30 por ciento de los que tiroidectectomizaba. En los países bajos Anthonius Mathijen (1805-1878) en 1852 defendía su técnica para la inmovilización de fracturas. En Gran Bretaña, James Paget (1814-1849) describía la obstrucción venosa del brazo o síndrome de Paget-Shoether (1866), el cáncer de mama (1874) y la osteitis deformante crónica (1877). Jonathan Hutchinson (1828-1913) en 1874 era el primero en realizar en un niño la intususcepción intestinal y en describir pormenorizadamente las lesiones de los sifilíticos (1817). William Mac Ewen (1848-1924) intervino un tumor de la duramadre cerebral (1879) y describió una técnica para la osteotomía en el genu valgum (1881). Frederich Treves (1853-1923) fue el primero en intervenir una apen-

\footnotetext{
72 Otros dos hechos van a potenciar la práctica de la anestesia local; el invento de la jeringa de inyecciones por Charles Gabriel .Pravaz (1791$1853)$ en 1853 y el de la aguja hipodérmica por Alexander Wood (1817-1874) en 1855. (Heder K.,Guerra F.,Laín Entralgo P.1963).

${ }^{73}$ Koller conoció los efectos anestésicos de la cocaína por medio de su amigo Sigmund Freud (1856-1939) quien intentando deshabituar a su colega Fleich Von Marxow, adicto a la morfina como consecuencia de su elevado consumo para aliviarse de los dolores que le comportaba un neurinoma que se le había producido en el muñon de la amputación de un dedo que hubo que practicarle para librarle de una infección sobrevenida a consecuencia de un corte fortuito realizando una autopsia, le administró cocaína y describió la insensibilidad en las mucosas nasal y bucal que se producía tras el contacto con ella. (Márquez C.1995).

${ }^{74}$ Algunos buscaron variantes a la técnica original de Lister. Así Thiersch sustituyó el acido fénico por el ácido salicílico en las curas. Volkman recurrió al cloruro de cinc, mientras que Cardenal utilizó el alcohol etílico diluído. Como paradigma de defensor del método Lister fue sin duda el cirujano alemán Johan Nepomak Ritter Von Nussbaum, así lo describe en su diario de viaje, John Berg, cirujano sueco: «Es católico fanático, gran nacionalista, amable con los pobres y campechano en sus formas. Ser un médico atareado y un operador diestro y admirador convencido de Lister y al mismo tiempo padecer todas esas rarezas, revela una combinación insólita de energía y debilidad. Cuando opera, sigue la costumbre francesa de vestir de etiqueta, aunque sin condecoraciones». (Haeger K., Laín Entralgo P.1963).
}

\footnotetext{
${ }^{75}$ El profesor de cirugía de Madrid Juan Creus y Mansó (1826-1897) llegó a afirmar: «El paso más grande que ha dado la cirugía se debe a la doctrina microbiana. Solo Eduardo Jenner es comparable a Lister en cuanto a beneficios efectivos aportados a la humanidad. (Guerra F., Riera J.).

${ }^{76}$ Thomas Spencer Wells (1818-1897) de St. Albans, Herfondshire. Médico naval intervino en la guerra de Crimea. Fue profesor de cirugía del University College Hospital. Practicó la ovariotomía y esplenectomía.

Aristide A.S. Vernuil (1823-1895) de París. Realizó gastrostomía en las retracciones cicatrizales de esófago modificando la técnica de Sedillot. Fue titular de cirugía del Hotel de Dieu.

Jules E. Pean (1830-1898). Cirujano del Hotel de Dieu: Realizó la primera gastrectomía con anastomosis gastroduodenal por carcinoma (1879). Fue el primero en operar divertículos de la vejiga urinaria. Eduard P.M. Chassignac (1804-1879). Introdujo el drenaje quirúrgico con sonda de goma.

James Young Simpson (1811-1870) Ginecólogo de Edimburgo que por primera vez utilizó cloroformo como anestésico en un parto. William Stewart Halsted (1852-1922) de Nueva York. Introdujo la anestesia por infiltración. La autotransfusión de sangre desfibrinada en la intoxicación por monóxido de carbono y describió múltiples técnicas quirúrgicas: Mastectomía, herniorrafia... Convencido de las técnicas antisépticas, las defendió e introdujo los guantes de goma en las intervenciones quirúrgicas en 1910. (Riera J.)
} 
dicitis tras un acceso agudo. Sin olvidar a los ya mencionados Lister, Wells... (107, 113).

En Alemania inicia la nueva cirugía Langenbeck (1810-1887) que destacó por sus postulados conservadores huyendo de las amputaciones. Johann Von Mikulick-Radecki (1850-1905) trabajó con intensidad sobre las gastroscopias y esofagoscopia (1881), implantó el uso de guantes de algodón en el acto quirúrgico. Langenbuch (1846$1901)$ en 1882 practicó la primera extirpación de vesícula biliar en una colelitiasis con empiema ${ }^{77}(107,113)$.

En Austria nació el gran creador de la cirugía abdominal Theodor Billroth. En 1859 publicó un trabajo sobre heridas por arma de fuego. Realizó la primera resección de esófago (1872), ejecutó una laringectomía total (1873) y la resección con éxito del píloro por cáncer (1881).

En Rusia destacó la figura de Nicolai Ivanovich Pirogov. En Escandinavia, Mathias Hieronymus Saxtorph (1822-1900) quien se distinguió en la cirugía oftálmica y en la de extremidades. Por su parte en Italia descollaba la figura de Eduardo Bassini (1847-1924) por sus trabajos sobre la nefropexia del riñón flotante (1882) y la reparación por planos de la hernia inguinal (1884). Enrico Bottini (18371903) destacó por su tratamiento de la obstrucción prostática (1874).

En Estados Unidos, Henry Jacob Bigelow (1816-1890) abrió por primera vez la articulación de la cadera resecando la cabeza del fémur (1852) e introdujo la litotricia de los cálculos vesicales para la extracción uretral fácil (1878). Henry Orlando Marcy (1837-1924) utilizó por primera vez el catgut fenicado en las ligaduras (1878). George Washington Crile (1864-1943) perfeccionó la anestesia troncular con cocaína y estudió en profundidad el choque quirúrgico (1887). Y, por supuesto, el mencionado Halsted (107, 113).

En traumatología los avances también fueron notables. Los principios generales del tratamiento de las fracturas fueron formulados por H. Owen Thomas (1834-1891), con la completa inmovilización adecuada e ininterrumpida, norma que mejoraría el cirujano francés Lucas Championiere al aconsejar la movilización oportuna y el masaje. Lo que revoluciona el tratamiento de las fracturas en los años centrales del siglo XIX es el vendaje enyesado, aportación del médico holandés Antonio Mathysen en 1851. De igual forma, Pirogov en Rusia, Von Bergman en Alemania y Manuel Bastos Ansart en España, consolidaron el uso del vendaje enyesado (107).

Finalmente, la cirugía en España, a pesar de los invonvenientes apuntados, mantuvo en este período una digna representación con Antonio Mendoza Rueda (1811-1872), aparte de su aportación al campo de la anestesia introdujo los estudios anatomopatológico y anatomoclínico de los enfermos. Juan Creus Mansó (1826-1897), aportó el termocauterio en la hemostasia. Alejandro San Martín Satrústegui (1847-1908) que en 1884 aportó sus estudios sobre el choque traumático. Salvador Cardenal, además de su aportación a la divulgación del método de Lister, en 1880 publicó una obra quirúrgica en la que abrió el camino a la cirugía electiva e introdujo variaciones técnicas a la gastroenterostomía. Eulogio Cervera Ruiz (18551916), Luis Guedea y Calvo (1860-1916). Víctor Escribano García (1870-1961), José Rivera Sans (1852-1912) y el ya citado Federico Rubio Gali conformaron un conjunto de cirujanos que mantuvieron un aceptable rol en el contexto de la cirugía europea (107).

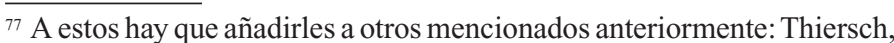
Von Esmarch, Nussbaum, Volkman, Von Bergman ó V. Czerney (Haeger K., Guerra F.).
}

Pagés nace en 1886, es el año en el que Pean describió la técnica de la histerectomía fragmentada, el británico MacCormac relató un caso de ruptura intraperitoneal de vejiga urinaria, el norteamericano Mc Ewen propuso la técnica para la cura radical de hernia mediante el taponamiento interno con pliegue del saco y sutura externa por planos. Von Bergman describió su método de asepsia de esterilización mediante calor, Victor A. Horsley extirpó por primera vez la hipófisis en un perro y en el mismo año operó con éxito un caso de epilepsia jacksoniana traumática por ablación de la zona cortical afecta.

El alemán Mikulicz describió la reconstrucción del esófago después de la resección de su parte cervical por carcinoma, el austríaco Víctor Von Hacker (1852-1933) propuso una nueva técnica para la gastrostomía. Authur Barker (1850-1916) abrió con éxito por primera vez un absceso cerebral resultado de una otitis y, finalmente, José Rivera y Sans publicó una monografía quirúrgica titulada «Estudios clínicos de la cirugía infantil» $(106,107,108,113)$.

Pagés cursó sus estudios universitarios en la primera década del recién llegado siglo. Unos años dominados, en lo político, por el agonizar de la generación de políticos de la restauración canovista, la inestabilidad gubernamental ${ }^{78}$, la falta de prestigio español en el ámbito internacional, el fin de la regencia de María Cristina, la mayoría de edad de Alfonso XIII, el nacimiento del sentimiento regionalista, especialmente en Cataluña, las revueltas sociales y proliferación de atentados y frustrados magnicidios ${ }^{79}$ (111).

Los sucesivos e intermitentes gobiernos de Sagasta, Maura, Silvela, Raimundo Fernández Villaverde, Eugenio Montero Ríos, Moret, el interregno liberal (1905-1907) y el intento de renovación maurista (1907-1909), condujeron a la sociedad española a una actitud de incredulidad en el sistema, a múltiples contestaciones sociales, y a una creciente violencia callejera pasando por una mal disimulada crispación de los influyentes sectores militar ${ }^{80}$ y clerical (111).

En lo concerniente a la vida social, destaca en España la concesión del premio Nobel de Literatura a José Echegaray en 1904, en 1907 Pablo Picasso con su obra «Las señoritas de la Calle Avinyó» da nacimiento al cubismo. Esta década ve desaparecer políticos de prestigio como Sabino Arana y Gori, Sagasta, Francisco Silvela y Francisco Pi i Margall.

En otras partes del mundo el siglo se inicia con el principio y fin de la revuelta xenófoba Bóxer en China, el primer vuelo a motor de los hermanos Wright se produce en 1903 en Kilty Hawk, Rusia y Japón entran en guerra por Manchuria en 1904, un año después,

\footnotetext{
${ }^{78}$ La gobernabilidad de España queda bien definida por uno de los hombres conservadores de fin de siglo: Francisco Silvela «El país por su clase gobernante, es ingobernable. Así que mi enorme sacrificio de gusto, fortuna, tranquilidad y salud será completamente estéril, y me juro a mi mismo aprovechar la más pequeña ocasión que me ofrezca esta crisis para retirarme de la política. Dios lo haga» (Seco C.).

${ }^{79}$ El 12 de abril de 1905 Antonio Maura fue apuñalado en el epigastrio por un joven anarquista llamado Joaquin Miguel Artal, al salir de la Iglesia de la Merced de Barcelona, de los funerales de la ex Reina de España Isabel II. El día 31 de mayo de 1906 Victoria Eugenia de Battemberg contrae matrimonio con Alfonso XIII, al salir de la Iglesia de los Jerónimos y al pasar a la altura de la calle Mayor 88, el anarquista Mateo Morral arrojó una bomba entre flores causando una veintena de muertos (Seco C.).

${ }^{80} \mathrm{El}$ incidente más destacado fue el promovido por un grupo de oficiales que el 25 de noviembre de 1905 arrasó las sedes del semanario $\mathrm{Cu}$ Cut y del diario La Veu de Catalunya en señal de protesta por unas caricaturas publicadas días antes en el semanario (Seco C.).
} 
fruto del malestar social ruso por esta contienda se produce la insurrección del acorazado Potemkin.

En este mismo año el presidente de los Estados Unidos, Theodore Roosevelt, anuncia su decisión de intervenir militarmente en América del Sur. Un año más tarde, un terremoto asola San Francisco. En Francia fallece Paul Cesanne y la justicia militar rehabilita a Dreyfus. Otro terremoto en 1908 devasta en Italia las regiones de Messina y Reggio Calabria (112).

Los avances de la cirugía continúan de forma incesante en los albores del nuevo siglo, durante la etapa universitaria de Pagés, contradiciendo la sentencia que un brillante cirujano como J.M. Marjolin espetó en 1836: «La cirugía ha llegado hasta el punto de no tener ya nada que adquirir» (113).

En lo concerniente a la anestesia, continúan las aportaciones tanto en la incorporación de nuevos anestésicos como en la descripción de nuevas técnicas o inventos de novedosos aparatos para mejorar la administración de la anestesia por inhalación. Así, el ayudante de Billroth, Von Hacker en 1895 incorporó el cloruro de etilo como anestésico en la práctica diaria ${ }^{81}(119)$. Se perfeccionaron los aparatos destinados a la narcosis llegando, en 1902, a convertir la anestesia en un circuito cerrado que permitía recuperar el gas anestésico y eliminar el anhídrido carbónico mediante el uso de cal sodada, extendiéndose el uso de la intubación.(107). En 1907, Ombredanne ideó su inhalador de éter, muy extendido en todas las clínicas hasta la década de los cincuenta (119).

La anestesia local va a experimentar, a su vez, una importante evolución. Paul Reclus en 1889 y tres años más tarde el alemán Scheleich popularizaron la práctica de la anestesia por infiltración de planos $^{82}$. En 1884 August K. G. Bier (1861-1949) introdujo la anestesia espinal con cocaína ${ }^{83}$, técnica seguida por Matas en Estados Unidos y Tuffier en Francia. Sicard y Cathelin en 1901 describieron la introducción de cocaína en el espacio epidural por vía sacra con fines anestésicos $(106,107,108,113,115,120)$.

Aparecen nuevos anestésicos locales de vida efímera (Akoin, ortoformo, nirvanina, tropocaína, eucaína...) hasta que en 1904 Fourneau y Einhorn dan un paso decisivo al sintetizar la estovaina y la procaína (comercializada con el nombre de novocaína) respectivamente. Esto unido a la recomendación que el cirujano alemán Heinrich Braun (1862-1934) hizo en 1903 de añadir al anestésico adrenalina para favorecer la anemia de la zona quirúrgica y la menor

\footnotetext{
${ }^{81}$ Las propiedades anestésicas del cloruro de etilo fueron descritas en 1846 por Fluorens, pero su uso no se generaliza hasta 1895 con Von Hacker (Miguel J).

${ }^{82}$ El mérito de Schleich estuvo fundamentalmente en reducir al mínimo la concentración de cocaína utilizada, si Reclus la usaba al $1 \%$ Schleich lo hizo desde el $0,1 \%$ al $0,001 \%$ con buenos resultados. Cuando en Berlin expuso sus conclusiones finalizó su disertación con estas poco diplomáticas palabras: «Puesto que este método es inocuo, considero que, por motivos idealistas, morales y jurídicos ya no se justifica el uso de la peligrosa narcosis, cuando la anestesia local es suficiente». Sus colegas, como Bardeleben al frente, Presidente del Congreso, le increparon duramente y no supieron valorar, en su medida, la importancia de lo expuesto. (Haeger K, Guerra F., Márquez C.1995).

${ }^{83}$ James Leonard Corning intentando utilizar cocaína con fines terapeúticos por vía espinal, viendo los efectos que producía concluyó su informe en 1886 con estas palabras: «Que el método pueda aplicarse como sustituto de la administración de éter en cirugía genitourinaria u otras ramas, sólo la experiencia lo dirá». (Miller R.D.).
}

absorción del anestésico, supusieron incorporaciones decisivas para abundar en nuevas técnicas ${ }^{84}(115,120)$.

Todo ello permitió que en esta década se desarrollaran las técnicas de anestesia regional de uso más común: bloqueo del plexo braquial, anestesia regional intravenosa de Bier, bloqueo del plexo celíaco, anestesia caudal, técnicas de anestesia intradural hipobárica e hiperbárica y la mayoría de bloqueos nerviosos que se emplean en la actualidad en cirugía dental ${ }^{85}(113,120,121)$.

Destacar también que en esta década comenzó a esbozarse el concepto de anestesia balanceada, en la cual la anestesia intravenosa es el componente principal. Es G.W. Crile quien primero la define en 1901 con el nombre de «Anociasociación», completándola posteriormente Harvey W. Cushing (1869-1939) (120).

España aportó interesantes novedades tanto en el campo de la anestesia inhalatoria como en el de la anestesia regional. En 1898 Alberto Suárez de Mendoza presentó en Madrid en el Congreso Hispano-Portugués de Cirugía un nuevo «Método-Español». Botella E. en 1902 y posteriormente el otorrinolaringólogo barcelonés Ricardo Botey dieron a conocer e incluso presentaron ilustraciones del aparato ideado por el Doctor Redondo para la anestesia clorofórmica en operaciones laríngeas. Alejandro San Martín y Satrústegui (1847-1908) presentó en el XIV Congreso Internacional de Cirugía en Madrid en 1903 una comunicación titulada «Anestesia por insuflación», en la que recomendaba la insuflación del cloroformo por una fosal nasal (122).

La anestesia local se extendió en España en el inicio del siglo de la mano de odontólogos y otorrinolaringólogos. Entre los primeros, destacan el cirujano dentista de la Facultad de Medicina de Madrid Tirso Pérez, Bernardino Landete, Florestán Aguilar y el Dr. Losada con sus estudios sobre la estovaina.

Entre los otorrinolaringólogos que más contribuyeron al desarrollo de la anestesia local nos encontramos con Ángel Baltar Cortés (1868-1934), realizó más de cien laringectomías con anestesia local, el malagueño Pablo Lazárraga y el ya mencionado Ricardo Botey (Franco A.1996). No debemos tampoco obviar la aportación de Oscar Amoedo que en 1893 publicó un trabajo en el que recoge todas las características del cloruro de etilo y su uso clínico como anestésico local. $(122,123)$ Salvador Cardenal en 1894 publicó un opúsculo en el que describe sus experiencias en la técnica de anestesia por infiltración. Otros trabajos como la tesis doctoral de Miguel Kirchoffer Sorá (1902), los estudios de Emilio Pérez Noguera sobre la alipina y novocaína (1906) y, especialmente el entusiasmo del cirujano Luis Gueder Calvo (1860-1916) fervoroso practicante de la técnica de anestesia local de Braun, consiguieron introducir esta útil práctica anestesia. (114). Por lo que respecta a la introducción en España de la anestesia espinal, Emilio Pérez Noguera recogió el descubrimiento de Sicard y Cathelin de anestesia extradural por vía

\footnotetext{
${ }^{84} \mathrm{La}$ adrenalina se aisló de la corteza suprarrenal merced a los trabajos del farmacólogo John J. Abel en el Johns Hopkins Medical School en 1827, posteriormente fue cristalizada por Takamine. Lermoyez, dado que la acción de la adrenalina favorece la anemia del campo operatorio, la denominó: «El alcaloide de la venda de Esmarch». (Miller R.D., Puchet V.).

${ }^{85}$ En Francia Johonesco y Le Filliatre obtuvieron la raquinestesia general por técnicas diferentes. El primero empleando inyecciones de estovaina sobre los segmentos cervicales o dorsales y el segundo, utilizando la cocaína con su gran poder de difusión, conseguía anestesia con nivel metamérico muy alto aunque la punción se hiciera en el espacio lumbosacro, gracias al barbotage. (Puchet V.).
} 
caudal con cocaína, lo aplicó por primera vez en España así como la técnica de Boleris de raquianestesia en el parto.

Francisco Rusca Domenech, cirujano del Hospital del Sagrado Corazón de Barcelona, comunicó las primeras realizaciones prácticas de la raquianestesia siguiendo a Tuffier. Pero, definitivamente fue Ricardo Lozano Monzón, Catedrático de Patología Quirúrgica de Zaragoza quien generalizó el uso de la anestesia espinal con cocaína. En 1903 en el XIV Congreso Internacional de Medicina de Madrid publicó 152 casos (124).

No haríamos justicia si no consideramos en este período la interesante aportación del cirujano lucense José Goyanes Capdevila ${ }^{86} \mathrm{al}$ mundo de la anestesia. En 1909 describió su original técnica de la anestesia intraarterial $(108,113)$.

Los avances en la medicina continuaron de forma inexorable. Así tras las tentativas incipientes de Brundell, Prevost y Dumas, Hasse, Scheel Dieffenbaach, la transfusión sanguínea pudo realizarse cuando en $1900 \mathrm{~K}$. Landsteiner descubrió la existencia de los grupos sanguíneos ${ }^{87}$. G.W. Crile en 1906 practicó la transfusión arteria-vena, generalizándose el uso de la transfusión cuando en 1914 A. Hustin y L. Agote emplearon la sangre citrada (113).

Paso a paso se va imponiendo el uso de guantes por los cirujanos, primero Mikuliz de algodón, y con posterioridad el norteamericano Halsted de goma ${ }^{88}$ en 1894. También fue el polaco de Czerwowizz Mikuliz, el que extendió el uso de la mascarilla bucal (1897). Todas estas novedades, con el cambio conceptual de Bergman de la antisepsia a la asepsia, permitieron una reducción radical en el porcentaje de la mortalidad quirúrgica $(106,107,113)$.

En 1904 Ernest Ferdinand Sauerbruch (1875-1951) estudió las bases fisiológicas para la prevención del neumotórax durante la cirugía torácica con el empleo de una cámara de presión negativa, idea que había sido sugerida por A.V. Quenu y M. T. Tuffier en $1896^{89}$ $(107,113)$.

\footnotetext{
${ }^{86}$ José Goyanes Capdevila nació en Monforte. Se doctoró en 1901 en la Facultad de Medicina de Madrid. Fue médico del Hospital General, Profesor Auxiliar de Quirúrgica en 1905 y Director del Instituto del Cáncer en 1907. Se centró fundamentalmente en cirugía vascular, publicando en 1911 un texto «La sutura en cirugía del sistema vascular». El profesor F. Guerra lo considera, junto a Pagés, una de las figuras más importantes españolas del final del positivismo (Guerra F.).

${ }^{87}$ Landsteiner descubrió los grupos sanguíneos ABO. Veintisiete años más tarde P. Levine completó su trabajo identificando los grupos M,N y P y, finalmente, A.S. Wierner en 1940 estableció el problema del sistema RH, permitiendo predecir la existencia de la eritroblastosis fetal. (Guerra F.).

${ }^{88}$ Aunque Halsted extendió el uso de guantes de goma (la primera vez que lo hizo fue para proteger a su enfermera de un eczema de las manos provocado por la solución de bicloruro de mercurio que usaban para esterilizar los instrumentos) hay antecedentes de su utilidad. En 1878 el North Carolina Medical Journal describió una ovariotomía realizada por el Dr.Thomas cuyos ayudantes se protegían las manos con guantes de goma. (Haeger K.).

${ }^{89}$ A.V. Quenu (1852-1933) natural de Calais, Profesor de anatomía quirúrgica en Paris. Diseñó varias intervenciones que llevan su nombre como la toraplástica y la resección ganglionar perirrectal. Theodore Tuffier (1857-1929) natural de Belleure. Cirujano de la Pitié. Precusor de la raquianestesia quirúrgica. Realizó avanzadas intervenciones en el tórax, como la primera cura de la tuberculosis pulmonar por exéresis del vértice lesionado. En 1882, C. Forlanini había ideado por primera vez la necesidad del neumotórax artificial, en detrimento de la ablación del pulmón preconizada por la mayoría de cirujanos. (Hernández e., Guerra F.).
}

Como dice el Profesor Laín Entralgo, «En sólo cincuenta años, el mundo del quirófano se había hecho un mundo nuevo. Sobre la base de este conjunto de técnicas el cirujano pudo ampliar el campo de sus metas operatorias» «También porque su creciente formación científica le condujo a emplear esas técnicas al servicio de una intención operatoria rigurosamente inédita: Crear en el organismo enfermo condiciones anatómico-funcionales que le hagan posible un mejor cumplimiento de su actividad vital» (113).

El espléndido progreso de la cirugía se extendió paulatinamente a todas las especialidades quirúrgicas. El cirujano se fue convirtiendo en un verdadero hombre de ciencia, valorándose más sus conocimientos fisiopatológicos que la rapidez manual, no ya tan necesaria, por lo que se fue imponiendo en los quirófanos el «tempo lento» preconizado por Kocher y Halsted.

La cirugía vascular profundizó en técnicas más sofisticadas, Mathieu Jaboulay (1860-1913) utilizó las suturas en U para unir la arteria carótida seccionada en animales de experimentación (1898). Trendelemburg propuso en 1890 la ligadura de la vena safena en el tratamiento de las varices. Ludwin Rehn (1849-1930) practicó la primera sutura, con éxito, de una herida penetrante de corazón (1896).

El mismo año Guido Farina (1868-1959) en Roma suturó una herida incisa en el ventrículo derecho. En España, Goyanes utilizó injertos de vena para restaurar el flujo arterial (1906). En Estados Unidos, Halsted fue el primero, en 1891, en ligar con éxito la subclavia en un caso de aneurisma. Murphy ejecutó la sutura boca a boca de vasos sanguíneos mediante la invaginación (1897).

Rudolph Matas fue todo un precursor de la cirugía vascular, que alcanza su mayoría de edad con Harvey W. Cushing (1869-1939) que con sus intervenciones en perros, preparó la posterior cirugía de las válvulas auriculoventriculares. Finalmente, Alexis Carrel (18731944) consiguió, en 1902, desarrollar una técnica para la sutura boca a boca de los vasos, protegiendo el instrumental con parafina para evitar coágulos $(106,107,113)$.

La neurocirugía se convierte en otras de las especialidades quirúrgicas que más progresaron en este cambio de siglo, los trabajos de Kocher, Mac Ewen ${ }^{90}$, Gigli ${ }^{91}$, Broca, Bennet, Godlee, Horsley y Keen ${ }^{92}$ permitieron sentar las bases anatómico-quirúrgicas de esta especialidad. Especialidad que adquirió su madurez merced a los trabajos de Cushing, quien destacó progresivamente como neurocirujano con el tratamiento de la parálisis facial en el hombre mediante la anastomosis del nervio espinal accesorio y el facial (1903) y descomprensión intracraneal por hemorragia en el recién nacido (1905). Su interés, constancia y capacidad de experimentación le llevó a reducir la mortalidad neuroquirúrgica del cien por cien al diez por ciento.

De la misma forma, la cirugía endocrina se inició ya con Kocher en 1878 con la tiroidectomía y se fue asentando con los estudios de Horsley, Halsted, Rehn, Reverdin y Cushing. La traumatología y la ortopedia alcanzaron también su autonomía en el último tramo del siglo $\mathrm{XIX}^{93}$. Hasta la fecha, la cavidad articular había sido otro «noli

\footnotetext{
90 1893 publicó las bases anatómicas de la cirugía cerebral en el Atlas of Head Sections (Guerra F.).

${ }^{91}$ Leonardo Gigli (1863-1908) de Sesto Fiorentino, diseñó la sierra de alambre para la craneotomía.(Guerra F.).

${ }^{92}$ William Keen (1837-1932) de Filadelfia. Alcanzó los ventrículos cerebrales y ejecutó la craneotomía linear que describió en «Linear Craneotomy»- (Gerra F.).

${ }^{93}$ El nombre de ortopedia fue propuesto en 1741 por N. Andry(Laín Entralgo P.1982, Laín Entralgo P.1963).
} 
me tangere», por lo que la cirugía de articulaciones, el tratamiento de las fracturas, cirugía ósea y la cirugía de la columna vertebral suponen los elevados niveles técnicos de la traumatología hasta el comienzo de la primera contienda mundial .(106, 107, 108, 113).

El tratamiento incruento de las fracturas se debe a la aportación de Fitz Steiman que en 1907 describió el tratamiento de las fracturas mediante agujas colocadas en los cóndilos femorales y a Martín Kirschner quien en 1909 introdujo la tracción esquelética con agujas de diámetro pequeño ${ }^{94}$.

Entre los impulsores de la cirugía ortopédica descollaron los ingleses Mac Ewen W.A. Lane (1856-1943) que dio a conocer una técnica de osteosíntesis en las fracturas dobles de tibia y peroné (1894) y empleó placas atornilladas en la consolidación de fracturas (1907). Los alemanes Carl Schlatter (1864-1934) y Albert Hoffa (1859-1906), el primero describió la afección dolorosa de la tuberosidad tibial (1903) y el segundo diseñó un tratamiento quirúrgico de la dislocación congénita de cadera (1890). Los italianos Leonardo Gigli, que en 1902 utilizó la sierra de alambre para la sección lateral del pubis, y Alessandro Codivilla (1865-1912) a quien se le debe la técnica de tracción y extensión ósea en las fracturas de miembros inferiores mediante la inserción de un clavo en el talón (1902). Otros nombres que merecen ser destacados en esta faceta son F. Koenig (1832-1910), Conrad Biesalki (1869-1930), E. Kinmissow (1848-1927), Auguste Broca (1859-1924), y Louis Ombredanne (1871-1956) (106, 107, 108, 113).

La cirugía plástica había comenzado a andar desde que en 1869 Felix Jean Casimir Guyon (1831-1920) describió en París cómo había tomado pequeños fragmentos de piel para reparar una herida abierta sin necesidad de mantener el aporte de sangre original. (106) .Finalmente las trasplantaciones cutáneas de Reverdin, Ollier, Thiersch, así como las brillantes intervenciones plásticas de Langenbech consolidaron esta especialidad ${ }^{95}$. Posteriormente, los trabajos de Crile y los buenos resultados obtenidos en el cáncer de labio y de G. Vanghetti (1861-1940) que logró utilizar los músculos de los miembros amputados para dar movimientos a los aparatos de prótesis, perfeccionaron las técnicas reparadoras. Los innumerables heridos de la I Guerra Mundial pondrán a dura prueba la inventiva y habilidad de los cirujanos. Así Sir Harold Gillies (1882-1960) perfeccionó los injertos de piel e instrumentos en los quemados ${ }^{96}(106$, 107, 108, 113).

Este es el panorama político-social y médico-quirúrgico con el que Pagés se encuentra cuando finaliza sus estudios universitarios, obtiene el título de licenciado en medicina y cirugía y aprueba las oposiciones a Sanidad Militar. Cuando accede a su primer destino en el Hospital Militar de Carabanchel es el año 1909. España aún estaba conmovida por los sucesos de julio en Melilla, donde unos obreros de la Compañía Minera del Rif fueron muertos por cabileños.

\footnotetext{
${ }_{94}$ Aunque se considere a Kirschner y Steiman como los pioneros del tratamiento de la fractura de fémur por tracción, existen precedentes como Guy de Chauliac en el siglo XIV o Percival Pott en el siglo XVIII. También N.Smith en 1831 introdujeron las férulas de tracción. (Guerra F.).

${ }^{95}$ El entusiasmo por la cirugía reparadora era tal que el lema de Alexandre Hugh Fergusson (1853-1911) de Woooville, Ontario era: «Salvar aunque sólo sea la punta del pulgar» (Laín Entralgo P.1982,Riera J.).

${ }^{96}$ No haríamos justicia si no destacáramos la labor en este campo que realizó el cirujano español Diego de Argumosa y Obregón (17901865).(Laín Entralgo P.1963, Laín Entralgo P.1982).
}

Este incidente desencadenó un conflicto bélico que costó mil quinientas bajas al ejército español, y fue el origen de la llamada semana trágica de Barcelona que se convirtió en un incipiente movimiento revolucionario y que acabó con el fusilamiento en octubre de ese año de Francisco Ferrer Guardia ${ }^{97}$, al que se le hizo máximo responsable del levantamiento. Como consecuencia de todos estos incidentes el Gobierno Maura cayó en octubre de 1909 (111).

La vida de Pagés comprendida entre los años 1909-1923 va a estar verdaderamente condicionada por los diversos y turbulentos acontecimientos de la vida política nacional. Las continuas guerras en Marruecos, la ya mencionada de la construcción del tren de las Minas del Riff, la guerra del Kert con la ocupación por el general Gómez Jordana del Valle de Tikenmin en 1912, y el Desastre de Annual el 27 de julio de 1921 con la caída del general Fernández Silvestre y la sublevación de los rifeños encabezados por Abd elKrim Ben Mohamed el Jatabi; van a ocasionar que Páges vaya en todas esas ocasiones allá donde estalla el conflicto (111).

En esos años la vida política en España no se puede catalogar precisamente de pacífica, la inestabilidad gubernamental es la norma. A la caída de Maura le suceden los liberales Moret y Canalejas quien muere asesinado el 12 de noviembre de $1912^{98}$ (111).

Romanones, Dato (también muere asesinado el 8 de marzo de 1921), Allendesalazar, Maura, Sánchez Guerra, García Prieto se suceden a lo largo de estos años en la Presidencia del Consejo de Ministros sin saber encontrar las soluciones a los muchos problemas que tiene España. Todo ello va a desencadenar el Golpe de Estado del 13 de septiembre de 1923, auspiciado por el capitán general de Barcelona, Miguel Primo de Rivera. Era el principio del fin de la Monarquía de España. (111, 125, 126, 127).

El episodio central que domina este período de la historia es sin lugar a dudas la primera contienda mundial. Un conflicto en el que España permanece neutral merced a las buenas artes y saber diplomático de Eduardo Dato. Para Pagés la primera Gran Guerra va a suponer una nueva experiencia quirúrgica al ser comisionado en la inspección de los campos de prisioneros del Imperio AustroHúngaro.

Para la cirugía ya queda dicho lo que supuso esta gran tragedia mundial. Desgraciadamente los grandes avances de la medicina en general, y de la cirugía en particular siempre son frutos de tragedias previas de la humanidad.

Otros sucesos acontecen en el mundo: en 1909 el Francés Louis Bleriot atraviesa el Canal de la Mancha en avión entre Calais y Dover. Al año siguiente es derrocado en Portugal el rey Manuel II, proclamándose la República. En 1911, Marie Curie recibe el premio Nobel de química por su descubrimiento del radio y del polonio. En este mismo año fallece el compositor austriaco Gustav Mahler. El majestuoso Titánic realiza su primera y última travesía en el 1912, hundiéndose el 15 de abril. (112).

E1 28 de junio de 1914 es asesinado en Sarajevo el Archiduque Francisco Fernando, heredero del trono Austrohúngaro, pretexto para el estallido de la guerra que se declara el 3 de agosto, y finalizaría el 28 de junio de 1919 con la firma de la paz de Versalles. Durante el conflicto destacan dos nuevos acontecimientos; la aparición

\footnotetext{
${ }^{97}$ Fue fundador de la Escuela Moderna y fue sospechoso de colaborar en el atentado contra Alfonso XIII.(Seco C.).

${ }_{98}^{98}$ Lo asesina el anarquista Manuel Pardiñas en la Puerta del Sol de Madrid cuando se acercó al escaparate de la librería San Martín.(Seco C.).
} 
de Estados Unidos como nueva potencia mundial y la caída del viejo régimen zarista en Rusia, sustituido por la dictadura soviética.

El premio Nobel de Física a Einstein (1921), el Estado libre de Irlanda (1921), la creación de la Unión de Repúblicas Socialistas Soviéticas (1922), el descubrimiento de la tumba de Tutankamon (1922), la marcha de Mussolini sobre Roma (1922) y la ocupación francesa del Ruhr (1923), son parte destacada de los sucesos mundiales durante estos años (112).

Encuadrado Pagés dentro del contexto necesario del mundo sociopolítico que le rodeó a lo largo de su corta vida y de los niveles técnicos quirúrgicos que le precedieron y que fueron coetáneos durante el desarrollo de su labor como cirujano, estamos ya en disposición para entrar a valorar su obra científica.

Fidel Pagés Miravé, evidentemente, no forma parte de ese grupo selecto de hombres que revolucionaron el mundo de la medicina merced a sus opiniones, investigaciones, decisiones o aportaciones de nuevas técnicas; pero sí estimamos que debe ocupar un digno lugar en la historia de la cirugía y de la anestesia, gracias a su dedicación, trabajo y aportaciones originales.

Pagés pertenece a la época de la moderna cirugía. Su labor se desarrolla dentro del positivismo-naturalista, como ya se ha apuntado anteriormente.

Es un hombre que lleva el pulso científico de su tiempo, inquieto por los nuevos avances (así queda reflejado en sus artículos donde hace constante referencia a las comunicaciones publicadas más actuales), abraza con entusiasmo, y las pone en práctica, las tres facetas más importantes por las que se caracteriza esta gloriosa época de la cirugía: anestesia, asepsia y hemostasia; lo que permite acceder a una cirugía restauradora y funcional, huyendo de la cirugía exerética prelisteriana ${ }^{99}$.

Como decíamos, Pagés trata esos tres temas cruciales en toda la trayectoria de su obra científica. La anestesia es casi constante en todos sus artículos. Aparte de su obra cumbre «Anestesia Metamerica» (62), en otras publicaciones siempre le confiere una gran importancia, tratando de adecuar la técnica anestésica a cada tipo de intervención $(98,105)$. La asepsia y la hemostasia, son otra constante en la cirugía de Pagés y así lo manifiesta en algunos de sus artículos $(97,100)$. Por último, el interés de Pagés en conseguir una cirugía reparadora y funcional es evidente y notorio en todos sus escritos $(96,97,99103,104,105)$.

Pagés, por tanto, fue un prototipo del cirujano de su época, el paradigma de una nueva generación de quirúrgicos que Paul Reclus bien definió en el prefacio de la presentación de un tratado de cirugía en 1908: «Ella pone de manifiesto las cualidades de la nueva generación un sutil desdén de las teorías alambicadas y de los sistemas prematuros, un sólido y penetrante estudio de la clínica y la robusta confianza en sí mismo, fundada en una técnica impecable y en la práctica de una asepsia rigurosa» (128).

Con el fin de efectuar una correcta y sistematizada crítica a su obra científica, conviene sectorizarla en tres apartados. Estos, componían las facetas más sobresalientes del quehacer profesional de Pagés.

- Aportaciones anestésicas

- Obra quirúrgica-traumatológica

- Otras aportaciones

\footnotetext{
${ }^{99}$ Decía Harvey Graham: «En la historia de la cirugía no hay más que dos períodos: el anterior y el posterior a Lister. El primero comienza en la primera edad del mundo; el segundo, no hace todavía 30 años. Sin embargo en esos treinta últimos años se ha avanzado más que en los treinta mil que le precedieron». (Graham H.).
}

\section{Aportaciones anestésicas}

Realizando un pormenorizado estudio de la obra de Pagés es difícil escapar a la sugestión y a la importancia que nuestro personaje sentía por la práctica anestésica y su trascendencia a la hora de aplicarla a sus pacientes.

Esta preocupación se puede sentir en tres vertientes: comentarios a publicaciones realizadas por otros cirujanos. La entidad propia que le confiere a la anestesia en sus propios artículos $(97,99$, 105, 110 Pagés. Y, finalmente, su artículo dedicado exclusivamente a esta disciplina; «Anestesia Metamérica» $(62,69)$.

En el primer apartado, en la Revista Española de Cirugía desde su fundación son incesantes los comentarios a artículos publicados por otros profesionales y que hagan referencia a la anestesia. En el número del mes de marzo de la Revista Española de Cirugía comenta el artículo de Pol Coryllos «La anestesia raquidiana alta y baja por la novocaína ${ }^{100}$. En el número de agosto, hace referencia al artículo de V. Riche «La raquianestesia general con novocaína por vía lumbar» ${ }^{101}$. En marzo de 1920 comenta el famoso trabajo de Johonesco «La raquianestesia general» ${ }^{102}$.

En el número de abril hace aportaciones al original de Manuel Altuna «Principales métodos que se practican en Estados Unidos para obtener la anestesia» ${ }^{103}$. En la Revista Española de cirugía de enero de 1921 también comenta el trabajo de J.R. Eastman «Ventajas de la anestesia local en las operaciones de tiroides» ${ }^{104}$. En este año y en el número de abril-mayo hace referencia al artículo de A. Roussel «Estudio crítico de los procedimientos de anestesia utilizados en cirugía gástrica» ${ }^{105}$. Finalmente en 1923 en el número del mes de marzo, comenta la comunicación presentada por M. Fornesco en el XXXI Congreso de Cirugía celebrado en París el 3 de octubre de 1922, titulada «Nueva técnica para la raquianestesia».

La segunda vertiente que comentábamos que caracteriza a Pagés en su preocupación por la anestesia es la constante importancia que le da en sus propios artículos. En concreto, en cuatro de ellos insiste en la trascendencia y en la necesidad de elegir el método anestésico adecuado a cada tipo de intervención.

Estos artículos son: «Contribución al estudio de la cirugía plástica de la mejilla» (98), «Sobre un caso de estrangulación retrógrada de epiplón» (97), «Heridas abdominales de guerra, mi experiencia personal» (105) y «Aspectos quirúrgicos del estreñimiento» (110).

En el primero de ellos hace una referencia a los distintos tipos de anestesia posible para esta técnica quirúrgica y resalta la necesidad de una cuidadosa asepsia por parte del «Anestesiador» para no provocar con la mascarilla una inoportuna infección de la zona intervenida. Textualmente apunta: «Pondremos el mayor

\footnotetext{
${ }^{100}$ Publicado originalmente en Bull. Et Mem. Soc. Chir de París 1918. 101 Tratado publicado en Presse Med. 1919

${ }^{102}$ Publicado en 1919. Edit. Masson. El método Jonnesco consistía en realizar la punción intradural dependiendo de la región a operar con una aguja de $6 \mathrm{~cm}$. sin mandril, usado como anestésico estovaína asociada a estricnina. Las dosis variaban con la zona operatoria: cabeza y cuello $1 \mathrm{cg}$. estovaina y $1 / 2 \mathrm{mg}$. de estricnina. Tórax y miembros superiores $2 \mathrm{cg}$. de estovaína y $1 \mathrm{mg}$. de estricnina. Abdomen superior $3 \mathrm{cg}$. de estovaína y 1-2 mg. de estricnina. Pelvis y periné de 2-5 cg. de estovaína y 1-3 estricnina (Puchet V.).

${ }^{103}$ Publicado en revista Médica Cubana. 1920.

${ }_{104}$ Publicado en J. Of. Am Med. Ass. 1920.

${ }^{105}$ Publicado en Journal de Chirurgie tomo 17 n. ${ }^{\circ} 5$.
} 
cuidado en que el anestesiador no nos haga correr los peligros de infección mencionados, para lo cual administrará el narcótico por debajo de uno de los paños (el opuesto al operador) de los que cubren el campo y que, para que no se desplacen durante la intervención, se sujetarán a la carne con los imperdibles. La mascarilla estará hervida en su parte metálica y cubierta por una compresa esterilizada».

Abundando en el rol que el «Anestesiador» debe interpretar en un quirófano, Pagés insiste en que las pertinentes medidas de asepsia deben extenderse también a aquel, poniendo como ejemplo a imitar lo que se practica en la clínica de Von Eiselberg ${ }^{106}$ : «El anestesiador se esteriliza como el resto del personal, poniéndose blusa, guantes y gorro esterilizado, y, en realidad, aún cuando sea una práctica poco seguida, en materia de asepsia no cabe la palabra exageración».

He aquí dos de las constantes que caracterizan a los cirujanos de finales del XIX y principios del XX: la anestesia y la asepsia. Constantes que Pagés mantendrá a lo largo de su obra.

Más adelante hace una relación de las posibles técnicas anestésicas a utilizar en este tipo de intervención, indicando sus ventajas e inconvenientes. La anestesia intratraqueal a lo MeltzerAuer, de la que opina que ofrece garantía completa de asepsia. El método de Ombredanne ${ }^{107}$, el aparato de Delbet, la cánula de Trendelenburng y la de Kuhne; en opinión de Pagés son utilizables en preferencia a la previa traqueotomía, recomendada por otros autores.

La anestesia intrarrectal por éter de Horsley y Dunahn, la recomienda porque suprime los aparatos de la vecindad del campo operatorio.

También, afirma, se obtienen buenos resultados con la anestesia intravenosa por hedonal ${ }^{108}$ y por el método de anestesia general intrarraquídea, según la técnica de le Filiatre ${ }^{109}$.

Finalmente, apuesta por la anestesia local por infiltración, según la técnica de Schleich con soluciones débiles de novocaína con suprarrenina al 1 por 200 o por 300, a pesar del inconveniente que algunos observan de una excesiva congestión consecutiva al uso de adrenalina. Este método lo complementa Páges con la infiltración del plexo cervical siguiendo la técnica de Braun (98).

${ }^{106}$ Anton Von Eiselberg (1860-1939) de Steinhaus, trabajó bajo la dirección de Billroth y colaboró con Koch en Berlín. Fue el primero en detectar una tetania paratiroideapriva (1890) tras la extirpación del bocio. Estudió los problemas de las metástasis del cáncer de tiroides e inició la cirugía de la hipófisis. (Riera J.).

${ }^{107}$ Ombredanne insuflaba los vapores clorofórmicos por medio del aparato de Richardson que llevaba el aire a un depósito donde se encontraba el anestésico. Este salía mezclado con el aire a través de un tubo en cuyo extremo se instalaba un pieza de cristal en «Y», insertándose sendos tubos de goma en sus dos ramas, que se introducían por las aberturas nasales hasta la epiglotis. (Pagés F.1920).

${ }^{108}$ Según Pagés, este método fue usado por primera vez en España por González Olivares y preconizado por Cortés Llano (Pagés F.1920).

${ }^{109}$ La técnica de Le Filliatre consistía inicialmente de una premedicación, media hora antes de la intervención, con $1 \mathrm{cg}$ de clorhidrato de morfina, $5 \mathrm{mg}$ de sulfato neutro de esparteina, $2 \mathrm{mg}$ estricnina, $1 / 4 \mathrm{mg}$ escopolamina, $1 \mathrm{cc}$ agua destilada. La punción intrarraquídea se practicaba con una aguja de $1 \mathrm{~mm}$ de diámetro y $12 \mathrm{~cm}$ de largo, con el paciente sentado se puncionaba por debajo de la línea media de L5, extrayendo tanto LCR como solución anestésica a administrar. Esta era una disoloución de cocaína al 1/50 y las dosis oscilaban en tre 8-3 cg. El barbotaje es esencial para conseguir la altura de la anestesia deseada. (Puchet V.).
En su artículo «Sobre un caso de estrangulación retrógrada de epiplón» (97) Sigue mostrando su preferencia por la raquianestesia versus anestesia por inhalación. En esta ocasión sienta la indicación de la anestesia intradural para evitar la intoxicación que produce la narcosis y para prevenir la presentación del shock operatorio, más previsible con la anestesia inhalatoria que con la locorregional. Literalmente sostiene: «Yo recuerdo a este respecto una extirpación de $90 \mathrm{~cm}$ de intestino estrangulado, que realicé hace poco y el enfermo presentaba al siguiente día de la operación un estado general comparable al que pudiera tener un amputado de un dedo, por ejemplo. La operación se practicó con raquianestesia, y esto, sin duda alguna, tuvo mucha influencia en el buen curso postoperatorio, ya que se suprimió la intoxicación que siempre produce la narcosis, que en estos enfermos, ya intoxicados por la estercoremia, es muy perjudicial, haciendo al mismo tiempo asociación nociva por el uso de aquella anestesia, con lo que se combate la presentación del shock operatorio».

En su artículo «Heridas abdominales de guerra» (105) da muestras de su interés y conocimiento sobre la indicación anestésica en pacientes con hemorragias o importantes heridas así como de la importancia que le confiere a la prevención del shock en este tipo de pacientes. Resuelve claramente la duda sobre la técnica anestésica y se inclina abiertamente por la raquianestesia dorsolumbar. Sus ventajas: la rapidez de instauración, sencillez de aplicación, gran relajación muscular abdominal y mayor seguridad para el paciente. Describe la posible complicación que puede surgir en pacientes hipovolémicos y por ende hipotenso, al practicarle una raquianestesia se corre el evidente riesgo de aumentar y agravar esa previa hipotensión. Pagés sostiene que esta complicación se puede yugular con la administración de sueros.

Es llamativa su precisión a la hora de describir la situación de shock con la que llegan estos pacientes a quirófano y la necesidad de remontar hemodinámicamente a estos heridos antes de proceder a la intervención.

Para ello indica Pagés que es preciso la administración de sueros, calentamiento del herido, aportación de tónicos cardíacos y posición de Trendelemburg. Refiere también la necesidad de conservar temperatura adecuada en el quirófano, entre 24 y 26 grados. Y sugiere, a su vez, como factible en el tratamiento del shock la introducción de cafeína intrarraquídea según lo propuesto por Johonesco.

Finalmente, describe la ausencia de sangrado en el shock profundo, momento que considera fundamental para realizar la hemostasia, aunque apunta la posibilidad de un nuevo sangrado ante la inyección masiva de suero.

De igual forma, en su póstumo trabajo «Aspecto quirúrgico del estreñimiento» (110) insiste en la elección de la raquianestesia dorsolumbar para las intervenciones abdominales por la gran miorresolución que produce. En este caso recomienda el uso de estovaina como anestésico local con inyección previa de siderol o de pantopón escopolamina a modo de premedicación.

Resalta también en este artículo su preocupación por la aparición del shock en el transcurso de las intervenciones abdominales. En esta ocasión refiere la importancia que tiene la tracción y manipulación del meso en la aparición del shock. Dice Pagés: «Cuando los mesos son largos la operación se practica con facilidad no es preciso para exteriorizar las vísceras ejercer tracciones sobre ellas que tanto favorecen la aparición del shock». 
Hoy en día es un fenómeno que puede ser observado en el transcurso de una intervención con un nivel de anestesia insuficiente, en caso de anestesia intradural o epidural, o ante una profundidad inadecuada de anestesia general; la tracción de los mesos puede provocar trastornos neurovegetativos, percibidos como intensas molestias por el paciente.

La tercera vertiente, y la más importante, en la que Pagés destaca dentro del campo de la anestesia, es su original aportación a esta disciplina. Aportación que se plasma en la publicación de su artículo «Anestesia Metamérica», primero, en la Revista Española de Cirugía (62), y, con posterioridad en la Revista de Sanidad Militar (69).

Es la primera vez que en la historia de la medicina se sientan las bases para abordar el espacio epidural por vía dorsolumbar con fines anestésicos. En él se indica minuciosamente la técnica de abordaje y se describe detalladamente las estructuras anatómicas que intervienen en este tipo de anestesia, refiere el número y tipo de intervenciones que practica con este nuevo método, detalla la forma paulatina de instalación de la anestesia y no se olvida de anotar las complicaciones surgidas y los errores cometidos.

Llama la atención la correcta sistematización del trabajo, dividido en seis apartados, y las referencias bibliográficas o de los autores que más habían aportado a la materia referenciada.

La constante referencia a los principales autores que aportaron algo al estudio de la anestesia epidural, es indicativo tanto de la preocupación de Pagés por encontrar el método anestésico ideal como de su conocimiento de las más novedosas aportaciones en este campo.

$\mathrm{La}$ inicial referencia a Cathelin indica el conocimiento que tenía Pagés de su trabajo (66). Del mismo modo, también era conocedor de los estudios de Reclus, Sicard y Tuffier $(67,101$, 129) en sus vanos intentos de aprovechar la vía sacra como lugar de penetración de las sustancias anestésicas en espacio epidural para practicar intervenciones abdominales.

También describe y hace alusión a los ensayos de Kappis (130) sobre cadáveres con los que se demostró que soluciones coloreadas inyectadas en el espacio paravertebral difundían al espacio epidural a través del agujero de conjunción. El temor de penetrar el anestésico a través de la duramadre le hizo desistir de profundizar en la práctica de la anestesia extradural, según Pagés.

Menciona a dos autores alemanes, Bleeck y Strauss quienes en sendos artículos hablan del peligro que tienen las anestesias extradurales altas y de sus experiencias. Sobre estos autores se lamenta Pagés de no tener las comunicaciones completas, sólo las referatas que no dan detalles de la técnica empleada ${ }^{110}$.

Conocedor de los últimos estudios sobre la anestesia intrarraquídea, hace alusión a los trabajos de Johonesco y Le Filliatre sobre anestesia general intradural así como los de Braun, Hirschel y Allen. Aparte, como ya se ha apuntado anteriormente, conocía ampliamente las iniciales y originales aportaciones de Reclus, Sicard, Tuffier y Cathelin.

${ }^{110}$ Bleeck: Monuntschr. F. Geburtshilfe Uno Gynäcol, BO. 37, mún, 1. Strauss: Zeitsch F. Geburtshilfe Uno Gynácol, Bo. 72, núm 1. Sobre estos autores no hemos encontrado ninguna referencia posterior y nigún autor los menciona como precursor del método de anestesia epidural. Posiblemente al referirse a anestesia extradural, se estuvieran refiriendo a la técnica paravertebral.
Pagés en su artículo es conocedor que hasta la fecha dos procedimientos eran los habituales para conseguir bloqueo anestésico de las raíces nerviosas medulares: la anestesia raquídea y la paravertebral. Así lo refiere: «la idea de insensibilizar la región quirúrgica por el bloqueo anestésico de las raíces nerviosas es puesta en práctica corrientemente por dos procedimientos: el de la anestesia raquídea, en el que el agente se vehiculiza por intermedio del líquido cefalorraquídeo y el de la paravertebral».

Ya hemos mencionado como Pagés tiene un amplio conocimiento del trabajo realizado por los precursores de la técnica intrarraquídea. De la misma forma cita a Sellheim ${ }^{111}$ como precursor en 1905 de la técnica paravertebral y los estudios sobre el mismo método de Laewen, Kappis, Finsterer, Wilms y Pauchet. ${ }^{12}$

Pagés desecha la práctica de la punción paravertebral por la complejidad de su aplicación, por requerir un excesivo tiempo para su eficacia y por la gran dosis de sustancia anestésica para su eficacia. Altas dosis que en ocasiones producen peligrosos fenómenos de intoxicación.

Encorsetada la técnica paravertebral en las precauciones antedichas y limitada la vía caudal al área dependiente de la cola de caballo como campo operatorio (131) Pagés se basa en estos razonamientos y en su experiencia para buscar otra técnica que comporte más seguridad, confort al paciente y facilite el acto operatorio: «después de haber practicado muchos centenares de raquianestesias y algunas anestesias radiculares paravertebrales, es cuando nos hemos decidido a alcanzar los pares raquídeos a su paso por el espacio epidural, a la altura necesaria para insensibilizar los nervios que se distribuyen por la región operatoria».

Pagés, por tanto, al realizar esta introducción en la que efectúa un análisis de los antecedentes conocidos sobre anestesia intra, extradural o paravertebral, llega a la conclusión de que no se ha escrito ni comunicado nada parecido a lo que él apuntaba: «Así como tampoco en algunas de las obras últimamente aparecidas sobre anestesia se menciona ningún procedimiento que sea parecido al metamérico, por todo lo cual habré de limitarme a describir el que nosotros ponemos en práctica para lograr la anestesia de que nos ocupamos».

En el inicio de su artículo Pagés nos describe cuando ideó poner en práctica esta técnica, cómo se desarrolló por primera vez y justifica la acuñación del término metamérica. ${ }^{113}$

Fue en noviembre de 1920 cuando Pagés inició sus experiencias sobre lo que él denominaba anestesia metamérica. Realizando una raquianestesia tuvo la idea de detener la aguja antes de atravesar la duramadre, después de haber perforado el ligamento amarillo, y bloquear las raíces nerviosas fuera del espacio meníngeo antes de atravesar los agujeros de conjunción. Después

\footnotetext{
${ }^{111}$ H. Sellheim, también destacó por practicar por primera vez en 1908 una cesárea cervical. (Laín Entralgo P.1963).

${ }^{112}$ H. Finsterer. (1877-1955). Fue un innovador de la cirugía gástrica, proponiendo la gastrectomía parcial en algunas dolencias. Wilms. (1867-1918) Fue discípulo de Trendelemburg. Fue profesor de cirugía en Basle. Describió el embrioma de riñón y diversas técnicas quirúrgicas en la TBC pulmonar (Riera J.1985, Laín Entralgo P.1963).

113 Aunque Pagés denomina metamérica a su novedosa técnica anestésica, en su artículo en veinticinco ocasiones utiliza el término epidural, peridural o extradural para referirse al tipo de anestesia, cavidad, espacio o punción.
} 
de depositar el anestésico, relata cómo se fue instalando una zona de hipoestesia que se iba acentuando progresivamente por la zona infraumbilical y cara anteroexterna de miembros inferiores, dejando indemne el periné, escroto y planta de los pies. A los veinte minutos inició el acto quirúrgico practicando una cura radical de hernia inguinal.

El éxito de la intervención le movió a continuar con la experiencia y a sentar la justificación del término con el que designa a su innovador método: «El resultado de este intento nos animó a seguir estudiando este método, al que en la clínica denominamos anestesia metamérica, por la posibilidad que nos proporciona de privar de sensibilidad a un segmento del cuerpo, dejando con ella a las porciones que están por encima y por debajo del segmento medular de donde proceden las raíces bloqueadas».

Con esta introducción Pagés pone de manifiesto varias cuestiones. Primero, que era conocedor de los antecedentes de abordaje del espacio epidural por vía sacra (Cathelin, Sicard, Tuffier) (66, 67, 101, 129), por vía paravertebral (130); las técnicas de anestesia espinal general de Le Filliatre y Johonesco (121) y los precedentes más remotos de anestesia intrarraquídeas (132, 133). Segundo, conocedor de estos antecedentes, estaba convencido de aportar una nueva técnica anestésica y de que ésta tenía una clara utilidad quirúrgica.

Aunque hay algunos autores como Bromage (134) que conceden la primicia de utilizar la analgesia epidural a Corning (133), lo cierto es que James Leonard Corning en su conocido trabajo publicado en 1885 introduce cocaína en la zona espinal sin estar seguro de encontrarse en el espacio epi o intradural, y lo hace con el único y exclusivo fin terapéutico de aliviar a un paciente que padecía de debilidad espinal e incontinencia seminal. En ningún momento prevé un uso quirúrgico de esta práctica, así lo refleja en su artículo: «Que el método pueda aplicarse como sustituto de la administración de éter en cirugía genitourinaria u otras ramas, sólo la experiencia lo dirá»» ${ }^{114}(120,133)$.

Por lo contrario, Pagés no sólo hace una pulcra descripción de la técnica, inconvenientes, ventajas, etc., sino que convencido de su utilidad, su originalidad y su aplicación quirúrgica llega a afirmar: «El bloqueo de las raíces nerviosas con sustancias anestésicas, en el espacio epidural, es susceptible de producir analgesia, utilizable en intervenciones quirúrgicas, y de la misma manera que Cathelin, Reclus, Laewen, Gaza y otros muchos han logrado con la anestesia sacra tan buenos resultados, que adoptan para ciertas intervenciones en la clínica, los estudios que llevamos practicados hasta la fecha nos autorizan a afirmar que

\footnotetext{
${ }_{114}$ James Leonard Corning. (1855-1923). Neurólogo natural de Nueva York. Pensó que los productos inyectados dentro del canal medular podían ser absorbidos por los plexos vasculares de la zona y dirigirse hacia la médula, por lo que creía haber encontrado una forma directa de aplicación de medicación para las enfermedades neurológicas. Así lo describe: «Para este fin, inyecté 30 minims de una solución al 3\% de clorhidrato de cocaína en el espacio situado entre las apófisis espinosas de las vértebras torácicas $11^{\mathrm{a}}$ y $12^{\mathrm{a}} \gg$. Tras un lapso de seis a ocho minutos repitió la dosis hasta conseguir anestesia en las extremidades inferiores pudiendo introducir una sonda uretral sin causar dolor. Muy lejos de ser pionero de la técnica epidural, si hay que reconocer el mérito de este neurólogo de que transcurrido más de 100 años de sus ideas, hoy se valora como acertada su teoría de que el lugar de acciónde los anestésicos por vía epidural es la médula (Miller R.D., Bromage P.R.1985, Corning J.L.).
}

las anestesias metaméricas obtenidas nos proporcionan ventajas no despreciables en el acto operatorio»».

Después de esta introducción Pagés sistematiza su artículo dividiéndolo en seis apartados:
A.- Descripción anatómica.
B.- Técnica de anestesia metamérica
C.- Extensión y particularidades de la anestesia metamérica
D.- Fenómenos colaterales que acompañan a la anestesia meta- mérica.
E.- Ventajas e inconvenientes de la anestesia metamérica.
F.- Indicaciones y contraindicaciones.

\section{A.- Descripción anatómica}

La descripción de los límites del espacio epidural que hace Pagés en su artículo resulta tan exacta que hoy puede encontrarse en cualquier opúsculo de anestesia epidural una idéntica codificación a la efectuada por él. Así lo describe: «El espacio epidural está limitado por dos superficies irregularmente cilíndricas, que corresponden: la exterior, a la superficie interna del raquis, la interior, a la externa de la duramadre. Entre ambas se extiende un espacio que alcanza por arriba hasta el contorno del agujero occipital, donde la duramadre, fuertemente adherida al hueso, cierra el paso por fuera de ella a la cavidad craneal, y por abajo, hasta el coxis». «...ya que, por delante, el íntimo contacto de la paquimeninge con el ligamento vertebral común posterior reduce considerablemente aquellas».

Del mismo modo refiere que el espacio epidural tiene unas dimensiones que no son fijas y que varían dependiendo de la actitud del cuerpo, siendo la posición de flexión forzada la que favorecerá una mayor capacidad de espacio: «Esta disposición se traduce por aumento de la distancia que normalmente separa la cara anterior de las láminas y ligamentos amarillos y la posterior de la duramadre».

Bromage (134) en su libro no difiere en absoluto de los límites fijados por Pagés ni en su observación sobre el aumento del espacio epidural durante la flexión forzada de la columna vertebral. Así lo recoge: «Los límites del espacio epidural son: arriba: el agujero occipital, donde las capas periósticas y medulares de la dura se unen íntimamente. Abajo: la membrana sacrococcígea. Delante: el ligamento longitudinal posterior, que cubre la cara posterior de los cuerpos vertebrales y de los discos intervertebrales. Detrás: la superficie anterior de las láminas vertebrales y el ligamento amarillo. Lateral: los pedículos de las vértebras y los agujeros intervertebrales». Más adelante continúa: «En la región cervical inferior disminuye hasta 1,5 ó $2 \mathrm{~mm}$, pero por debajo de la VII cervical vuelve a aumentar, especialmente en la flexión, y a la altura del I ${ }^{\mathrm{o}}$ interespacio dorsal la distancia se sitúa en unos 3 ó $4 \mathrm{~mm}$ con el cuello en flexión forzada».

\section{B.- Técnica de la anestesia metamérica}

En este apartado Pagés diferencia la técnica de la punción epidural, la solución anestésica a administrar y el instrumental a emplear.

Basado en la experiencia de las 1500 raquianestesias que Pagés confiesa haber practicado, describe las dos vías de abordaje del espacio epidural así como los dos procedimientos de acceder al espacio. 
Las vías son la punción lateral y la central. En ambos casos Pagés refiere con gran precisión los fenómenos y sensaciones que cualquiera que realice una punción dural habrá experimentado. La punción lateral así la describe: «En la punción lateral, la cánula provista de su fiador camina suavemente por la masa muscular del tríceps espinal, hasta que a una profundidad variable con la gordura del enfermo y la altura de la punción, se experimenta una resistencia que detiene el avance del instrumento; un cuidadoso esfuerzo de la mano y la aguja se hunde ligeramente, con una sensación perfectamente perceptible por el oído (con instrumento de bisel muy corto y no muy afilado); si se retira el fiador no sale líquido». «Los dos chasquidos que se producen al paso del instrumento por el ligamento amarillo y por la duramadre son tan perceptibles, que pueden oírse por las personas que están en la más inmediata proximidad del enfermo».

Con la misma precisión y minuciosidad describe las sensaciones que se experimentan cuando se utiliza la punción medial: «En la punción central, las sensaciones varían por el completo. Como la densidad del ligamento interespinoso y del amarillo son iguales, no notamos con la aguja un aumento de resistencia a nivel de este, sino una brusca sensación cuando lo hemos atravesado».

Siguiendo una u otra vía Pagés afirma que se pueden seguir dos procedimientos para inyectar anestésico en el espacio epidural. El primero consistiría en practicar una punción aracnoidea y retirar la cánula hasta que dejara de rezumar líquido cefalorraquídeo, la seguridad de encontrarse en el espacio epidural lo dará, dice Pagés, «Cuando al inyectar líquido penetra en la cavidad epidural con la misma suavidad que en la subaracnoidea, $y$, en cambio, hay que apretar mucho el émbolo y hacer presión para vencer la resistencia, tanto de los ligamentos como del tríceps».

Pagés se inclina abiertamente por el segundo procedimiento, al que cataloga como «positivamente más elegante». Este consistiría en detener la aguja de punción inmediatamente atravesado el ligamento amarillo e inyectar la solución anestésica. Continúa la descripción de este método con todo tipo de detalle, entre los que incluye la esterilización de la zona, referencias al nivel de punción dependiendo de la zona a intervenir, detalles anatómicos como la profundidad que se encuentra el ligamento amarillo o la mayor inclinación que hay que darle a la aguja en las punciones dorsales y cómo consigue anestesia precoz de la mitad del cuerpo más declive a la hora de hacer la punción.

A continuación Pagés refiere una interesante matización técnica con objeto de obviar la punción dural y la fuga de anestésico del espacio epidural: «Teniendo en cuenta que los ligamentos amarillos están orientados de atrás adelante y de dentro afuera, procuraremos que la parte puntiaguda del bisel este hacia afuera, con lo que lograremos un cierto paralelismo entre éste y el plano de los ligamentos indicados. Este detalle técnico da por resultado que se aprecie más fácilmente la perforación ligamentosa necesaria para situar la inyección en el interior del raquis y, además, aún cuando toquemos la duramadre con el trócar en la dirección indicada, resbalaremos sobre su superficie convexa sin atravesarla, desplazándose ligeramente al contacto del instrumento. Una punción, según esta técnica, evita también el inconveniente de que parte del bisel quede por fuera de la cavidad raquídea, y la inyección no se realice totalmente dentro de éste».

Si bien Sicard es el primero en describir por primera vez la prueba de la pérdida de resistencia con mandril líquido para detectar el espacio epidural ${ }^{115}(64,134)$ es indudable que Pagés aporta un procedimiento auténticamente novedoso y propio, basado fundamentalmente en el extenso conocimiento anatómico y una amplia experiencia en la práctica de raquianestesia. Aunque posteriormente otras técnicas han venido a perfeccionar este método, como la gota colgante de Gutiérrez (135), pérdida de resistencia de Dogliotti (70), el indicador de Odom (136.), el balón epidural de Souza (137), el balón indicador de Mc Intosh (138) o el tubo en «U» de Zelenka (134); todos tiene como fundamento los principios asentados por Pagés en su propio y original procedimiento.

En este mismo apartado de la descripción de la técnica, Pagés no hace omisión del instrumental necesario y de la solución anestésica adecuada. Para aquello recomienda como más apropiado una cánula de raquianestesia corriente, con bisel muy corto y no afilado ${ }^{116}$. Como solución anestésica Pagés usó la novocaína suprarrenina en concentraciones al $1,1^{1 / 2}$, y 2 por 100 . Aquí también efectúa dos matizaciones que son interesantes. En primer lugar, recomienda el uso del anestésico al 2 por 100, al obtener mejores resultados anestésicos: «La solución al 1\% nos ha proporcionado en dos casos anestesias incompletas (hipoestesias) de la región operatoria». «La solución preferible nos parece una al 2\%». Esta es una observación precisa, pues en la actualidad se conoce que las sustancias anestésicas tienen un mayor grado de impregnación en las fibras sensitivas cuanto mayor sea su concentración. Por otra parte, añade suprarrenina al anestésico para retrasar la absorción y permitir un contacto más prolongado del anestésico con la raíz nerviosa e impedir fenómenos tóxicos por la rápida incorporación de los agentes anestésicos al torrente circulatorio ${ }^{117}$.

Otra observación fisiológica interesante la realiza Pagés cuando describe la importancia que tiene el volumen anestésico inyectado con el nivel de zona metamérica anestesiada. Realizando un mayor nivel anestésico al incrementar el volumen de sustancia anestésica. Así refiere como, por error, se inyectaron 45 ó 50 cc de solución de novocaína al $1,5 \%$ a un paciente que iba a ser intervenido de litiasis biliar. A los doce minutos la insensibilidad era completa en todo el territorio corporal a excepción de las zonas inervadas por los pares

\footnotetext{
${ }^{115}$ Años más tarde un colaborador de Sicard, Forestier, completa la sucinta descripción de la técnica que aquel había realizado : «Penetrar en un espacio interlaminar, como en la punción lumbar, luego, cuando la punta ha atravesado el ligamento amarillo, lo que se traduce en una vibración que la mano del operador percibe y la sensación de haber perforado algo (una piel de tambor, por ejemplo), no presionar más que lo necesario para avanzar 1 ó 2 milímetros sin penetrar a través de la duramadre en la cavidad subacnoidea; el líquido cefalorraquídeo no debe rezumar. Puede deducirse que la punta de la aguja está bien situada si la inyección de la solución de cocaína contenida en la jeringa, que antes ofrecía notable resistencia, se produce con la misma facilidad que si la aguja estuviera en la cavidad subaracnoidea». Pocas novedades aporta Forestier en sus estudios después de esta técnica. (Lee A.L.1981, Sicard A.1921, Sicard A.1926).

${ }^{116}$ Esta precisión no es baladí. Pagés era consciente de que con un bisel romo se conseguían dos objetivos: uno tener una mayor precisión de la punción del ligamento amarillo, y dos, impedir la punciòn de la duramadre con un bisel más fino. En la actualidad las agujas más utilizadas para las punciones epidurales, como las de Mc Intosh, Crawford o Tuohy, tienen un bisel romo o curvo por esta razones (Bonica J., Killian H., Morisot P., Lee A.L.1981, Bromage P.R.).

${ }_{117}$ Pagés utilizaba las pastillas Braun como anestésicos, que eran una síntesis que Heinrich Braun realizó basándose en el estudio de Einhorm para sintetizar la novocaína y los de la casa Parke-Davis, el extracto de suprarrenales de animales. (Killian H.).
} 
craneales. Aprovechando el amplio campo anestésico obtenido, la paciente le pidió que le interviniera de unas hemorroides que le molestaban mucho. El curso postoperatorio fue normal, siendo dada de alta a los diez días de la intervención.

Esta precisión la completa en el apartado siguiente cuando afirma: «La inyección de una solución anestésica en el triángulo de bloqueo radicular intrarraquídeo seguida de la difusión de la sustancia empleada en el espacio epidural, siendo la zona de difusión mayor o menor, según la cantidad de solución empleada».

\section{C.- Extensión y particularidades de la anestesia metamérica}

En este apartado Pagés basándose en el esquema nervioso descrito por Sherrington (139) justifica y describe el modo progresivo de instauración de la anestesia epidural: «Al poco tiempo de inyectar, a los cinco minutos, empieza a aparecer una zona de hipoestesia en un segmento del cuerpo correspondiente a las raíces bañadas por la mezcla anestésica; esta zona es bilateral, pero al principio algo más extensa en la mitad del cuerpo correspondiente al lado de la inyección. La motilidad permanece en un principio inalterada, así como las reacciones vasomotoras. La sensibilidad se va haciendo más obtusa a medida que pasa el tiempo, y se extiende en el lado no inyectado hasta alcanzar los límites del otro. Desaparece, en primer término, la sensibilidad al dolor, y casi paralelamente la térmica; de modo que al cabo de quince minutos, y a veces antes (diez minutos, y menos en algunos enfermos), la anestesia es completa en las metámeras inervadas por las raíces que sufrieron el bloqueo. La sensibilidad táctil persiste casi siempre, aún con analgesia absoluta, siendo este uno de los hechos más curiosos tanto de la raquianestesia como de la que describimos».

Es una descripción prolija, pormenorizada y que denota una enorme capacidad de observación y sistematización del trabajo.

Destacan en este apartado también, dos apreciaciones fisiológicas. En una de ellas Pagés apunta como el anestésico afecta antes a la fibra sensitiva que a la motora, y en la otra resalta las diversas formas en que el simpático se ve afectado por la anestesia epidural.

Pagés estima que con su método se consigue una de las cosas más importantes en operaciones abdominales como es la sensibilidad visceral, y que ello acarreará una ausencia de respuesta simpática cuando se manipulen las vísceras. Así comenta: «Con la anestesia metamérica lograremos no sólo la analgesia absoluta necesaria para una buena y cómoda intervención del cirujano, sino que el silencio abdominal se acompaña de inhibición simpática, no presentándose las bruscas alteraciones de presión más que por violentas tracciones viscerales»».

Bromage (134) así relata la afectación simpática visceral: «el bloqueo simpático de las vísceras abdominales aparece cuando la anestesia se extiende e influye los seis segmentos dorsales inferiores. La denervación esplácnica previene la respuesta simpática normal a los estímulos nocivos y otorga numerosas ventajas potenciales a los órganos abdominales».

También Pagés insiste en que la afectación del simpático va a producir una paresia vasomotriz que conduce a una vasodilatación: «La paresia vasomotriz mencionada exige colocar más pinzas hemostáticas en el campo operatorio, pues vasos pequeños, que no sangrarían, sangran bajo la influencia de la vasodilatación; pero esto, lejos de ser un inconveniente, es una ventaja, ya que pasada la acción del anestésico, la herida queda completamente seca, y esto favorece el proceso cicatricial».

Siguiendo, una vez más a Bromage éste apunta en este sentido: «La analgesia epidural provoca un bloqueo simpático eferente segmentario, con resultado dilatador de resistencia y capacitancia».

Es sorprendente las precisiones de afectación del simpático que describe Pagés en la anestesia epidural, en todo similar a la que realizan autores actuales $(63,64,65,68)$.

Finaliza Pagés este apartado haciendo referencia a los trabajos de Crile ${ }^{118}$ sobre la combinación de anestesia local con general, lo que nos indica el conocimiento que tenía sobre la medicina norteamericana. Aunque Pagés no llega a utilizar fármacos por vía general no desecha la idea de su bondad: «El uso de pequeñas dosis de pantopón escopolamina, en la forma de todos conocida, sólo puede mejorar los resultados obtenidos, eso sin contar con que todo cirujano debe esforzarse en procurar a su enfermo un mínimo de traumatismo moral y orgánico, para cumplir exactamente con los preceptos de Crille, de los que el sueño crepuscular es uno de los más atendibles».

\section{D.- Fenómenos colaterales que acompañan a la anestesia metamérica}

Como hombre metódico Pagés recoge aquí las variaciones tensionales, de pulso y respiración, así como los fracasos en la técnica, los accidentes habidos y el curso postoperatorio.

En lo concerniente a las posibles oscilaciones de pulso, respiración y tensión arterial, tomada con el oscilómetro de Pachón ${ }^{119}$, no aprecia alteraciones, sólo los descensos tensionales transitorios cuando se anestesian todos los pares raquídeos.

En los fracasos, hemos detectado una contradicción, pues si bien en este apartado refiere haberse producido un fracaso en un paciente al que se le practicó una resección costal por pleuresía, en la parte final de su artículo, cuando relaciona los tipos de intervención realizados con su método anestésico, termina afirmando: «En las 43 anestesias practicadas, la anestesia ha sido completa en 40. En dos casos (una pleuresía y una luxación de hombro), la anestesia fracasó, seguramente por defecto de técnica»».

Desconocemos la razón por la que Pagés excluye el caso de la luxación de hombro en su relato inicial de fracasos, posiblemente se debiera a que en esta ocasión no pudiera realizarse la punción o la técnica fallara totalmente, pues en el paciente de la pleuresía, específica que la técnica fue defectuosa al practicar una punción baja y con dosis insuficiente de anestésico. Sea cual fuere la razón, queda claro que Pagés en esta ocasión, como en el resto del artículo, trata de reflejar, con toda su capacidad de

\footnotetext{
${ }_{118}$ Aunque Pagés en su artículo cita a Crille, es indudable que a quien se refiere es a George Washintom Crile (1864-1943) nacido en Chili, Ohio. Colaborador de Victor Horsley y profesor de la clínica quirúrgica en la Western Reserve University. Publicó varias monografias sobre presión arterial y hemorragias que le llevaron a la deducción que para reducir los riesgos operatorios era conveniente combinar anestesia local con general. (Guerra F.).

119 ) Michel Victor Pachon (1893-1946). Médico Francés inventor del oscilómetro y del método que lleva su nombre, consistente en realizar una cardiografía estando el paciente en en decúbito lateral izquierdo. (Diccionario terminológica de ciencias médicas)
} 
observación, cualquier detalle que aprecia para anotarlo y darlo a conocer.

En lo referente a los accidentes, relata tres tipos de complicaciones, Las primeras son las náuseas y vómitos que se presentan en algunas pacientes por efecto de la transitoria depresión tensional. Pasa pronto, dice Pagés, y su evolución favorable se acelera por la inyección de éter o cafeína.

En segundo lugar describe un accidente que cataloga de desagradable y que apareció en dos ocasiones. Es la presentación de una verdadera lipotimia después de realizar una anestesia epidural total.

Pagés explica este fenómeno como consecuencia del desplazamiento que sufre el líquido céfalo-raquídeo en dirección ascendente al repleccionar todo el espacio epidural con solución anestésica, ello conllevaría una compresión de los vasos de la piamadre y por ende una isquemia encefálica, «Subtratum funcional de la lipotimia».

Es muy factible que la verdadera razón de este cuando se debiera a una extraordinaria difusión ascendente de la solución anestésica, con la consiguiente simpatectomía farmacológica que provocan los anestésicos locales en el espacio epidural y la consecuente severa hipotensión y lipotimia. Estos estados son relativamente frecuentes y han sido, posteriormente, recogidos en la literatura médica $(140,141)$.

Como tercera complicación describe un caso típico de inyección subaracnoidea masiva accidental. La sucesión de acontecimientos que se produce en este tipo de complicación, así como las medidas para yugular sus consecuencias y los fundamentos del accidente están perfectamente recogidos: «Cuando llevábamos introducidos unos $14 \mathrm{cc}$, el enfermo torció la cabeza hacia el lado izquierdo y sus brazos adquiriendo una laxitud especial. Inmediatamente retiré la aguja y di vuelta a la mesa para situarme frente al enfermo, mandando acostarle en la cama de operaciones. Su cara obnubilada y un nistagmus transversal rápido me hicieron juzgar la situación de bastante grave; el conocimiento estaba perdido, el color era normal, el pulso no había variado y sólo los movimientos respiratorios iban disminuyendo en número y en profundidad, llegando al cabo de un minuto a ser tan distanciados que empezamos a practicar respiración artificial. Antes de los dos minutos, la respiración había cesado por completo; pero el pulso continuaba, aunque casi imperceptible. La pupila se había ensanchado».

«Estimulación cardíaca y continúa la respiración artificial. El nistagmus había cesado y el conocimiento no se recobraba; encargué a varios de los internos de insistir en las maniobras respiratorias».

«Yo me inclino a atribuir estos alarmantísimos fenómenos a que el líquido inyectado pasando una cantidad de solución concentrada de novocaína a la cavidad subaracnoidea en las proximidades del ventrículo bulbocerebeloso»».

Entre las complicaciones tardías aparecidas en el postoperatorio refiere las cefalalgias habidas en los pacientes a los que se les practicó el bloqueo radicular intrarraquídeo, y que Pagés bien atribuye a la pérdida de líquido cefaloraquídeo; y la raquialgia. Resulta curioso que el porcentaje de aparición de esta complicación en el estudio de Pagés, 6'9 por ciento, en tres pacientes de cuarenta y tres, coincide, con una mínima e imperceptible variación, 6'8 por ciento, con uno de los últimos trabajo publicados sobre punciones durales. (142).

\section{E.- Ventajas e inconvenientes de la anestesia metamérica}

Después de reconocer que el principal inconveniente de la anestesia metamérica es el tiempo que tarda en instaurarse: «El método que describimos tiene el inconveniente de la tardía presentación de la analgesia». «la anestesia metamérica puede calcularse que tarda en ser completa unos quince minutos»; Pagés deshecha la idea de comparar su método a la anestesía general : «Siempre existirán cirujanos que prefieran ver dormido a su enfermo, aún para la práctica de las más sencillas intervenciones», y realiza un estudio comparativo con la anestesia paravertebral, la anestesia espinal de Johonesco y le Filliatre y la espinal lumbar: «El bloqueo radicular intrarraquídeo hay que estudiarlo al lado de otros métodos parecidos de anestesia, para poder definir cuál es preferible, o, por el contrario, a cuál de ellos son atribuibles mayores desventajas»».

Con respecto a la anestesia paravertebral nos dice que es preferible la metamérica, toda vez que aquella no posee un campo de aplicación tan amplio como esta, por no ser tan inofensiva dado el riesgo de colapso grave por inyección intravascular y por la necesidad de usar altas dosis de anestésico.

Por último, considera que el tiempo que exige la práctica de este método es aún mayor que el preciso para la anestesia metamérica.

Del mismo modo considera excesivamente peligrosa la práctica de la anestesia aracnoidea según el método de Johonesco y Le Filliatre por las graves crisis hipotensivas y de colapso que ocasionan: «En algunos enfermos, la hipotensión producida por anestesias altas (método de Le Filliatre) era tan considerable, que he podido seccionar de intento la arteria facial antes de pinzarla, en una extirpación de glándula y ganglios submaxilares, y apenas daba sangre». «Recuerdo, por ejemplo, que en dos enfermos, con cáncer de estómago, en los que la raqui (uno anestesiado por el procedimiento de Filliatre, y otro por el de Johonesco, con novocaína) había producido una analgesia absoluta, después de practicada la laparotomía y la exploración visceral, el estado del pulso empeoró de tal manera, a pesar de los estimulantes cardíacos, que no me atreví a seguir operando».

En comparación con la anestesia lumbar corriente, considera que en intervenciones de la parte supraumbilical del cuerpo es preferible la anestesia metamérica, mientras que en operaciones infraumbilicales estima que la anestesia epidural no es un procedimiento inferior a la técnica intradural, incluso, añade Pagés: «le concedo a aquel, en todo caso mayor inocuidad».

F.- Indicaciones y contraindicaciones.

Finaliza su trabajo siendo rotundamente contundente a la hora de sentar las indicaciones y contraindicaciones de su técnica.

Ante aquellas, afirma categóricamente: «Siempre que haya que operar en zonas inervadas por nervios raquídeos, es utilizable la anestesia metamérica, con ventajas sobre la aracnoidea y paravertebral». Para, a continuación, abundar en los argumentos en los que se basa para su elección. Sobre la anestesia paravertebral vuelve a insistir en sus inconvenientes, a los que suma el hecho de que con este tipo de anestesia sólo se consigue insensibilizar la mitad del cuerpo.

A la anestesia intrarraquídea le imputa un nuevo inconveniente: «Los anestésicos disueltos en el líquido cefalorraquídeo no sólo impregnan las raíces sino la médula misma, y transportados con la corriente del mencionado líquido a partes distantes, pueden provocar fenómenos funcionales a distancia».

Pagés sostenía la teoría que la acción de los anestésicos locales se centraba única y exclusivamente, en la anestesia metamérica, en 
los nervios raquídeos en su salida de la misma y en su trayecto en el espacio epidural. Es patente que desconocía, como años más tarde se pudo demostrar $(134,143)$, que parte de los anestésicos depositados en el espacio epidural, atraviesan la duramadre pasando al líquido cefalorraquídeo y causando cierto grado de bloqueo subaracnoideo ${ }^{120}$.

Las contraindicaciones Pagés las reduce a dos: la edad y los procesos sépticos. Contraindica la analgesia epidural en niños por su incapacidad para diferenciar la sensación táctil de la dolorosa. De la misma forma, destaca que todo proceso séptico de espalda situado en la zona en que haya de practicar la inyección o en la proximidad, constituye otra contraindicación formal ${ }^{121}$.

Ya finalizando, Pagés relaciona las 43 intervenciones practicadas, haciendo mención a los problemas surgidos:

\begin{tabular}{|l|c|}
\hline Hernias inguinales & 18 \\
\hline Hernias crurales & 3 \\
\hline Apendicitis & 4 \\
\hline Gastroenterostomías & 2 \\
\hline $\begin{array}{l}\text { Resecciones gástricas por úlceras liberación de adherencias y } \\
\text { peritonización en caso de ileocrónico. Consecutivo a apendicec- } \\
\text { tomía }\end{array}$ & 1 \\
\hline Colecistectomias y exploración de vías biliares & 2 \\
\hline Riñón flotante & 1 \\
\hline Pleuresías (una con deficiente resultado) & 2 \\
\hline Espolones calcálneos & 2 \\
\hline Amputaciones muslos & 1 \\
\hline Resección de rodilla & 1 \\
\hline Reducción de luxación de hombro (sin resultado) & 1 \\
\hline Hemorroides & 1 \\
\hline Hidroceles & 2 \\
\hline Toilette ganglionar de cuello (anestesia completa, pero accidentada) & 1 \\
\hline
\end{tabular}

Pagés, conocedor de que se encontraba ante una nueva aportación al campo de la medicina, se muestra cauto a la hora de plantear las últimas conclusiones: «Los resultados, para ser los primeros, me parecen lo suficientemente aceptables para justificar ulteriores investigaciones»».

Con estas palabras acaba uno de los principales trabajos originales y novedosos de la historia de la anestesia. Palabras prudentes que abren un posterior capítulo para nuevas investigaciones que corroboren las bondades del método descrito. Su precoz fallecimiento, dos años y dos meses después de la publicación de este

\footnotetext{
${ }^{120}$ Aunque todavía no está suficientemente aclarado cual es el mecanismo último de acción de los anestésicos locales en la anestesia epidural, ha quedado demostrado que buena parte de los anestésicos pasan con rapidez al interior del espacio espinal y producen un bloque a nivel medular. Así lo confirmaron los trabajos de Foldes y Davis (1954), Frey y Soehring (1954), Frumin y Cols (1953), Bromage y Cols (1963). Usubiaga y Cols en Harvard, en 1961, comprobaron que en las dos primeras horas se recuperaba en el líquido cefalorraquídeo entre el 3-10\% de anestésico depositado en espacio epidural (Bromage P.R.1985)

${ }^{121}$ En la actualidad se sigue contemplando el proceso infeccioso como una contraindicación absoluta, a la que se añaden, la hemorragia incontrolada y como contraindicaciones relativas; la enfermedad neurológica existente, deformidades medulares, sensibilidad a los anestésicos locales y ciertas cardiopatías determinadas (Bonica J., Killian H, Morisot P., Lee A.J.1981, Bromage P.R.1985).
}

artículo, impidió que Pagés concluyera sus iniciales investigaciones. El epílogo a las experiencias de Pagés lo escribieron Dogliot$\mathrm{ti}^{122}$ (70) diez años más tarde, y Gutiérrez ${ }^{123}(135$.), once después.

Dogliotti en su original artículo publicado en 1931 no hace referencia en ningún momento a los trabajos de Pagés, presentados diez años antes. El propio cirujano italiano presentó su experiencia en el Congreso de la Sociedad Internacional de Cirugía celebrado en Madrid en 1932 (90).

Ni en este Congreso ni en los trabajos posteriores de Martínez Sagarra (144) y Pi Figueras (145) se hace referencia alguna a los trabajos previos de Pagés. Tendría que ser el argentino Gutiérrez (135) quien al publicar sus primeras experiencias hace justicia.

Animado, quizás, por este redescubrimiento de la obra de Pagés, Jaime Pi-Figueras, el mismo que en el año 1932 ignoró a Pagés en su artículo sobre la anestesia peridural, con motivo de la Reunión de la Sociedad Italiana de Anestesia celebrada en Turín en abril de 1935 reivindicó ante el propio Dogliotti la originalidad del método para Pagés $(90,146,147)$.

Después de años de olvido, el artículo de Pagés fue traducido al inglés y publicado en 1961 (72) y catorce años después al francés (148). Paulatinamente la evidencia se ha ido imponiendo y el trabajo de Pagés ocupa, por derecho propio, un lugar en la historia de la anestesiología.

C. Hervás Puyal en su artículo ${ }^{124}$ llega a afirmar: «La aportación española a la historia de la anestesiología ha sido, lamentablemente, muy reducida. Sobran los dedos de una mano para enumerar a los autores cuya obra ha perdurado a través del tiempo: José Goyanes creador de la anestesia intraarterial; Fidel Pagés, el primero en abordar con fines anestésicos el espacio epidural y Jaume Raventós, farmacólogo cuyas investigaciones hicieron posible la aplicación en el hombre de un nuevo anestésico inhalatorio: el Fluothano ${ }^{125}$. De ellas la contribución de Pagés

122 ) Achile Mario Dogliotti (1897-1966) Nació en Turin donde se graduó en medicina en 1920. Después de trabajar en Catania (Sicilia) como cirujano sucedió a su maestro Uffreduzzi en la cátedra de cirugía de Turin. Fue uno de los primeros cirujanos europeos en abordar las intervenciones cardíacas, inventó una de las primeras máquinas corazón-pulmón, fue pionero de la radiografía de las vías biliares y organizador del primer banco de sangre en Italia. Demostró gran interés por la anestesia, desarrollando y describiendo su método de analgesia segmentaria peridural. En 1939 publicó un libro sobre anestesia. (Lee A.J.1981).

${ }^{123}$ Antonio Gutiérrez, médico argentino que describió el método de la «gota pendiente» como sistema para detectar el espacio epidural. (Bromage P.R.1985, Miller R.D.).

${ }^{124}$ En este artículo, siendo monográfico sobre Pagés se comete el desliz de citar Zaragoza como su lugar de nacimiento.

${ }^{25}$ Jaume Raventós (1905-1982) nació el 3 de agosto en Barcelona. Hijo del prestigioso cirujano del Hospital de Santa Cruz Antonio Raventós Avinyó, colaborador del fisíologo August Pi Sunyer. Finalizada la Guerra Civil Española tuvo que exiliarse en Gran Bretaña donde trabajó en el Departamento de Investigaciones Farmacológicas de la General Chemical División de la ICI. Consiguió aislar el Tialbarbital, al que denominó Kemithal como resultado para hallar un barbitúrico de acción ultracorta que ofreciera ventajas respecto a los que ya existía en la clínica diaria.En 1956 publicó un artículo titulado: «La acción del Fluothano. Un nuevo anestésico volátil», en el que daba a conocer las propiedades y cualidades de este nuevo gas halogenado. Fue usado por primera vez en una intervención quirúrgica el 20 de enero de 1956 en el Departamento de Anestesia de la Royal Infirmary de Manchester por Michael Johnston. (Hervás C.1992). 
es quizás la que ha conocido una mayor difusión, continuando todavía hoy plena vigencia» (90).

Del mismo modo se pronuncia A. Lee (68) y P. Morisot (65.). El primero apunta: «Su artículo, que con el título de "La Anestesia Metamérica" se publicó en la Revista Española de Cirugía, es el primero en el que no sólo el principio de la anestesia peridural, sino también sus aplicaciones prácticas, están codificadas perfectamente. En tal aspecto, Pagés puede ser considerado como el verdadero promotor del método». Más adelante insiste: «Este trabajo, que aún hoy nos parece comparable en más de un aspecto a los mejores que se han hecho sobre el tema, no había de gozar, sin embargo, de un gran triunfo. Incluso su autor moriría pocos años después a consecuencia de una enfermedad pulmonar aguda».

El autor francés llega a afirmar, en referencia al artículo de Pagés: «Un trabajo que aún hoy nos parece comparable en más de un aspecto a los mejores que se han escrito sobre el tema y puede afirmarse que en él está todo descrito, las bases anatómicas, las características de la analgesia y la parálisis motora; la técnica, los signos y las complicaciones y contraindicaciones».

También Bonica (63) hace referencia al trabajo de Pagés, aunque sin reconocerle su iniciativa en la descripción de la técnica epidural: «En 1921, Fidel Pagés, cirujano militar español, propuso el bloqueo segmentario lumbar peridural, que él llamó anestesia metamérica, con fines quirúrgicos»».

Bromage (134) le da el papel de mediador en la historia del acceso al espacio epidural entre los partidarios de abordarlo por la vía caudal o paravertebral: «Esta problemática se prolongó hasta 1921, fecha en que Fidel Pagés volvió a despertar el interés por la punción lumbar media y a resaltar la facilidad de su acceso y la amplitud de posibilidades que ofrecía en comparación con la caudal. Como el método de Pagés para identificar el espacio fue primeramente táctil, requería mucha destreza por parte del cirujano para sentir cómo la aguja atravesaba el ligamento amarillo y penetra en el espacio epidural».

Estimamos que a pesar de los olvidos intencionados o inadvertidos, los errores acumulados y asumidos durante años y las perífrasis cicateras de algunos autores, hoy ya no queda lugar a dudas para considerar a Pagés cómo el verdadero y auténtico pionero en la técnica descriptiva del abordaje epidural con fines quirúrgicos. No sólo se limitó a una somera descripción, sino que lo completó con un estudio cuidadoso, pormenorizado, detallado, sistematizado y codificado; tan sólo interrumpido, en sus primeras experiencias, por su prematuro y desafortunado fallecimiento.

\section{Obra quirúrgica-traumatológica}

En esta faceta de su vida profesional, Pagés no es verdaderamente un revolucionario, ni hizo variar los tradicionales cánones de la cirugía clásica, pero, indudablemente, es un cirujano que se posiciona al frente de las corrientes quirúrgicas más vanguardistas y llega a aportar algunos trabajos notables y merecedores de resaltar. Todo ello, constreñido por las limitaciones que le impuso su temprano fallecimiento.

En su concepto de la cirugía destacan dos características sobresalientes: su pragmatismo y su constancia en defender, en to- dos sus trabajos, los patrones quirúrgicos de su época: anestesia, asepsia, hemostasia y cirugía reparadora y funcional. $(106,107$, 108, 113).

El pragmatismo de su obra es una cualidad que deviene, incuestionablemente, de su quehacer en la cirugía de guerra, en donde el posibilismo se impone a cualquier otro condicionante. Las continuas contiendas bélicas a las que Pagés tiene que asistir (La Guerra de las Minas del Riff, 1909; la del Río Kert, 1912; estancia en los campos de la I Guerra Mundial, 1917 y tras el Desastre de Annual, 1921) le otorgaron la oportunidad de atender a un importante contingente de heridos en precarias condiciones, y con escasos medios, lo que condicionó y conformó su postrer trabajo profesional.

Aunque siempre ha estado en discusión los beneficios técnicos que le pueden reportar a un cirujano su incorporación a la cirugía de guerra, nos quedamos con la afirmación del Profesor Durán Sacristán al contestarle al discurso pronunciado por el Doctor D. Mariano Zúmel en su ingreso en la Real Academia de Medicina: «Aunque sonase a sarcasmo, para la formación de un cirujano la guerra es una ocasión de privilegio que históricamente ha constituido una de las mejores fuentes de conocimiento en la fisiopatología y terapéutica». El mismo Mariano F. Zúmel opina sobre el mismo tema: «El Capítulo importante es, en un cirujano formado, que tenga ya una experiencia, el injertarle dentro de la cirugía de guerra, ¿Qué puede suponer para su formación y para el desarrollo de la propia cirugía? Pues, indudablemente, tiene las ventajas que decíamos anteriormente de que la técnica, conociendo bien la anatomía humana, va a confirmar cómo escribe con renglones rectos la naturaleza» (Los médicos y la medicina en la guerra civil española).

Este condicionante hace que Pagés practique una cirugía huyendo de falsos protagonismos y de estadísticas manipuladas; así lo afirma en uno de sus mejores artículos: «Era necesario buscar la pequeña posibilidad de curación con el bisturí en la mano y con la mente alejada de los resultados estadísticos» (105).

Decíamos que otra característica de su obra es el continuo seguimiento de los patrones quirúrgicos de la época: anestesia, asepsia, hemostasia y cirugía reparadora. De la misma forma que la anestesia, como ya hemos podido relatar, es una constante en su obra científica, los otros patrones se repiten con idéntica preocupación.

Todos estos conceptos los va vertiendo de forma paradigmática en su artículo «Contribución al estudio de la cirugía plástica de la mejilla» (98). Aquí queda plasmado su obsesión por encontrar esa cirugía restauradora: "Los colgajos insuficientes producen la cara trastornos funcionales más grandes que en otras regiones; por eso nos preocuparemos en todo momento de contar con la retracción cicatricial evaluada, aproximadamente, en una sexta parte de la extensión del colgajo, para ponernos a cubierto del ectropión, del trismus cicatricial y de otras enojosas consecuencias»».

Para alcanzar una adecuada cirugía funcional era consciente de realizarla bajo unas adecuadas normas de asepsia: «La cirugía restauradora necesita en la cara, como en las demás regiones, pero todavía con mayor motivo, cumplir algunos requisitos que, hasta cierto punto, garanticen su éxito, y entre ellos, los más importantes son la asepsia perfecta y la vitalidad asegurada de los colgajos». Más adelante insiste en la necesidad de una extremada 
asepsia: «Para hacer en lo posible limpia la boca debemos prescribir una minuciosa extirpación del sarro dentario, que generalmente existe en abundancia, aún en personas de clase elevada, y que, por ser depósito de infinidad de microbios, es muy apto para acarrear la infección postoperatoria. Este detalle corre a cargo del dentista, a quien se recomendará, además, que proceda a la extracción de las piezas dentarias con caries avanzadas, o al empaste, en su defecto, dejando la boca en condiciones de perfecta limpieza. Algunos días antes de la intervención, el paciente hará, por encargo nuestro, colutorios antisépticos al agua oxigenada o al timol, o al ácido salicílico, que se repetirán varias veces en las veinticuatro horas, pero en especial después de cada comida, sin descuidar el cepillado de los dientes, que se practicará otras tantas veces» (98).

En su trabajo «El tratamiento de las fracturas del olécranon por el enclavijamiento y la extensión continua» (99), vuelve a poner de manifiesto su preocupación por la asepsia y la restauración funcional:

«Aún en grandes centros quirúrgicos donde se dispone de todo, hay un tanto por ciento no despreciable de fracasos consecutivos a la fijación operatoria (en 22 suturas metálicas practicadas por Tuffier, tres supuraciones), comprenderemos que no es estéril la labor de poner en práctica nuevos procedimientos terapéuticos, sobre todo si hacemos de ellos armas más inofensivas».

De la siguiente forma describe la conducta terapéutica a seguir en este tipo de fracturas: «Restablecer el equilibrio de los músculos antagonistas y evitar la atrofia muscular; esto lo lograremos por la fijación de los fragmentos y por el masaje y la movilización.

Favorecer la desaparición del hematoma y de los exudados procedentes del hueso y de los músculos desgarrados, y que, ejerciendo presión sobre las partes vecinas, retarda la circulación de retorno sanguínea y linfática, con notorio trastorno de la troficidad de los tejidos. La punción aspiradora puede prestarnos buenos servicios en caso de hematrosis abundante.

Restablecer la continuidad anatómica del hueso para devolver al miembro fracturado su capacidad funcional». Defensor de la tracción permanente de Steinmann y Codivila ${ }^{126}$ en la terapia de las fracturas de extremidades por considerarla más funcional y con menor riesgo de infecciones, toda vez que la tracción se ejerce sobre puntos alejados del foco de fractura, no duda en aplicarla: «Partidarios decididos de la extensión continua siempre que se puede poner en práctica, pensamos en aplicarla: Partidarios decididos de la extensión continua siempre que se puede poner en práctica, pensamos en aplicarla, desde luego, utilizando unas clavijas de acero niquelado susceptible de enclavarse en el hueso por la presión de la sola elasticidad de sus ramas» (99).

Pagés se inclina por la actitud abstencionista, en este tipo de fracturas, después de conocer perfectamente la polémica suscitada en el Congreso de Cirugía de Berlín de 1908 por Kocher sobre el tratamiento operatorio de las fracturas. Desde ese instante se marcaron dos tendencias: los intervencionistas como Tuffier o

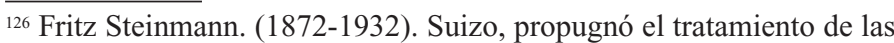
fracturas de miembros por extensión ejercida en el fragmento distal del hueso fracturado por medio de clavos implantados en él.

Alesandro Codivilla (1861-1912). Natural de Bologna. Fue director del Instituto Rizzoli de cirugía ortopédica de esa ciudad. Describió la técnica de tracción y extensión contínua ósea en las fracturas de miembro inferior, mediante la inserción de un clavo en el talón. (Guerra F.).
Lane ${ }^{127}$ y los que creían que con la extensión continua, el masaje, el enyesado y otros métodos conservadores se consiguen resultados tan brillantes como con la actuación cruenta, al menos, a lo que a la restitución funcional se refiere ${ }^{128}$.

De igual forma, en su artículo «Sobre algunos casos de utilización de las fascias en cirugía» (100), hace una extensa introducción sobre los beneficios del uso de las fascias como material para injertarse y su gran adaptabilidad especial para ser aprovechadas como material plástico.

Refiere la enorme utilidad de estas para ocluir orificios en las paredes de los órganos huecos. Resumiendo su intención de practicar una cirugía reparadora dice: «Los parches aponeuróticos se destinan a ocluir las pérdidas de substancia de los aparatos respiratorio, digestivo y urinario, y tiene por objeto reconstruir las cavidades primitivas de los órganos sobre los que se aplican» (100).

Relata, a su vez, tres casos clínicos en los que se vio obligado a utilizar fascias, en un caso como protector del nervio cubital, al que se le envolvió en una lámina de la aponeurosis intermuscular interna, para evitar la extensión de la infección del brazo al nervio reparado. En las otras dos ocasiones, Pagés utiliza las fascias con fines hemostáticos. El primero de ellos se trataba de un epitelioma de cuero cabelludo extenso, que al extirparlo se produjo una copiosa hemorragia, tan solo controlada y yugulada con la interposición de la aponeurosis de cubierta del músculo temporal sobre la zona sangrante. Finalmente, aunque reconoce que en cirugía vascular la utilización de las aponeurosis es escasa, estima que su uso, en determinadas circunstancias, puede ser ampliable al tratamiento de las heridas arteriales como se vio obligado a hacérselo a un joven banderillero ${ }^{129}$ que con un rejón se produjo una herida en la arteria humeral y otra en la cubital, tan solo pudiéndole reparar la lesión tubulizando las arterias en la aponeurosis de envoltura del brazo en la parte correspondiente al bíceps braquial.

Este es uno de sus trabajos en los que Pagés con más empeño trata de encontrar una cirugía funcional y restauradora. Para lo cual, tampoco obvia la necesidad de practicar una adecuada asepsia y hemostasia. Pagés da muestras de su extremada preocupación por la asepsia: «Ningún cirujano sería capaz de intentar, dado el estado actual de nuestros conocimientos, la implantación de un segmento libre de piel en una úlcera varicosa sin una desinfección previa verdaderamente radical de la superficie cruenta, ni de un trozo de hueso en una cavidad osteomielítica infectada, porque de antemano conocería el fracaso a que se vería

${ }^{127}$ William Arbuthnot Lane (1856-1943) de Fort George, Escocia, propuso una técnica de osteosíntesis en las fracturas dobles de tibia y peroné y el empleo de placas atornilladas en la consolidación de las fracturas. Curiosamente, como haría Pagés, en su libro «The operative treatment of chronic constipation» (1909) propuso la resección del ciego y un cortocircuito intestinal como tratamiento quirúrgico del estreñimiento crónico. (Guerra F.).

${ }^{128} \mathrm{El}$ tratamiento conservador con masajes e inmovilización en extensión no muy prolongada, fue sostenida por un buen número de autores: Tripier y Bellin, Tilanus y Lucas, Championniere, Malgaigne, Berthomier y Sachs. Tan sólo permitían la actuación cruenta en las fracturas con gran separación en jornaleros y en las fracturas abiertas. Siempre en extremas condiciones de asepsia. (Begouin R.1925, b).

${ }^{129}$ Ya apuntamos anteriormente que Pagés fue uno de los pioneros cirujanos de las plazas de toros. Así lo relata el Dr. Mariano Fernández Zumol en una entrevista en la Revista Jano de 3-9 febrero de 1984 
conducido». «La esterilización de le herida requería, en realidad, una toilette quirúrgica extensa, a base de extirpación de todos los tejidos infectados»».

«Una vez eliminado el tejido de esfacelo, el Carrel ${ }^{130}$ implantado desde el primer momento dominó la infección, y todas las superficies cruentas empezaron a cubrirse de granulaciones sanas»».

También resalta, de manera insistente, la trascendencia de hacer una adecuada hemostasia: «Una de las complicaciones que más han preocupado al cirujano de todos los tiempos, y que ha sido objeto de más amplio y detenido estudio, es la hemorragia. Hay que hacer una cuidadosa hemostasia mediante ligaduras del borde del orificio, que se traduce en la producción de diversas zonas de necrosis, que pueden comprometer el éxito operatorio».

La importancia de una buena hemostasia le lleva a extremos tal como para afirmar: «La hemostasia defectuosa puede ser suficiente para comprometer el éxito de meloplastias, que no presentan, por lo demás ningún otro defecto» (98).

En su trabajo «La gastroenterostomía con collar epiploico» (104) vuelve a incidir en la obligación que tiene todo acto quirúrgico de reparar la funcionalidad del órgano y respetar al máximo la anatomía: «Entre el estómago y el intestino aproximados, se practica una vez hecha y vueltas las vísceras a su posición, quedan rodeadas por dos anillos, uno mesocólico y otro epiploico, que se sujetan y adaptan mediante unos puntos de sutura al contorno de la boca anastomótica. La reposición de las vísceras y la oclusión de la pared terminan el acto operatorio»».

En esta nota de técnica, Pagés trata de evitar los procesos sépticos peritoneales en los pacientes con gastroenterostomía: «Aún cuando la peritonitis es actualmente una rarísima complicación de la gastroenterostomía, y con la técnica moderna hemos logrado reducir casi a cero las defunciones por dicha contingencia, todos cuantos esfuerzos realicemos por proteger el peritoneo de las causas de infección inmediata o lejana perfeccionarán las estadísticas operatorias»».

Insistiendo en extremar al máximo las medidas antisépticas comenta: «Payr ${ }^{131}$, tocando con tintura de yodo las superficies de sección gastrointestinales, y otros cirujanos, al hacer la abertura de la mucosa con termocauterio, acentúan los procedimientos antisépticos como profilaxia contra la infección peritoneal».

Tampoco olvida en este artículo la importancia de la hemostasia: «Hecha la hemostasia que algunas veces requiere el desprendimiento coloepiploico».

$\overline{130}$ Alexis Carrel (1873-1944) natural de Lyon. Fue ayudante de J.L. Testut. En unión con el conocido químico inglés Henry D. Dakin (18801952). Introdujo la irrigación de las heridas con soluciones antisépticas para prevenir la infección. Previamente destacó en el desarrollo de una técnica para la sutura boca a boca de los vasos. En 1910 publicó un artículo que marcó el inicio de la cirugía vascular. Fue profesor de fisiología en la Universidad de Chicago y en el Rockefeller Instituto de Nueva York. En 1912 obtuvo el Premio Nobel. En 1935 publicó un libro de dudosa ética «La incógnita del hombre» y tres años más tarde con Lindbergh editó «La cultura de los órganos», base doctrinal de los trasplantes. (Haeger K., Guerra F.).

${ }^{131}$ Erwin Payr (1871-1947). Natural de Innsbruck, fue profesor en Greifswald y en Leipzig. Utilizó injertos de tiroides de madre a hija en 1906. Estudió técnicas de sutura en la unión de los vasos sanguíneos e intestinales, mediante tubos de magnesia. Practicó artroplastias mediante la interposición de músculo, fascias y cámimas metálicas. (Guerra F., Laín Entralgo P.1963).
Idénticos parámetros marcan las líneas básicas de su artículo «Drenaje transcerebral»" ${ }^{132}$ (109): «Si en el cerebro pudiera extirparse todo el trayecto del proyectil y hacer una hemostasia cuidadosa con aproximación de las paredes quirúrgicamente formadas, a la manera de lo que se hace en un sedal de cadera, por ejemplo, sería imposible pretender encontrar por el momento una cosa mejor».

«Tres condiciones parecen indicarnos el empleo del drenaje: Infecciones, grandes lesiones destructivas y hemorragias».

Tampoco en su trabajo póstumo, «Aspecto quirúrgico del estreñimiento» (110) va a olvidar las directrices principales de su obra. En lo concerniente a su actual idea de ejercer una cirugía restaurada y funcional, no da lugar a dudas en estas palabras: «El cirujano debe tratar de cumplir la eficacia del tratamiento con la operación menos cruenta, y, por consiguiente, siempre que pueda se limitará a la práctica de las intervenciones que hemos mencionado; pero hay casos particulares graves por la extensión de las lesiones y por la intensidad de los trastornos acarreados por la estercoremia en los cuales es indispensable desintoxicar rápidamente al paciente, al mismo tiempo que compartir las disposiciones anatómicas del intestino incompatibles con su funcionamiento normal».

Por último, vuelve a insistir en la conveniencia de una estricta asepsia: «Además existen razones técnicas que justifican la mayor gravedad de una colectomía frente a una resección de intestino delgado de la misma longitud. No podemos olvidar que el intestino grueso tiene un contenido más séptico que el delgado y su rica flora bacteriana puede determinar infecciones locales a nivel de las suturas con producción de abscesos ulcerosos y perforación».

Es patente que, en lo referente a su obra quirúrgica, Pagés sigue unos rígidos parámetros que se mantienen constantes en todos sus trabajos.

Analizando detalladamente cada uno de sus artículos nos encontramos con el que publicó a finales del año 1922 en la Revista Española de Cirugía «Heridas Abdominales de Guerra. Mi experiencia personal» (105), en donde compendia de una forma palmaria todas las características que definen su trabajo quirúrgico. Un trabajo basado en unos profundos conocimientos científicos, en el reconocimiento de las aportaciones de otros cirujanos, en una enorme, inevitable y forzada experiencia prematura y en una llamativa capacidad de observación.

Este trabajo es, así al menos lo estimamos, su más importante aportación, desde el punto de vista quirúrgico. En él se plasma un amplio conocimiento de lo realizado por otros cirujanos y sus estadísticas (Chavannaz, Abadie, Bergmann, MacCormac, Delorme, los hermanos Mayo, Cadenat, Gosset, Schwartz, Bouvier, Picqué y Rouvillois), sus propias experiencias personales quirúrgicas, anestésicas, fisiopatológicas; y basándose en todo ello alcanza unas prácticas conclusiones.

Es un trabajo descriptivo y práctico en el que presenta, sin ambigüedades y con una pasmosa sinceridad, la experiencia alcanzada en la guerra de África con este tipo de heridos: «Hemos operado casos desesperados, en los que por anticipado podía hacerse el pronóstico fatal, por tanto; pero era necesario buscar la pequeña posibilidad de curación con el bisturí en la mano y con la mente alejada de los resultados estadísticos».

${ }^{132}$ Escrito por Pagés y E. Luque, cirujanos del equipo quirúrgico número 1. (Pagés F.1923, b). 
Se muestra, encendidamente, partidario del intervencionismo inmediato en los heridos abdominales. Critica a Bergmann por su abstencionismo: "La frase de Bergmann "Yo no opero moribundos", hizo un proselitismo que seguramente ha acarreado más perjuicio que ventajas». Lo propio hace con MacCormac, calificando de tremendo error su taxativo axioma: «A herida de vientre abstención», y a Delorme por preconizar el tratamiento incruento como más favorable para la evolución de los heridos de abdomen.

A pesar de que los hermanos Mayo $^{133}$ apoyan la teoría abstencionista sosteniendo que el $75 \%$ de las perforaciones evolucionan hacia la curación, Pagés insiste en la mayor gravedad de las heridas penetrantes que en las simples perforaciones.

Niega el argumento de las abstencionistas que se oponían a practicar una intervención a un paciente chocado. Al contrario, Pagés demostrando amplios conocimientos de la fisiopatología del shock, sostiene que lo primero que hay que realizar es recuperar al paciente de esa situación para intervenirle inmediatamente, una vez remontadas las constantes vitales: «El calentamiento general, el suero y los tónicos generales, no deben desecharse, pero no pretendamos con ellos reparar definitivamente el estado creado por la lesión de un vaso aislado o de un parénquima vascular que continuara sangrando a pesar de la aplicación de aquellas medidas; así pues por lo que al shock por hemorragia se refiere, de ninguna manera puede motivar aplazamiento en una intervención».

Por si hubiera alguna duda de su decidida actitud intervencionista, sentencia: «Además hay razones de índole moral que no autoriza a abandonar al herido de vientre a la evolución espontánea de sus lesiones, si se considera que la acción quirúrgica pueda modificarla favorablemente, aunque sólo fuera en pocos casos».

$\mathrm{Su}$ resuelta posición intervencionista estaba basada, fundamentalmente, en su concluyente estadística: «En resumen: cuatro abstenciones impuestas, cuatro muertos, además del herido de bazo y colon que ya he referido, y de los tres que se hallaban en la clínica cuando me hice cargo de ella. Esto es el 100 de mortalidad para las abstenciones no deliberadas»».

Frente a este 100 por 100 de mortalidad cuando se vio obligado a la abstención quirúrgica, presenta un 70 por ciento de curados entre los laparotomizados de forma precoz en los puestos quirúrgicos avanzados de Batel y Dar-Drius, y un 52 por ciento de casos satisfactorios cuando fueron operados en el Hospital Docquer de Melilla.

Esta diferencia favorable a los intervenidos precozmente es indicativa de los beneficios que reporta a los heridos abdominales ser operados de forma inmediata. Así lo refiere Pagés: «Un resultado global de 70 por ciento de curados entre los laparoto-

\footnotetext{
${ }^{133}$ William James Mayo (1861-1939). Natural de Le Sueur, Minnesotta, trabajó con su padre en el St. Mary Hospital de Rochester. Se orientó hacia la cirugía abdominal, destacó en la gastrectomía parcial en el cáncer de estómago y píloro. Ideó un método para laoperación radical de la hernia umbilical. Experto en cirugía hepática y biliar. Charles Horace Mayo (1865-1939). Nació en Rochester. Colaboró con su hermano y su padre, se interesó también en la cirugía abdominal, destacando en la resección sigmoidea en el cáncer. Fundando en 1915 la famosa Clínica Mayo de Rochester, especializada en la educación y la investigación clínica. (Haeger K., Guerra F., Laín Entralgo P.1963, Laín Entralgo P.1982).
}

mizados por heridas de vientre, es una proporción muy satisfactoria, no sólo para obtenerla utilizando instalaciones provisionales, sino para lograrla en el hospital mejor dotado».

Abunda en sus clásicos cánones diciendo: «...soy un convencido que con buena voluntad y personal auxiliar entrenado puede llevarse la asepsia a todas partes, y no otra cosa hace falta para laparotomizar un herido de guerra».

Basándose en todos los datos por él conocidos, Pagés quiso finalizar esta discusión entre abstencionistas e intervencionistas concluyendo: «...así es que las discusiones que sostenían los cirujanos de ambos bandos beligerantes al comienzo de la pasada guerra mundial, no tienen en la actualidad más que un interés histórico». (105). Pagés en esta discusión tenía razón. La polémica entre abstencionistas e intervencionistas ya, no tenía más que un interés histórico. Así lo recogen en su Tratado de Patología Quirúrgica $(149,150)$ autores del prestigio de P. Duval, E. Jeanbrau, A. Gosset, P. Lecenes y Ch. Lenormant ${ }^{134}$ : «Al principio de la guerra, por convicción o por necesidad, los cirujanos fueron abstencionistas. No se tardó mucho en comprobar los resultados deplorables de esta conducta cuando los hechos fueron analizados de cerca y se dejó de considerar como heridas penetrantes curadas, las heridas netamente parietales.

Así es como Dupont y Kendirdjy, Chavannaz, muchos otros y nosotros mismos, anotábamos una mortalidad que se aproximaba y llegaba un 100 por 100 con el método expectante en las heridas realmente penetrantes del abdomen. Como, por otra parte, la intervención bien conducida y practicada en condiciones materiales suficientes no agrava el pronóstico, la casi totalidad de los cirujanos, incluso los abstencionistas del principio, son en la actualidad francamente intervencionistas». Más adelante concluye: «La laparotomía es la regla en todos los casos de heridas del abdomen por arma de fuego» $(149,150)$.

Pagés no es que fuera el primero en preconizar la actitud intervencionista, pero sí hay que reconocerle la prontitud y valentía con las que abraza esta causa y especialmente, la diligencia y seguridad con las que la lleva a la práctica.

Hay que recordar que esta polémica se suscita en el período en el que se desarrolla la primera gran guerra, 1914-1919. Pagés, tan sólo dos años después, y durante su estancia en Melilla como consecuencia del Desastre de Annual, es cuando inicia sus experiencias sobre este tipo de pacientes y asienta sus firmes convicciones en cuanto la terapia a seguir.

Por otra parte, el Tratado de Patología Quirúrgica $(149,150)$ al que hemos aludido, en su edición española, data de 1925, por lo que se puede deducir que cuando Pagés publica su trabajo (105) en 1922, aún estaba viva esta polémica y los principales tratados quirúrgicos se posicionaban en un sentido u otro.

Aunque Pagés en su artículo hace referencia a las estadísticas obtenidas por otros cirujanos, obteniendo resultados, comparativamente, superiores, sus números siguen siendo buenos si los comparamos con datos de otros autores de la época y posteriores.

Edouard Quenu presentó en 1916 unas notas en las que indicaba los resultados obtenidos entre 152 laparotomías por heridas

\footnotetext{
${ }_{134}$ P. Duval, era profesor de cirugía de la Facultad de Medicina de París. E. Jeanbrau, profesor de cirugía de la Facultad de Montpellier. A. Gosset, profesor de cirugía de la Facultad de París. Igual que P. Lecene y Ch. Lenormant. (Begouin R.1925, c).
} 
penetrantes: 20 Heridos penetrantes con 35 por ciento de mortalidad, 84 Heridos univiscerales con 47 por ciento de mortalidad, 48 Heridos multiviscerales con 77 por ciento de mortalidad (149, 150). Lo que hace un global de $53 \%$ de mortalidad, frente al $48 \%$ que presenta Pagés en su artículo (105).

Sí son coincidentes el profesor de anatomía quirúrgica de París y Pagés a la hora de resaltar la diferencia de mortalidad que se produce en estos heridos, dependiendo del tramo del aparato digestivo afectado.

Quenu otorga una mortalidad del 55\% a los afectados en el intestino delgado, un 44\% a los de estómago, un 38\% a los lesionados en el intestino grueso y un $31 \%$ a los de hígado $(149,150)$.

Pagés indica que la mortalidad es superior en las perforaciones de duodeno, seguida de las perforaciones de otras porciones del intestino delgado, siendo las de menor mortalidad las lesiones del intestino grueso (105).

Si la relacionamos con otras estadísticas, aún los resultados de Pagés son mejores. Rouvillois comunicó 181 laparotomías por heridas penetrantes viscerales con los siguientes datos:

112 Heridas univiscerales con 67 por ciento de mortalidad;

69 Heridas multiviscerales con 74 por ciento de mortalidad.

Dando un total de $70,8 \%$ de mortalidad.

También son concordantes los datos obtenidos cuando se imponía una postura abstencionista y la mejoría de los resultados si los heridos eran operados en las primeras horas.

Así lo refiere A. Gosset ${ }^{135}$ : «La mortalidad se eleva de 57,5 por ciento para los operados en las seis primeras horas, a 100 por 100 para los operadores después de las veinticuatro horas» $(149,150)$.

Ya hemos aportado, anteriormente, cómo Pagés destaca que cuando interviene a estos pacientes en los puestos quirúrgicos avanzados, es decir, a los pocos minutos de producirse la lesión el índice de curación se eleva hasta un 70 por ciento (105) Por ello Gosset insiste: «El mejor momento para operar es de la primera a la octava o décima hora». Continúa Gosset afirmando: «Las heridas penetrantes no operadas en número de 183 han dado cerca de 90 por ciento de mortalidad; lo mismo las operaciones de Murphy» ${ }^{136}(149,150)$.

Otras estadísticas posteriores a estas nos revelan la bondad de los resultados de Pagés. La Dra. M. Herráiz Muñoz nos presenta unos datos referente a las heridas abdominales habidas en la Guerra Civil Española: «Un 90,4 por ciento 100 de estos enfermos se intervinieron, con un porcentaje de fallecimiento del 42 por cien. Sólo un 9,6 por ciento no se intervinieron por su gravedad; de estos heridos no intervenidos todos murieron. Pese a que un 42 por ciento de mortalidad es muy elevado, hay que tener en cuenta que en la primera Guerra Mundial el porcentaje era casi del 98 por 100; esto vuelve a ser indicador del avance

\footnotetext{
${ }^{135}$ Laín Entralgo lo incluye dentro de los cirujanos de la Escuela de París que desarrollan en compañia de Monod, Reclus, Delorme, Tuffier, Doyer, Jalaguier, Quenu, Delbet, Hartmann, De Martel y Pozzi. Junto con Kehr destacó en la cirugía de la litiasis biliar. (Laín Entralgo P.1963)

${ }^{136}$ La operación de Murphy consistía en practicar un ojal suprapúbico y drenaje del Douglas. No era otra cosa que un compás de espera en los casos muy graves e inoperables por laparotomía. Sus resultados fueron tan malos como los de la abstención operatoria. (Begouin R.1925, c).
}

de nuestros cirujanos. (Los médicos y la medicina en la guerra civil española).

Pagés finaliza este artículo relatando la técnica que sigue para este tipo de heridos. Recomienda la incisión longitudinal que se pueda reparar en un sólo plano, desaconsejando las complejas incisiones de Murphy-Sprengel o de Jaboulay (105).

De idéntica forma se pronuncian otros autores. Gosset: «La laparotomía media se impone sin discusión, pues las lesiones viscerales múltiples son probables» o el Doctor E. de Isla Bolomburu ${ }^{137}$ : «Los progresos clínicos y experimentales establecen que toda herida penetrante de vientre bien demostrada no hay más que una indicación: Laparotomizar, bien sea agrandando la abertura inicial o incidiendo en la línea alba; el objeto es investigar las lesiones para remediarlas debidamente, absolutamente cerciorado el operador de que la laparotomía, prolijamente antiséptica y rápidamente y con destreza ejecutada en una atmósfera caliente, no ofrece peligro» $(149,150,151)$.

Convencido de que los principales peligros de este tipo de heridas son la hemorragia y el vertido del contenido intestinal en el peritoneo, su técnica quirúrgica está basada, fundamentalmente, en yugular estas complicaciones. Para ello exterioriza las asas intestinales afectadas a las que tapona con una compresa e impide el paso de contenido intestinal por ellas con la colocación de una larga pinza flexible de coprostasis. Después de un minucioso examen de todo el posible trayecto perforado, dependiendo del tamaño, evolución de la lesión, decide suturar las perforaciones o proceder a la resección de algún segmento intestinal (105).

Idéntico proceder describe Gosset: «Abierto el abdomen, es conveniente observar antes de desplazar las asas intestinales, porque muchas veces se presentan los órganos lesionados por sí mismo. Señalando y protegiendo con cuidado las perforaciones, el cirujano debe hacer un inventario completo de las lesiones tomando como guía el trayecto del proyectil... Luego, según los casos, se practicará la sutura, previo avivamiento, en las heridas pequeñas, anastomosis después de resección más o menos extensa en las heridas múltiples y aproximadas, ligaduras en las heridas de los mesos. Una extensa pérdida de substancia del meso nutricio obliga al sacrificio del asa no vascularizada» $(149,150)$.

Como colofón anecdotario de la enconada polémica entre intervencionista versus abstencionista, que Pagés corta con rotundidad en el artículo referido, sirva el extenso capítulo que el Dr. Isla le dedica a esta discusión y sus curiosos argumentos del porqué del dominio de los abstencionistas en su época:

«Según acusa la historia, los cirujanos aprendieron cómo se morían los heridos, e ignoraron la manera de salvarlos. No es que les faltara la habilidad sutil que acompaña siempre a los que cuentan con escasos recursos, ni el interés humanitario que ha dado a los médicos el respeto y a veces, la veneración de los pueblos; nada de eso. Es que aceptaba la fatalidad la letalidad fatal de los traumatismos abdominales, veían que con reposo físico y funcional los heridos, aunque en muy escaso número, llegaban a curarse, mientras que interviniendo se morían todos. Se imponía, pues la conducta prudente del médico que se abstiene y no la del cirujano que interviene» (151).

«Muchos años consecutivos, más de veinticinco, vengo conociendo heridos penetrantes de vientre, sobre todo por arma blanca,

\footnotetext{
${ }^{137}$ Fue cirujano de número del Hospital General de Madrid en los finales del pasado siglo y principio del presente (Muñoz A.).
} 
y nunca he visto curarse ninguno con la expectación; en cambio he presenciado y hecho muchas autopsias, en las cuales he confirmado con tristeza, que con haber ligado una arteria mesentérica, extraído la sangre que llenaba el vientre, hecho una sola sutura intestinal, cosido un riñón o adosadas las paredes de la vejiga de la hiel, los enfermos se hubieran curado probablemente» (151).

Para finalizar, el Dr. Isla aduce una serie de curiosos, como decíamos antes, argumentos con los que trata de justificar por qué la mayoría de cirujanos se inclinaba por la tesis abstencionista: « ¿A qué es debido que en la práctica de las grandes poblaciones de todas partes abunden los abstencionistas sistemáticos, sin embargo de que los agentes vulnerantes son menos crueles por el volumen y la forma? Entiendo que son varias las causas; la primera, porque si constantemente se es servidor de una idea o discípulo de alguien, el ideal antiséptico no se ha inculcado debidamente en las escuelas, y los llamados maestros de cirugía han atendido más a glorificarse ellos que a iniciar adeptos de la ciencia; la segunda causa estriba en que, cuando hay médicos que quieren y saben intervenir, porque están empapados en la filosofía antiséptica y han aprendido de algún buen maestro, carecen de medios para hacerlo; si tienen puesto oficial subalterno, están coartados por la fiscalización severa de los compañeros de mayor categoría, educados en otra época, que, con raras excepciones, transigen con la juventud. Hay que ser jefe de sala de hospital para poder hacer laparotomías en forma y condiciones, lo cual constituye un exclusivismo irritante. Verdad es que hay el recurso particular de las operaciones a domicilio o las casa de salud; pero es sólo aparente: un herido con penetración de proyectil, ordinariamente bala de revólver, con poco diámetro, con desgarro visceral por arma blanca o asta de toro, o por contragolpe de una contusión abdominal, ha de precisar perentoriamente el cuidado facultativo, y es conducido por tanto al puesto de socorro más inmediato, llámese farmacia, casa municipal, de beneficencia u hospital, y como el reposo absoluto es la primera indicación que llenar, rico o pobre, allí suele quedarse el herido; que hay tiempo de transportarle a una casa de salud, entonces varía, porque todos los establecimientos de esta clase suelen estar convenientemente montados. Y finalmente, las otras causa que pudiera mencionar se reducen principalmente, en nuestros pueblos meridionales, a que, no habiendo unidad de doctrinas ni de iniciación quirúrgica, hace falta estar muy convencido y gozar de la impunidad de un prestigio, poseer, como antes decía, el cargo de jefe de sala de hospital o de casa de salud. A menos, repito, de los anteriores requisitos, no hay, por lo menos en la corte, quien abra un vientre para curar una herida penetrante, temeroso de crítica infundadas, cuando no de comentarios perjudiciales» (151).

De ser ciertos estos puntillosos razonamientos médico-sociales, es innegable que Pagés supo superar todas estas alambicadas trabas y posicionarse claramente a favor del intervencionismo basándose en sus resultados y experiencias, sin hacer mella en él, lo más mínimo, estos condicionamientos.

$\mathrm{Su}$ trabajo póstumo «Aspecto quirúrgico del estreñimiento» (110) es otra de las importantes aportaciones de Pagés al campo de la cirugía. Es uno de los escasos artículos sobre el tratamiento quirúrgico del estreñimiento en la literatura médica, después del trabajo originario de Arbuthnot Lane. (152).

Como aportación semiológica, apunta la concomitancia que ha encontrado en muchos casos de ciego móvil y el cuadro de apendicitis crónica. Estima, por tanto, que la etiología de esta sea la alte- ración anatómica inicial de un ciego móvil, esto provocaría una ectasia fecal y una tiflitis catarral, lo que comportaría que el apéndice fuera tributario del proceso inflamatorio de la mucosa cecal y de las alteraciones circulatorias de la primera porción del intestino grueso. Sigue afirmando: «Además, según he podido observar, es muy frecuente la existencia de ciego móvil y apendicitis crónica, hasta el punto que cuando diagnosticamos la primera afección podemos suponer que existe la segunda. En todos los ciegos móviles operados por nosotros había apéndices alargados, engrosados, con bastante exudación en su contenido y a veces coprolitos» (110).

Concluye sosteniendo que la apendicectomía o la cecopexia por sí solas no llevan a la curación. Se precisa de las dos intervenciones para un total restablecimiento de la buena función intestinal. Esta asociación de ciego móvil y apendicitis crónica, también la encuentra P. Duval, recomendando el mismo tratamiento quirúrgico: «Sitúa al ciego móvil entre esas deformidades que inducen la ectasia cólica y no encuentra otro tratamiento que la cecopexia y apendicectomía: "Toda apendicitis debe ser operada"» (150).

Más adelante, Pagés hace una detallada relación de las causas etiológicas de la estasia cólica, entre las que incluye; las bridas, adherencias, la enfermedad de Jackson o el ciego movible. A estas causas Duval añade el megaciego, la ptosis del ángulo hepático, el adosamiento del colon ascendente y del transverso en doble cañón de escopeta (150).

Sea la causa que fuere el origen del estreñimiento pertinaz, a Pagés le preocupa los graves trastornos que provoca la estercoremia en el estado de salud de los pacientes: «...Pero hay casos particularmente graves por la extensión de las lesiones y por la intensidad de los trastornos acarreados por la estercoremia en los cuales es indispensable desintoxicar rápidamente al paciente, al mismo tiempo que combatir las disposiciones anatómicas del intestino incompatibles con su funcionamiento normal» (110).

Para estos enfermos, Pagés reserva dos tipos de operaciones. La de Senn y Salzer ${ }^{138}$ y la colectomía. El se inclina por esta última: «Nosotros hemos preferido la colectomía total a la hemicolectomía, porque nuestros tres enfermos tenían acentuadísimas alteraciones en ángulo esplénico y en S. ilíaca, y por lo tanto, con la colectomía parcial hubiéramos podido proporcionarles poco alivio».

Finaliza el artículo dando su porcentaje de mortalidad el 33 por ciento y justificando su proceder: «En grandes series las estadísticas puede mejorarse considerablemente, pero debemos tener en cuenta que, aunque la operación de por sí es grave, el estado de los enfermos y el porvenir de los casos refractarios al tratamiento médico justifica la información quirúrgica con todos sus peligros» (110).

En la actualidad nos parecería excesivo solucionar un estreñimiento renuente al tratamiento médico con una colectomía, pero todo hay que encuadrarlo y relacionarlo con el entorno científico de

\footnotetext{
${ }^{138}$ Nicholas Senn (1844-1909) Nacido en Buch, St. Gall. Se graduó en el Colegio Médico de Chicago en 1868. Estudió las bases experimentales de la cirugía del páncreas y otros órganos. En 1888 en Chicago, dexcribió la técnica de insuflar hidrógeno por vía rectal para el diagnóstico de las hernias penetrantes de abdomen. Investigó las suturas intestinales, proponiendo el empleo de placas de hueso descalcificado. Aportó conocimientos sobre la embolia gaseosa y fue el primero en 1903 de utilizar rayos x en el tratamiento de la leucemia. Con F Salzer, quien en 1900 había dado los primeros pasos del trasplante de córnea, propuso un tratamiento quirúrgico del estreñimiento rebelde, consistente en practicar un cortocircuito por abocamiento del ileón a la S.ilíaca. (Guerra F., Riera J., Laín Entralgo P.1963).
} 
la época, y, para entonces, se trataba de una innovación alentadora para los pacientes con estercoremia. Así se recoge en el Tratado de Patología Quirúrgica (150), publicado dos años después del fallecimiento de Pagés.

En su artículo «Drenaje transcerebral» (109) hace Pagés una interesante incursión quirúrgica por el campo de la neurocirugía, fruto otra vez de su actuación como cirujano en la Guerra de África. Apuesta decididamente por el uso de drenaje en las heridas cerebrales siempre que haya riesgo de infecciones, grandes lesiones destructivas y hemorragia. Después de criticar los métodos de drenaje de Chevassu, Brosier, De Martel y Pauchet, por considerarlos insuficientes en pacientes con grandes destrozos, lo que impedía el drenaje de coágulos y esquirlas, haciendo más de taponamiento que de drenaje; Preconiza la técnica de Sedlicka ${ }^{139}$, a la que cataloga de «valiente proceder».

A este método, Pagés le incorpora tres variantes: « $1^{\mathrm{a}}$ sustituir el clamp o pinzas corrientes por una de Pita para extracción de cuerpos de uretra, ventaja indiscutible tanto por la disminución de grosor como por la comodidad de manejo. $2^{\circ}$ Aplicación de inyecciones frecuentes de agua oxigenada por los extremos del dren cada tres horas para impedir la coagulación de la sangre dentro del tubo y mantener cierto grado de humedad y limpieza en el foco, y $3^{\text {a }}$ Continuar al drenaje de caucho el de un manojo de crines al objeto de evitar los fenómenos exvacuo engendrados al retirar el tubo».

A continuación, y casi como en toda su obra, relata su casuística y describe minuciosamente un caso clínico. Concluyendo afirmando: «La impresión que hemos sacado del empleo del drenaje transcerebral en francamente favorable, ya que lo hemos reservado para casos sumamente graves, con grandes destrozos craneales y extensas lesiones de centros nerviosos, casos que abandonados a la evolución espontánea o sometidos a la precaria terapéutica de la toilette focal, hubieran fallecido con seguridad» (109).

El drenaje transcerebral era una de las técnicas quirúrgicas más vanguardista del momento. Así la literatura médica recoge algunos casos clínicos: el Dr. Slocker de la Rosa publicó un caso en «Clínica y Laboratorio» de una niña de siete años que había sido atropellada por un carro y una de las ruedas le pasó sobre su cabeza. Después de relatar la sintomatología que presentaba y las iniciales medidas terapéuticas, apunta que suturó y después colocó un desagüe de gasa, según costumbre, recubierto de una lámina de cautchú y con un curso posoperatorio admirable; la niña salió curada antes del mes (153).

El Dr. Vicente Fidalgo ${ }^{140}$ describió otro caso de un minero al que le produjo un fuerte traumatismo craneoencefálico abierto un golpe recibido por una piedra. Así relata la colocación del drenaje: «El día 15 de febrero, o sea a los seis días del traumatismo, introdujimos dos finos tallos de laminaria, esterilizados, a través del boquete de la fractura y por debajo del cerebro, descansando sobre las dos bóvedas orbitarias correspondientes. Los

${ }_{139}$ Sedlicka puso en práctica su técnica, consistente en la colocación de un tubo de caucho que se introduce en la herida por una pinza abocada por el orificio opuesto al que ha de asomar, en el Hospital Austríaco de Dorna Raudreny en 1917, durante la I Guerra Mundial. Donde Pagés colaboró en su estancia en el Imperio Austro-Húngaro. (Pagés F.1923, a).

${ }^{140}$ El Dr. Vicente Fidalgo Tato era médico del Hospital Minero de Triano, Vizcaya. (Ulecia R.). efectos fueron indiferentes; el enfermo se levantaba y razonaba como de ordinario. En las curas sucesivas se reemplazaron por tallos más gruesos» (153).

Quizás para tener una idea más exacta de lo que en esas fechas era hacer cirugía cerebral, convendría recordar lo que años antes escribía otro gran cirujano español; Alejandro San Martín Satrústegui: «La cirugía cerebral atraviesa un período, que la serena imparcialidad de todo práctico juicioso, induce a calificar como de verdadera decepción» (151).

Hoy, también nos puede parecer algo fuera de lugar el tratamiento de un traumatismo craneoencefálico abierto con un drenaje transcerebral, pero hay que valorar, en su medida, el nivel de la neurocirugía española y europea en la década de los años veinte. Fue en los años treinta cuando Cushing consiguió reducir al 5 por ciento la mortalidad de las operaciones cerebrales en Estados Unidos y, no olvidemos, que en los mejores tiempos de Víctor Horsley, la Sociedad Médica Británica estuvo a punto de prohibir las intervenciones cerebrales por la alta mortalidad que ocasionaban $^{141}(106,107)$.

Estimamos que estos tres artículos $(105,109,110)$ conforman la aportación más sobresaliente de Pagés al campo de la Cirugía. Es incuestionable que se trata de una obra incompleta y escasamente sistematizada en su desarrollo, pero estos defectos son fácilmente explicables por el corto tiempo en el que se produce y por la celeridad y extremada premura en la que se desarrolla su trabajo como cirujano. Siempre acudiendo a escenarios donde lo que se imponía era un trabajo ágil, rápido y poco propenso al estudio estadístico y a la observación reposada y experimental.

Daba la sensación que a Pagés la urgente le impedía ejecutar lo necesario. A pesar de estas lagunas en su obra, es muy difícil negarle su intuición natural por la cirugía, sus extraordinarias dotes de observación, aún en las peores condiciones operatorias como reportaban los hospitales de campaña, su valentía y sinceridad a la hora de defender sus postulados, contando su extremada juventud, así como su capacidad de trabajo, tratando de escribir y publicar, casi inmediatamente, todas las experiencias acumuladas en los quirófanos donde intervino.

Con esas características es complicado no dejarse sustraer por la fascinación que produce un cirujano prototipo y paradigmático de su época.

Aunque hemos comentado que consideramos tres de sus trabajos como los más destacados de su obra quirúrgica, no desmerecen tampoco algunas notas técnicas y detalles que apunta en otros artículos suyos.

«Sobre un caso de estrangulamiento retrógrada de epiplón» (97), es un artículo en el que describe, como caso poco frecuente una estrangulación retrógrada de epiplón. Ya de por sí, la estrangulación retrógrada de un asa intestinal es una afección relativamente

\footnotetext{
${ }^{141} \mathrm{Si}$ en Estados Unidos es Harvey Cushing quien reduce drásticamente la mortalidad en las operaciones cerebrales, en Europa el noruego Vilhelm Magnus (1871-1929) publicó en 1923 una estadíastica de unos cien casos de tumores cerebrales intervenidos con una mortalidad del 8\%. Con posterioridad el Sueco Herbert Olivecrona (18911980) profesor de neurocirugía del Instituto Karolinska de Estocolmo convertiría a este Instituto en el centro mundial de la neurocirugía con sus avances en el tratamiento de tumores de defectos vasculares cerebrales (Haeger K.).
} 
poco común ${ }^{142}$. A. Gosset así lo describe, denominándola estrangulación retrógrada de Peyrot. (150). Pero Pagés lo que quiere resaltar, por su rareza, es que la estrangulación se produce sobre el epiplón. De este manera comenta que en la recopilación de casos que hace Wendel ${ }^{143}$ presenta sesenta y ocho casos de intestino delgado y veinte casos de otras vísceras, de los que tan solo describe siete casos ocasionados por el epiplón. Para abundar en lo inusual del hallazgo Pagés insiste: «Posteriormente no he encontrado en las revistas profesionales ninguno análogo concerniente a dicha víscera, aún conociendo aún cuando bien puede haberse publicado y no llegar a mi conocimiento» (97).

Otra nota técnica nos da Pagés en la «Gastroenterostomía con collar epiploico» (104). El tratamiento de elección de las úlceras gástricas cuando fracasaba la terapia médica era la gastroenterostomía: «Esta es un procedimiento paliativo que proporciona, sin embargo, excelentes resultados, facilitando la evacuación gástrica y modificando el medio en el cual se desarrolla la úlcera» (150).

La principal complicación de esta intervención era la úlcera péptica de la boca anastomótica intestinal o de la porción eferente del asa yeyonal ${ }^{144}$ Apareciendo en un 2 por ciento de los casos, trayendo como consecuencia una perforación hacia la cavidad libre esta severa complicación ${ }^{145}(109,149,150)$. Para prevenir la aparición de este serio inconveniente, Pagés propone proteger la boca anastomótica gástrica-intestinal con dos anillos, uno mesocólico y otro epiploico que aislarían la perforación en caso de producirse.

Resulta curioso que A. Gosset, al explicar el tratamiento de las perforaciones gástricas propone una terapia quirúrgica que, sin ser exactamente idéntica a la descrita por Pagés, sí tiene mucho de similitud: «Si la perforación no puede ser ocluida (friabilidad, engrosamiento extenso de las paredes del estómago) es preciso aislar la perforación por medio de una epiploplastia, de compresas colocadas alrededor de un tubo grueso, de manera que las adherencias vengas a separar la perforación del resto de la cavidad sedosa» (150).

Otro detalle técnico nos lo apunta Pagés en su artículo «Sobre algunos casos de utilización de las fascias en cirugía» (100), aparte de describir las diferentes utilidades de las aponeurosis en distintas facetas de la cirugía, nos relata un caso clínico de un banderillero de herido por un rejón presentaba una lesión de la arteria humoral y cubital en su cara anterior. Conocedor de las técnicas de sutura $\operatorname{arterial}^{146}$, una vez más, debido a la urgencia y a la parquedad de

${ }^{142}$ Maydl describió ya en 1885 casos de estrangulación retrógrada de asas intestinales. Años más tarde, J. Polya (1876-1944) explicaba el mecanismo de estrangulación intrasacular de asas intestinales en W. (Pagés F.1919, a, Laín Entralgo P.1963).

${ }^{143}$ Waltter Wendel de Magdeburgo publicó su monografía en 1913 en los Ergebnisse Der Chirurgie Und Orthopädie De Payr y Kuettner (Pagés F.1919, a).

${ }^{144}$ El primero en describir esta complicación fue Carl Braun Von Fernwald (1822-1891) (Pagés F.1922, b, Laín Entralgo P.1963).

${ }_{145} \mathrm{~A}$. Gosset estima que las perforaciones tenían una mortalidad de un $65,9 \%$, aunque esta mortalidad es más débil cuando se opera entre la décima y la quinta hora. Antes de la quinta hora el enfermo sucumbe porque se encuentra en estado de shock; después de la décima hora, porque se ha declarado ya la peritonitis. Por lo que, concluyó, hay que operar una vez superada la fase de shock. (Begouin R.1925, c).

${ }^{146}$ Aunque Alexis Carrel en 1910 marca los principios de la cirugía vascular, ya en 1902 en España San Martín había llevado a la práctica humana la anastomosis arterio venosa, método que consiguió excelentes resultados y que luego prosiguió Goyanes. (Haeger K., Laín Entralgo P.1963). material por encontrarse en la enfermería de la plaza de toros, se le planteaba la ligadura de ambas arterias por encima y debajo de la lesión, lo que consideraba peligroso para la futura funcionalidad del miembro, optando, finalmente, por un método poco frecuente, la tunelización de ambas arterias en la aponeurosis de envoltura del brazo correspondiente al bíceps braquial. (100). Siendo este artículo publicado en 1921 y el caso clínico comentado acaeció tres años antes, suponemos la correcta funcionalidad del miembro y el éxito, por tanto, de la intervención.

El Dr. R. Torres Casanova abunda en la frecuencia y en la gravedad de las lesiones vasculares en la fiesta de los toros: «Una indicación vital es la hemostasia cuando han sido heridos vasos voluminosos, la cual obligará a practicar ligaduras, ya que la forma irregular de la solución de continuidad del vaso y las pocas garantías de asepsia perfecta son condiciones desfavorables para la sutura. Las ligaduras se harán "In situ", debiendo aplicarlas en los casos ordinarios a todos los puntos que dan sangre, no fiándonos demasiado en los taponamientos» (153).

Sin olvidar sus incursiones en el terreno de la traumatología: "Tratamiento de las fracturas diafisarias de los huesos largos de las extremidades producidas por proyectiles de armas de fuego» ${ }^{147}$, «La teoría y la práctica del injerto óseo» (96) y «Tratamiento de las fracturas de olécranon por el enclavijamiento y extensión continua» (99), la obra principal de Pagés es, esencialmente, quirúrgica. Donde, con las ausencias aportadas, creemos, destaca por su moderno concepto de la cirugía reparadora y funcional y el estricto seguimiento de los clásicos cánones de asepsia y hemostasia.

Su intuición y vocación quirúrgica, suplieron con creces la falta de tiempo para una mejor codificación y sistematización de sus experiencias.

\section{Otras aportaciones}

En este apartado vamos a hacer referencia a dos nuevas aportaciones. La primera es muy específica y se circunscribe al terreno de la semiología con la descripción de un signo llamativo en varios casos de neumotórax, descrito en su artículo «Sobre la existencia de un espacio paravertebral hipersonoro en los neumotórax a tensión» (103).

La segunda es más genérica y no referimos a su contribución a la Sanidad Militar. En el referenciado artículo Pagés describe varios casos clínicos de heridas abiertas de tórax con neumotórax a tensión, en los que observa ciertos hallazgos concomitantes y, para él, novedosos: «Los hallazgos postoperatorios de los dos casos descritos con el abombamiento de la pleura parietal a nivel de las costillas resecadas, el cambio de aspecto del fondo de saco pleural, la hipersonoridad de la zona cardíaca en la última de las heridas historiadas, eran datos suficientes para admitir en los neumotórax a tensión la existencia de modificaciones de percusión debidas a desplazamiento viscerales análogos a los que tienen lugar en los grandes derrames pleurales» (103)

Convencido de la existencia de este signo en los neumotórax a tensión, tuvo la ocasión de volver a estudiar a heridos en similares condiciones y a confirmar que en estos casos aparece una hiperso-

\footnotetext{
${ }^{147}$ Por este trabajo inédito se le concedió Mención Honorífica según Real Orden de 21 de agosto de 1914 anotado todo en su Hoja de Servicios.
} 
noridad en el lado contralateral de la lesión en la espalda, formando un triángulo isósceles cuya base longitudinal se extiende entre la $4^{\mathrm{a}}$ y $9^{a}$ vértebras dorsales y el vértice estaría situado a 10 centímetros o cinco traveses de dedo en la línea horizontal trazada desde el vértice de la apófisis espinosa de la $7^{\mathrm{a}}$ vértebra dorsal. Este triángulo hipersonoro él lo compara al triángulo paravertebral de Grocco en las pleuresías ${ }^{148}(103)$.

Como en toda su obra a Pagés le faltó tiempo para seguir investigando sobre este hallazgo semiológico. Muy posiblemente, atendiendo a la etiología, clínica y evolución de los pacientes, $\mathrm{Pa}$ gés se enfrentaba a heridos con traumatismos abiertos de tórax con todo el cortejo sintomático que acompaña a estas lesiones, especialmente cuando son producidas por arma de fuego ${ }^{149}$, con el colapso del pulmón del lado afecto, comprensión del pulmón sano por el desplazamiento mediastínico y la aparición del aire péndulo.

Todo ello comporta un severo desplazamiento de todas las estructuras mediastínicas hacía el lado sano, apareciendo la acumulación de aire (El enfisema subcutáneo que describe es orientativo de ello) que sobrepasa el hemitórax lesionado, alcanzando más allá de la línea media; justificando, por tanto, la hipersonoridad dorsal contralateral a la percusión $(154,155$.).

En lo relativo a sus aportaciones a la Sanidad Militar, también podemos hacer un doble apartado. Por una parte realiza un somero estudio de los procesos infecciosos en campaña en su artículo «La lucha en campaña contra las enfermedades infecciosas» (95); y por otra va a colaborar con el Estado Mayor en dos importantes proyectos: lo que sería el embrión del actual cuadro de exclusiones y el plan de reorganización del ejército ${ }^{150}$.

En dicho artículo, que es el primero que publica en 1912, hace una breve introducción sobre las precarias condiciones higiénicas de los soldados en campaña: «Hay un factor individual determinado por la fatiga, las emociones y la alteración en el régimen de vida y un factor colectivo de hacinamiento inevitable en muchas ocasiones, que transformado al soldado en medio muy apto para la adquisición y propagación de infecciones».

Insiste en la obligación que el Médico Militar tiene de combatir el germen que se halla en el soldado y en los medios y materiales que le rodean.

Con el tradicional concepto de la época nos relata la dificultad para tratar los microbios cuando estos han atravesado las barreras epiteliales de defensa del organismo: «Cuando radican (los microbios) en el interior de cavidades inaccesibles a nuestra acción directa, es imposible intentar su destrucción por procedimientos eficaces, porque siendo de composición similar las células del organismo y poseyendo parecidas propiedades vitales a las de los microbios, toda acción bactericida resultaría histolítica al mismo tiempo» (95).

Estas afirmaciones no eran baladíes, unos años antes $\mathrm{CH}$. Bouchard ${ }^{151}$ decía: «Hace pocos años se podían hacer las mismas

${ }^{148}$ El italiano Prieto Grocco (1856-1916) describió en los casos de amplio derrame en las pleuresías una zona mate a la percusión, de forma triangular situada en el dorso en el lado opuesto del derrame pleural. (Diccionario terminológico de ciencias médicas).

${ }^{149} \mathrm{El}$ profesor Vara tasa una mortalidad del 14\% para heridos por arma de fuego frente al 3-4\% en los producidos por arma blanca. (Vara R.).

${ }^{150}$ Datos obtenidos de la Hoja de Servicios.

${ }^{151}$ Charles I. Bouchard (1837-1915) Nacido en Montier, estudió en Lyon y se doctoró en París, donde fue decano de la facultad. Profe- objeciones, formuladas casi en los mismos términos, al laboratorio de fisiología de la Sorbona, al laboratorio de Patología Comparada de esta Facultad y a muchas de nuestras clínicas. "Una sustancia tóxica para una célula vegetal de fermento siempre será tóxica, y con mucha más razón para la célula nerviosa humana". Este es el argumento fundamental, verdadero fin sin réplica, que por todas partes encontraréis con variantes. Pues bien, hay sustancias, y yo os lo demostraré que, a una dosis determinada, son tóxicos para tal microbio y no lo son para ninguna de las células humanas» (156).

Concluye el trabajo sosteniendo que una de las medidas más útiles para evitar la difusión de las enfermedades infecciosas, era la instalación de lazaretos. Establecimientos que ya creó la Sanidad Militar nipona durante la campaña Ruso-Japonesa de 1904-1905. Estos lazaretos eran instalados en islas o zonas costeras y se creaban dos puertos, uno de desembarco o infectados y otro de embarque o limpios. Pagés finaliza su artículo resaltando la importancia que para la Sanidad Militar tiene, precisamente, la lucha contra las enfermedades infecciosas: «Dado el estado actual de la medicina, no puede hacerse nada más perfecto en los servicios de que tratamos, y la victoria conseguida por el Japón en la lucha contra las enfermedades infecciosas es un triunfo, del que puede vanagloriarse a los ojos de la ciencia» (95).

Nadie duda de la trascendencia que para esa fecha, y las posteriores, no olvidemos que este artículo se escribe dos años antes de que comenzara la I Guerra Mundial, tenía mantener un adecuado estado de higiene, especialmente con medidas profilácticas, en los contingentes combatientes. Las experiencias más reciente sobre este problema, se habían tenido durante la Guerra Ruso-Japonesa, que es a la que Pagés hace alusión, y la más remota guerra Franco-Prusiana.

Precisamente sobre esta contienda y sobre otros informes posteriores escribe el Dr. Rodríguez Méndez ${ }^{152}$, abundando en la trascendencia de mejorar las medidas higiénicas y profilácticas en los ejércitos: «El Ministro de la Guerra, General Billot, ha dirigido al Presidente con fecha 23 de febrero último, un informe análogo al redactado por sus predecesores desde 1889. En él se ve, por modo patente, el progreso higiénico en este ramo de la administración. Así lo prueban los siguientes números: en 1870, la mortalidad fue de 10 a 11 por 1.000; en 1896, de 5, 29; desde 1887 a 1896, el número de muertos ha descendido de 3.319 a 2900, y eso que entonces había un efectivo de 480.672 hombres, y ahora de unos 546.500. Este es el fruto de la investigación detenida de las causas morbosas, del aislamiento de los enfermos infectos y de la obligación disciplinaria de las medidas profilácticas. Las aguas que se bebían han sido reemplazadas por aguas de fuente, por aguas filtradas (bujía de Chamberland) o por aguas esterilizadas con el auxilio del calor, logrando así destruir varios persistentes focos de fiebre tifoidea: en 1894 hubo 3.060 casos de esta infección y 530 muertos; en $1895,2.557$ y 503, y en 1896 solo 2.442 y 441. Allá en 1896, la cifra de muertos era de 964».

sor de patología, describió con Charcot los dolores fulgurantes de la ataxia, autointoxicación intestinal y describió con Charcot y Brissaud un Tratado de Medicina y otro de Patología General. Fue miembro de la Academia de Medicina (Guerra F., Bouchard Ch.).

${ }^{152}$ El Dr. Rodríguez Méndez era catedrático de Higiene de la Facultad de Medicina de Barcelona a finales del pasado siglo. (Muñoz A.). 
Sus otras contribuciones a la Sanidad Militar, tienen más de acción burocrática que de actuación médica, aunque su colaboración, en este sentido, estuvo relacionado directamente con la organización y planificación de la Sanidad Castrense.

Desde su incorporación al Estado Mayor el 25 de enero de 1916 hasta 1918, Pagés estuvo colaborando en la elaboración del plan de reorganización del ejército. Reforma que quedaría recogida en la Ley de 29 de junio de ese año ${ }^{153}$. Esta ley afectaría en su estructura a la Sanidad Militar, equiparando los empleos de los oficiales médicos a los de las armas, por ello, en virtud del apartado II de la Base 9 de dicha Ley, a Pagés se le reconocía el empleo de capitán médico ${ }^{154}$, sustituyendo a la antigua denominación de Médico Primero.

Como reconocimiento a su labor en este grupo de trabajo dentro del Estado Mayor, por Real Orden manuscrita de 11 de marzo de 1918 se le inscribe una nota en su hoja de servicios en la que consta sus dotes de inteligencia y alto interés en el cumplimiento de las obligaciones encomendadas ${ }^{155}$.

Pagés también colaboró de manera activa y formó parte de la Junta, creada al efecto, que elaboró un cuadro de heridos y lesiones «De que disponen o puedan disponer los ejércitos combatientes». Fue asignado a esta Junta por Real Orden de 21 de enero de $1920^{156}$. Este cuadro de heridos y lesiones sería el verdadero embrión sobre el que germinaría el actual cuadro de exclusiones para el Servicio Militar.

Como consecuencia de la labor desarrollada en esta Junta y en el Estado Mayor Central, se le concede la Cruz de Primera Clase del Mérito Militar con distintivo Blanco el 22 de enero de 1921.157

\section{CONCLUSIONES}

Una duda que puede plantearse es la posibilidad de que los trabajos de investigación de Pagés y de Dogliotti sobre la aplicación quirúrgica del abordaje epidural con anestésico local fueron simultáneos o si, por el contrario, pudiera existir una prelación en las experiencias del cirujano español sobre las del catedrático de Quirúrgica de Módena.

Para tratar de dilucidar esta lógica diatriba, habremos de recurrir a un pormenorizado análisis de sus artículos originales así como a un detallado estudio de las publicaciones que, de una u otra forma, comentan y evalúan el trabajo de ambos.

En su artículo (62) Pagés apunta una serie de cuestiones que quizás nos ayuden a clarificar estas dudas. Al inicio del mismo hace una clara referencia a la datación cronológica del inicio de sus experiencias, relata textualmente: «En el mes de noviembre del pasado año, al practicar una raquianestesia, tuve la idea de detener la cánula en pleno conducto raquídeo...». Como es sabido, la Revista Española de Cirugía publica Anestesia Metamérica en 1921, por lo que con una perfecta concreción podremos datar el inicio de los trabajos de Pagés en esta materia, en noviembre de 1920.

\footnotetext{
${ }^{153}$ Publicado en el Diario Oficial $\mathrm{n}^{\circ} 145$.

${ }^{154}$ Hoja de Servicios.

${ }^{155}$ Hoja de Servicios.

${ }^{156}$ Diario Oficial N ${ }^{\circ} 17$.

${ }^{157}$ Real Orden del 22 de enero de 1921. Diario Oficial No 19 . Como compromiso en el artículo 27 de la Real Orden de $1^{\circ}$ de junio de 1911.
}

Convencido también estaba que, hasta esa fecha, nadie había abordado el espacio epidural a nivel lumbar. Así lo expresa: «Pocos datos históricos hemos encontrado que nos permita filiar la Anestesia Metamérica con un antiguo abolengo científico que para ello deseáramos». Aunque sí conoce los resultados de Cathelin (66) para alcanzar el espacio epidural a través del hiato sacro, pero cuya utilidad quirúrgica quedará reducida a los territorios inervados por las raíces del plexo coxígeo de los pares $4^{\circ}$ y $5^{\circ}$.

Incluso llega a abundar en los frustrados intentos de Sicard y Tuffier $(67,101)$ de aprovechar esta vía de penetración de sustancias anestésicas para curas radicales de hernias.

Este hallazgo de Pagés no es meramente teórico o carente de aplicación práctica. No se trata de una apreciación vacua o exenta de utilidad clínica. Muy al contrario, insiste en su aplicabilidad quirúrgica inmediata: «El bloqueo de las raíces nerviosas con sustancias anestésicas en el espacio epidural, es susceptible de producir analgesia, utilizables en intervenciones quirúrgicas».

Tampoco es atribuible a Pagés que su descubrimiento fuera fruto de la casualidad, sino de su experiencia y conocimientos anatómicofisiológicos: «Después de haber practicado muchos centenares de raquianestesia y algunas anestesias radiculares paravertebrales, es cuando nos hemos decidido a alcanzar los pares raquídeos a su paso por el espacio epidural, a la altura necesaria para insensibilizar los nervios que se distribuyen por la región operatoria».

Protocoliza, aunque quizás de forma excesivamente subjetiva, la técnica de localización del espacio epidural. Relata tanto el abordaje lateral como el medial, así como introduce dos variantes. La primera, retirar la cánula después de haber practicado la punción aracnoidea y situarla en el espacio epidural cuando no refluya líquido cefalorraquídeo. El segundo procedimiento, que cataloga de más elegante, confiere a la habilidad táctil del cirujano la sensación de atravesar el ligamento amarillo para asegurar la ubicación epidural de la punta de la aguja.

Por último, en este análisis que estamos realizando sobre el artículo de Pagés, el cirujano militar no da por concluidas sus experiencias, sino que las considera un simple inicio de futuros trabajos que vendrán a profundizar y a mejorar la técnica y los resultados por él descritos. De hecho, tras referir las 43 intervenciones practicadas con anestesia epidural, finaliza el artículo afirmando: «Los resultados, para ser los primeros, me parecen lo suficientemente aceptables para justificar ulteriores investigaciones».

Ante estos hechos, podemos entresacar varias conclusiones:

- PRIMERA.- Pagés inicia sus trabajos sobre la anestesia epidural en noviembre de 1920

- SEGUNDA.- Es claro conocedor de los antecedentes existentes descritos en la literatura médica de la época. (Sicard, Cathelin, Tuffier.).

- TERCERA.- Está convencido que se trata de un método novedoso, hasta ahora no descrito, y que puede reportar un avance sustancial a las técnicas operatorias de territorios infra y supraumbilicales.

- CUARTA.- La técnica la describe con claros y concretos fines quirúrgicos, es decir, con una decidida aplicabilidad inmediata en la clínica diaria, no como hallazgo fortuito, anecdótico o de futura aplicación.

- QUINTA.- Llega al abordaje lumbar del espacio epidural después de una vasta experiencia y conocimientos en las técnicas radiculares paravertebrales y en raquianestesias. 
- SEXTA.- El procedimiento para la localización del espacio epidural que describe se basa, fundamentalmente, en la experiencia y habilidad del cirujano en la percepción del paso de la aguja por el ligamento amarillo.

- SÉPTIMA.- Desde noviembre de 1920 a marzo de 1921, que es cuando publica su trabajo de la Revista Española de Cirugía, describe cuarenta y tres casos realizados con notable éxito, aunque sin darse por satisfecho, considera que son sólo los primeros resultados y habrá que justificar ulteriores investigaciones. Dejando un diáfano anuncio de su voluntad de continuar abundando en esta técnica.

Según Bonica, (63) Dogliotti y sus colaboradores inician sus trabajos experimentales y clínicos sobre lo que llamaría Anestesia Segmentaria Peridural, cuatro años antes de la publicación de sus conclusiones (70). Si esta se produjo en 1931, sus primeras pruebas se iniciaron en 1927.

Otro autores como Killian, Morisot, A. Lee o Bromage (64, 65, $68,134)$ sostienen con Bonica la diferencia temporal que se produce entre los trabajos de Pagés y Dogliotti. Este, presenta su trabajo como original diez años más tarde, sin hacer la menor referencia a las importantes evidencias apuntadas con anterioridad por Pagés. Así, Morisot describe lo sucedido: «Hubieron, pues, de transcurrir unos diez años más antes que la anestesia peridural alcanzase la categoría propia de las técnicas anestésicas confirmadas. A partir de 1931, Dogliotti y sus discípulos reemprendieron de modo exhaustivo el estudio del método. Lo dieron a conocer con amplitud publicando sus trabajos en las grandes revistan médicas, italianas, francesas, alemanas, y americanas. Sin la menor deferencia para con Pagés» (65).

Del mismo modo M.A. Cuesta (91), relata cómo Dogliotti siendo presidente del Colegio Internacional de Cirujanos pudo difundir sus ideas especialmente en Inglaterra. Otros, como Hervás Puyal (90) llegan a aseverar: «Años más tarde, en 1931, el cirujano Achile Mario Dogliotti (1897-1966) dio a conocer su técnica de anestesia epidural que dominó "peridual segmentaria". La presentó como original, aunque en realidad reproducía la descrita por Pagés en su trabajo; trabajo que desconocía Dogliotti».

El propio Dogliotti, convencido de la originalidad de su método, presenta sus experiencias en el Congreso de la Sociedad Internacional de Cirugía celebrado en Madrid en 1932. Sorprendentemente ninguno de los cirujanos españoles asistentes hacen la mínima referencia a los trabajos precedentes de Pagés. (90).

Pero aún resulta más llamativo que en la literatura médica española comienzan a aparecer artículos $(144,145)$ donde, sin mencionar las primitivas aportaciones de Pagés, se recopilan experiencias sobre el método que denominan «Nuevo procedimiento de anestesia lumbar llamado peridural del Doctor Dogliotti».

El trabajo de Dogliotti pocas novedades incorpora con respecto al primitivo de Pagés, aunque es preciso reconocer una interesante aportación en cuanto al método de localización del espacio epidural. Como decíamos anteriormente, Pagés dejaba a la experiencia y habilidad del cirujano el procedimiento idóneo para la correcta ubicación de la aguja en la zona peridural. Dogliotti, conocedor de la presión negativa existente en el espacio epidural y favorecido posiblemente por los trabajos previos de Sicaard y Forestier $(157,158)$ sobre la exploración radiográfica del espacio epidural con contraste que facilitaba un mejor conocimiento de la zona, introduce la técnica del mandril líquido en la jeringa, lo que facilita la localización del espacio epidural, sustituyendo un método basado en la experiencia personal por otro más objetivo y de aplicación más universal.

Hasta este instante es la propia cirugía española la que le niega, o al menos la ignora, la paternidad de Pagés en la descripción de la técnica epidural.

Pero en 1932, un cirujano argentino Alberto Gutiérrez, publica un artículo al que ya denomina «Anestesia Metamérica Epidural» (135), en el que conociendo el método Dogliotti, reconoce al cirujano militar español su carácter pionero en esta técnica. Incorporando, además, un método original para la localización del espacio epidural: «El signo de la gota colgante», como complemento o sustitución del ideado «mandril líquido» de Dogliotti .

Merced a este trabajo y al generoso reconocimiento del autor argentino, la obra de Pagés empieza a ser redescubierta por sus compatriotas. Curiosamente, Pi-Figueras que en 1932 había publicado sus experiencias como método Dogliotti (145); en 1935 realiza una nueva aportación a su previo trabajo y ya lo domina «La Anestesia Peridural Segmentaría de Pagés-Dogliotti» (146).

Y si años antes la comunicación de Dogliotti en el Congreso de Cirugía de Madrid se quedó sin réplica, es preciso ahora recordar el gesto que protagonizó el cirujano del Hospital de la Santa Creu i San Pau, D. Jaime Pi-Figueras, en la Reunión de la Sociedad Italiana de Anestesia que se celebró en Turín en abril de 1935. El cirujano catalán tuvo la valentía de reivindicar, ante el mismo Dogliotti, la paternidad del método para Pagés $(90,91)$.

Con estos datos podemos plantearnos varias premisas:

- PRIMERA.- Resulta indiscutible que Dogliotti consigue una pronta y rápida difusión de su trabajo como consecuencia de su precoz traducción al inglés en 1933, así como sus diferentes conferencias por distintos países europeos y presentación en diversos Congresos.

- SEGUNDA.- Dogliotti realiza una interesante y novedosa aportación al método de la localización del espacio epidural, como es la técnica del mandril líquido, lo que la populariza al tratarse de un sistema relativamente fácil y didáctico de emplear.

- TERCERA.- Dogliotti desconoce completamente los trabajos previos de Pagés e inicia los suyos siete años después a los publicados por el cirujano aragonés. No se entendería que el cirujano de Módena, Catania y Turín, conociera las experiencias de Pagés e ignorándolas, osara exponer un trabajo, en casi todos sus extremos similar, en el Congreso de Cirugía de Madrid en 1932, tan sólo nueve años después del fallecimiento de Pagés, con el evidente riesgo de que alguien le pudiera recriminar la injusticia de la omisión de Pagés, o lo que sería peor; de plagio.

- CUARTA.- Finalmente, cuando Jaime Pi-Figueras en la reunión de la Sociedad Italiana de Anestesia de Turín en 1935, le recuerda a Dogliotti los trabajos previos de Pagés, aquél reconoce la existencia de los mismos así como su desconocimiento.

- QUINTA.- El artículo de Alberto Gutiérrez sitúa en su justo equilibrio la polémica sobre las respectivas aportaciones de PagésDogliotti al campo de la anestesia epidural, no siendo rebatido ni contestado por éste, como un tácito reconocimiento a su olvido, dando por aceptado lo apuntado por el cirujano, argentino.

A la luz de los datos aportados bien pudiéramos abordar la diatriba que nos planteábamos al inicio acerca de la posible simultaneidad de los descubrimientos de Pagés y Dogliotti. 
Mientras que Pagés inicia sus primeras experiencias en noviembre de 1920 y publica sus iniciales conclusiones en marzo de $1921^{158}$, Dogliotti comenzará sus primeras indagaciones en 1927, siete años después de la inicial idea de Pagés, seis después de la publicación del médico español en la Revista Española de Cirugía y cuatro después de la muerte del cirujano militar oscense. Publicando su artículo una década después que lo hiciera Pagés.

Estimamos que la cronología no deja lugar a dudas en cuanto a que resulta, materialmente imposible considerar descubrimientos simultáneos los de Pagés y Dogliotti.

Pagés, conocedor, como queda recogido en su artículo (62), de la literatura médica publicada hasta esa fecha sobre las técnicas paravertebrales, caudales y raquídeas, no podía citar en ellas a Dogliotti pues no hay nada publicado del Cirujano de Módena sobre anestesia locorregional hasta la década de los treinta.

Si bien Dogliotti no menciona a Pagés en su trabajo inicial sobre la anestesia peridural segmentaría, ni en su traducción al inglés dos años después, ni en la comunicación que hace al Congreso de la Sociedad Internacional de Cirugía en 1932; estimamos que lo hace por un verdadero desconocimiento de las experiencias de Pagés más que por un afán de hurtarle o plagiarle la primicia del descubrimiento al cirujano español.

De hecho, ya lo hemos apuntado con anterioridad, tanto ante los apuntes de A. Gutiérrez, como ante la reivindicación que le plantea Jaime Pi-Figueras en el Congreso de Anestesia de Turín de 1935; no consta objeción ni réplica por parte de Dogliotti, asumiendo como omisión involuntaria por desconocimiento la no inclusión en su artículo de la obra de Pagés.

Pagés, por tanto, aporta un trabajo original a la literatura médica y Dogliotti, años más tarde, desconociendo el anterior, reedita casi en su totalidad lo descrito por Pagés, aportando, como única novedad, la técnica del mandril líquido para la localización del espacio epidural. Técnica más práctica y más sencilla que la manual de Pagés, basada más en la habilidad personal del cirujano.

De cualquier forma, lo que resulta incuestionable es que el método se populariza como «método Dogliotti», y Pagés cae en un profundo olvido de donde sólo en los últimos años se ha iniciado un obligado proceso de reconocimiento. Las causas de ese prolongado olvido serán analizadas y abordadas en las conclusiones finales.

Pocas dudas se pueden plantear hoy acerca de la figura de Pagés como verdadero pionero y promotor del abordaje con fines anestésicos del espacio epidural. Hemos comprobado a lo largo de este trabajo cómo Pagés busca, de una forma intencionada, depositar el anestésico local en el espacio epidural para conseguir insensibilizar determinada parte del organismo, infra o supraumbilical, para proceder al acto quirúrgico con el menor daño y una mayor confortabilidad para el paciente.

No se trata de un hallazgo casual, sino que tratando de encontrar un método anestésico que obvie los inconvenientes de la anestesia intradural (cefalalgias, restricción de campo quirúrgico a la zona infraumbilical del cuerpo y riesgo de inundación bulbar), de la

${ }^{158}$ Hay que recordar que en ese mismo año, en julio, Fidel Pagés acude urgentemente a los hospitales de Campaña de Melilla como consecuencia del Desastre de Annual, viéndose obligado a interrumpir sus investigaciones en este terreno. Con posterioridad y hasta su fallecimiento en 1923, publicará cino nuevos trabajos relatando en alguno de ellos sus experiencias en la cirugía de guerra. anestesia paravertebral (prolongado tiempo de latencia y riesgo de intoxicación por exceso de las dosis de anestésicos locales a administrar) y amplíe el campo quirúrgico de las limitaciones que impone la anestesia caudal, Pagés decide, como él mismo dice, detener la cánula tras pasar el ligamento amarillo e inyectar el anestésico para interrumpir la conducción nerviosa de los nervios raquídeos en su paso por el espacio epidural.

Basándose en sus amplios conocimientos anatómicos de la zona y en su vasta experiencia en la práctica de raquianestesia, describe minuciosamente la técnica de la punción para detectar el espacio epidural, aconseja la dosis anestésica a administrar, relata con detalles la paulatina instauración de la insensibilidad y de la parálisis motora que ocasiona, apunta las complicaciones habidas en su experiencia, sienta las indicaciones y contraindicaciones y después de hacer un estudio comparativo con otros procedimientos afirma, rotundamente, que su método es preferible a la punción aracnoidea ya la paravertebral. Con prudencia manifiesta al final del artículo que los primeros resultados siendo buenos, precisarían de investigaciones ulteriores.

Esta prudencia no empece el convencimiento que tenía Pagés de estar ante un método, hasta ahora, no descrito en la literatura médica mundial y de una utilidad práctica inmediata.

Tal vez, mayor controversia pueda suscitar las razones del prolongado olvido que esta original aportación de Pagés ha tenido durante tantos años.

Es incuestionable que la primera razón de este olvido sea su prematuro fallecimiento. Pagés muere dos años y seis meses después de haber publicado sus experiencias sobre la anestesia epidural. Experiencias que deja abierta a posteriores investigaciones que, de no ser por ese trágico accidente, hubiera continuado y divulgado aún más. Esta falta de continuidad le impidió que este trabajo, u otros posteriores sobre la misma materia y que, indudablemente, hubiera escritor fuera traducido a otros idiomas y divulgado en los foros científicos internacionales.

Ya hemos relatado que "Anestesia Metamérica», se traduce al inglés en 1961 (72) y al francés en 1975 (148), reproduciéndose por primera vez, desde su fallecimiento, en 1955 en la Revista Hypnos de la Asociación de Anestesiología de Barcelona (159).

Esto contrasta con la precocidad con la que Dogliotti traduce su artículo al inglés (71) sólo dos años. El original data de 1931 y la publicación en inglés de 1933. Entre tanto, tuvo tiempo de presentar su trabajo en el Congreso de la Sociedad Internacional de Cirugía celebrado en Madrid en 1932 .Todas estas circunstancias contribuyeron a que, erróneamente, se designara a este procedimiento como «Método Dogliotti» y recayera sobre el cirujano de Módena la paternidad de lo que él denominó: «Anestesia Peridural Segmentaría».

Lo que convendría reconocerle a Dogliotti es su mayor capacidad en la divulgación de sus experiencias. Capacidad que favoreció una longevidad (Murió en 1966) de la que Pagés no disfrutó.

Otra de las razones que favoreció la preterición de la obra anestésica de Pagés fue el aislamiento científico y político en los que se vio envuelta España en la primera mitad del siglo XX. Aislamiento científico que bien puede sintetizarse con la exclamación del profesor Vicent Czerney al oír la exposición de José Ribera y Sans en el Congreso Internacional de Cirugía celebrado en Bruselas en 1908: «No teníamos ni idea de nada de esto». Frase patognomónica de la autarquía científica española. A este severo inconveniente se le sumó 
el aislamiento político de España como consecuencia de los sucesivos avatares por los que atravesó nuestra más reciente historia: la Dictadura del general Primo de Rivera (1923-1930), instaurada sólo unos días antes de la muerte de Pagés (13 de septiembre), la proclamación de la Segunda República y la precedente caída de la Monarquía Borbónica (14 de abril de1931), la Sublevación Minera de Asturias (1934), la Guerra Civil Española (1936-1939), La Segunda Guerra Mundial (1939-1945) y la forzada neutralidad española; la posguerra y nuestra ausencia de los ámbitos internacionales y, por supuesto, la singular especificidad autárquica del régimen político español hasta 1975.

Pero junto a estos factores particulares, creemos que existe otro factor más genérico que ha contribuido, y no en pequeña cuantía, al escaso realce que la aportación de Pagés ha merecido para diversos autores hasta hace pocas fechas.

Este elemento global no es otro que el propio desuso en el que cayó la práctica de la anestesia epidural en general. El estallido de la segunda gran guerra, la introducción en la clínica de los relajantes neuromusculares en 1942 por Griffith y Johnson, el perfeccionamiento de los respiradores artificiales tras la epidemia de poliomielitis en Dinamarca en 1952, (160), y la incorporación de nuevos hipnóticos intravenosos, fueron elementos desencadenantes del brusco descenso que experimentó la práctica de la anestesia local, troncular, intradural y epidural.

Durante muchos años nada se ha opuesto al poder de los «curares», de la intubación, de la respiración controlada y del uso de la neuroleptoanalgesia. Desde la cirugía cardíaca hasta el parto vaginal nada se resistía a esta práctica anestesia. Este auge, de la llamada Anestesia general, trajo un retraimiento en la práctica de la anestesia epidural, un desuso que se tradujo en una ausencia en la formación de los anestesiólogos y en un creciente desinterés por los antecedentes de esta técnica, que, en algunos centros, no llega ni a enseñarse como recuerdo histórico.

La incorporación a la clínica de nuevos anestésicos locales con escaso poder tóxico y amplio margen de seguridad en su uso, la introducción de nuevas agujas más seguras y de los catéteres epidurales permanentes, así como la descripción de nuevas técnicas y aparatos para detectar el espacio epidural; han devuelto a la actualidad a un método anestésico con ochenta años de vigencia.

Es por ello que en las décadas de los ochenta y noventa, cuando la anestesia epidural se ha impuesto en la clínica diaria claramente en algunas especialidades como la obstétrica, el recuerdo a la obra de Pagés se ha ido abriendo paso entre la bruma del olvido. Reconocimiento justo y tardío pero que tampoco ha estado exento de reiterativos errores. Estando de acuerdo con lo apuntado por C. Hervás Puyal: «La aportación española a la historia de la anestesiología ha sido, lamentablemente, muy reducida. Sobran los dedos de una mano para enumerar a los autores cuya obra ha perdurado a través del tiempo: José Goyanes, creador de la anestesia intraarterial; Fidel Pagés, el primero en abordar con fines anestésicos el espacio epidural; y Jaume Raventós, Farmacólogo cuyas investigaciones hicieron posible la aplicación en el hombre de un nuevo anestésico inhalatorio: el fluothane. De ellas, la contribución de Pagés es quizás la que ha conocido una mayor difusión, conservando hoy plena vigencia». Y valorando su aportación al estudio de la figura de Pagés, yerra al ubicar en Zaragoza su lugar de nacimiento. (90).

Del mismo modo reconocemos el excelente trabajo de M.A. Cuesta (91) y coincidimos con él cuando manifiesta: «También exis- te un Hospital Militar Fidel Pagés en Melilla y un Aula Fidel Pagés en la escuela de Sanidad Militar en Madrid, pero en estos centros nadie recuerda con claridad quien es Pagés ni lo que su figura significa. Su nombre y su biografía no figuran, además, en ninguna enciclopedia de divulgación popular ni científica. En segundo lugar, su figura es la de un cirujano que;' trabajando en circunstancias difíciles y con inestabilidad en el lugar de trabajo (trabajó probablemente desde el año 1909 hasta el año 1923 en seis ciudades diferentes, en 18 empleos diferentes y en dos campañas de guerra) demostró siempre un entusiasmo en su trabajo que le llevaba a describir sus experiencias de la manera tan genial ya referida».

Pero creemos que comete un desliz al incorporar en la bibliografía de su trabajo a artículos como «El shock traumático», «Arteritis de la arteria subclavia» y «Las infecciones difusas de la mano», atribuidos a Pagés y que no hemos encontrado ni en la Revista de Sanidad Militar, ni en la Revista Española de Cirugía. Muy posiblemente, el error se deba a que se ha utilizado como fuente la obra de Álvarez Sierra (61) en la que se hace mención a estos trabajos.

Siendo la aportación de la anestesia epidural lo más destacable de la obra general de Pagés, sería injusto si no se realzara de él su gran capacidad de trabajo y su acendrado espíritu multidisciplinar. Cultivó, como hemos visto, las más variadas técnicas quirúrgicas y traumatológicas, colaboró con la reorganización del ejército y de la Sanidad Militar, fue redactor jefe de la Revista de Sanidad Militar y Cofundador y director de la Revista Española de Cirugía. Su función y labor en ésta debieron ser tan intensos que no le sobrevivió, publicándose un sólo número tras su muerte en el que aparecía su nota necrológica y un trabajo póstumo. Esta revista tuvo una sucesora en la Revista Española de .Cirugía y Urología, que apareció en 1928, conservando la misma numeración.

Por último, sería injusto no resaltar la notable aportación que hace Pagés a la Sanidad Militar en particular y a la cirugía en general. Su experiencia en heridas abdominales durante el Desastre de Annual, le lleva a defender, basándose en su experiencia, con encomiable entusiasmo, la teoría intervencionista frente a la abstencionista defendida por Delorme, Bergman o MacCormac. Incluso va más lejos cuando aconseja intervenir a estos pacientes lo más próximo del frente, para evitar demoras letales en el traslado: «...soy un convencido que con buena voluntad y personal auxiliar entrenado puede llevarse la asepsia a todas partes, y no otra cosa hace falta para laparotomizar un herido de guerra». Esta aseveración de Pagés, expresa de forma contundente la conveniencia de la existencia y actuación de los puestos quirúrgicos avanzados en caso de conflictos armados.

Cierto es que a la obra de Pagés se le puede catalogar de estar poco articulada y un tanto dispersa en relación a las materias que aborda. Siendo esto así, no es menos cierto que ciñéndose su trabajo profesional a sólo catorce años, tuvo la dificultad añadida de realizarlo en circunstancias precarias y adversas y como característica común la urgencia sobrevenida por los conflictos bélicos a los que acude.

Conociendo estos antecedentes, habrá que coincidir en lo meritorio de trasladar sus rápidas vivencias profesionales a un trabajo escrito en el que resaltan sus dotes de observación, su capacidad analítica y su pragmatismo. Como decíamos antes, su intuición y vocación quirúrgica, suplieron con creces la falta de tiempo para una mejor codificación y sistematización de sus experiencias. 


\section{Aproximación a la obra científica del Comandante médico Fidel Pagés Miravé}

\section{BIBLIOGRAFÍA}

1. García del Real, E. (1946)-- Surgical Anesthesia In Spain. Journal Of The History Of Medicine And Aillied Sciences I, 641-643

2. García del Real, E. (1934).- Historia Contemporanea De La Medicina Madrid, Ed. Espasa Calpe; $664 \mathrm{Pp}$

3. Sánchez Guisande G. (1966).- Breve Historia De La Medicina Buenos Aires, Ed.; El Ateneo, $245 \mathrm{Pp}$.

4. Granjel L.S. (1969).- Historia De La Medicina Salamanca, Ed.- Universidad Salamanca, $267 \mathrm{Pp}$.

5. Barquín. M. (1971).- Historia De La Medicina Méjico, Ed.- Modernas, 400 Pp.

6. Laín Entralgo P. (1982).- Historia De La Medicina Barcelona, Ed.- Salvat, $582 \mathrm{Pp}$.

7. Hernández E. (1929-30).- Los Progresos En El Campo De La Anestesia En Libro Homenaje Goyanes Madrid, Ed.- Gacota Médicas Española, 155 P.

8. Álvarez Sierra J. (1961).- Historia De La Cirugía Española Madrid, Ed.- Artes Gráficas, $651 \mathrm{Pp}$.

9. García Del Real E. (1946).- Centenario Del Descubrimiento De La Anestesia Quirúrgica. Papel Desempeñado Por Los Médicos Españoles Medicamenta, 5; 178-182

10. 1Garcia Del Real E. (1946).- Centenario Del Descubrimiento De La Anestesia Quirúrgica. Papel Desempeñado Por Los Médicos Españoles Medicamenta, 98; 178-182

11. Franco A. (1976).- Evolución Histórica De La Anestesiología Como Especialidad Médica Revista Española Anestesiol Y Reanim, 23; 1-12

12. Sanchez R. (1978).- Reflexiones Sobre Los Adelantos De La Anestesiología Como Especialidad. Gac.Med.Mex, 115; 31-35

13. Montañés E. (1978).- Evolución Histórica De La Anestesia Regional Revista Española De Anest Y Reanim, 25; 163-181

14. Franco A. (1979).- Veinticinco Años De Anestesia Organizada Revista Española De Anestesiol Y Reanim, 27; 42-48

15. Franco A. Et. Al. (1980).- Primeras Tesis Doctorales Sobre Anestesia En Lengua Castellana Revista Española De Anestesiol Y Reanim, 27; 357

16. Victoria M. (1981).- Introducción De La Anestesia En España Los Médicos Y Su Contribución Gac. Med. Bilbao, 78; 531-576

17. Prosper F. (1935).- Historia De La Sanidad Militar Y Sus Aportaciones A La Medicina Española Madrid, Trabajos De La Cátedra Historia Crítica De La Medicina, Vi; 101-146

18. Parrilla M. (1964).- Sobre La Historia De Nuestras Publicaciones Sanitario- Castrense En Su Centésimo Aniversario Med. Cirug. Guerra, 26; 3-5

19. M. (1965).- La Medicina Militar Española. Apuntes Cronológicos Para Su Historia Med.Cirg. Guerra, 27; 131-146, 509-523

20. M. (1968).- La Medicina Militar Española. Apuntes Cronológicos Para Su Historia Med.Cirug. Guerra, 30; 3-16

21. J. (1970).- Cuerpos Médicos Especiales: Médicos De La Armada Y Del Ejército Asclepio, 21; 327-334

22. R. (1933).- Evolución Histórica De La Sanidad Militar Madrid, Trabajos De La Cat. Hist. Crítica De La Medicina, I; 459-473

23. S. (1946).- La Medicina Militar A Través De Los Siglos Madrid, Ed. Servicio Geográfico Ejército, 565 Pp.

24. Sierra J. (1956).- La Medicina Y La Beneficencia En El Barrio De Chamberi Medicamenta, 2; 174-176

25. Sierra J. (1964).- El Sucesor De D. Cristóbal Pérez De Herrera. D. Marcos García El Primer Médico - Director Del Hospital General De Madrid Medicamenta, 42 222-224

26. M. (1971).- Maestros De Ayer Trib. Med., 8; 14-15

27. J.A. (1961).- Cincuenta Años De Cirugía Med. Esp., 45; 390-398

28. J. (1950).- Historia Sucinta De La Medicina Mundial Buenos Aires, Ed. Espasa Calpe, 252pp.

29. B. (1968).- Historia De La Medicina Barcelona, Ed. Grijalbo, 223 Pp.

30. H. (1971).- Lehrbuch Der Geschichte Der Medicin Hildesheim $2^{\text {a }}$ Ed. Georg Olms Verlag, 3 Vol (875 Pp. I.) (1120 Pp. II) (994 Pp. III).

31. F. (1966).- Historia De La Medicina $4^{\mathrm{a}}$ Ed. Mexico, Ed Interamericana, $664 \mathrm{Pp}$.

32. R. (1970).- History Of Medical Illustration London., Pitman Medical \& Scientfic Publissing Co, $178 \mathrm{Pp}$.

33. V. Et Al (1978).- Storia Della Medicina Bologna, Ed Pátron, 354 Pp.

34. F.F. (1977).- A Social History Of Medicine New York, Ed Longman Inc, 209 Pp.

35. A. (1941).- Historia De La Medicina Barcelona, Ed. Salvat, 906 Pp.

36. H. (1942).- Historia De La Cirugía Barcelona, Ed. Iberia Joaquín Gil, 550 Pp.
37. E. (1964).- Geschichte Der Chirurgie Hildesheim,Ed. Geor Olms Verlangs Buchhandlung (3 Vols - 976 Pp.; 926 Pp.; 834 Pp.).

38. K. (1966).- Historia De La Medicina Barcelona, Ed. Credsa, 423 Pp.

39. I. (1962).- Biographisches Lexikon $2^{\text {a }}$ Ed. Berlin, Ed. Verlag Vun Urban \& Schwarzenberg, $1741 \mathrm{Pp}$.

40. J. (1971).- The History Of Medicine $2^{\mathrm{a}}$ Ed. Huntington, Ed. Robert E. Krieger Publishng Co. Inc, 1773 Pp.

41. S. (1975).- Historia De La Medicina Zaragoza, Ed. Anatole, 463 Pp.

42. A. (1967).- Historia Sinoptica Da Anestesia Rev. Assoc. Paul. Cir. Dent. 21; $172-$ $180 ; 205-221$

43. A. (1968).- Historia Sinoptica Da Anestesia Rev. Assoc. Paul Cir. Dent, 22; 26$35,74-92$

44. A.(1966).-Historia Sinoptica Da Anestesia Rev.Assoc. Paul. Cir. Dent, 20; 284-299

45. J. (1971).- History Of Local Analgesia Brit. J. Chirop., 36; 245

46. E. (1932).- La Medecine Espagnole. Quelques Etapes; Quelques Hommes. Gal. Med. Esp. Vi, 68; 240-245, 69; 269-276

47. J. (1954).- 110 Years Of Anesthesia J.Med. Assoc. Ga, 43; 193

48. J.P. (1972).- A Short History Of Local Anesthesia. Bull. Hist. Dent, 20; 27-31

49. J. (1972).- Four Decades Of Association With The Pionners Of Anesthesilogy Anesth Analg, 51; 665-670

50. J. (1974).- Evocación Histórica De La Anestesiología. An. Med. Cir, 54; 23-40

51. W.S. (1976).- The Perilous Development Of Safe Local Anesthesia. Dent. Surv.; $52(6) ; 30-32$

52. O. (1979).- Nicolae Ionescu-Sisesti, Neurologist (1888-1954). Rev. Méd. Interna; 24 (2); 143-146

53. A. (1980).- Current Finding In The History Of Anesthesiology. Masui. 29; 15411546.

54. A. (1982).- Current Finding In The History Of Anesthesiology. Masui, 31; 408-414

55. Al (1982).- The Pioneer Of Regional Analgesia For Pain Relief In Childbirth Anaesthesia, 37; 663-669

56. M. (1973).- Pioneers In Anaesthesia Lamp, 30; 31-34

57. M. (1973).- Pioneers In Anaesthesia Lamp, 31; 33-40

58. P.C. (1971).- History Of Spinal Anesthesia.- En : Lund Pc. Principles And Practice Of Spinal Anesthesia.- Springfield, Thomas, Pp, 3-39

59. P.C. (1964).- The History Of Peridural Anesthesia Int. Anesth Clin, 2; 471-475

60. P. (1966).- Evolution Des Conceptions Et Des Materiels D' Anesthesie Pour L' Emploi Militaire Rev. Corps. Santé. Armees, 7; 1005-1017

61. Sierra J. (1959).- Diccionario De Cirujanos Españoles, Hispanoamericanos Y Filipinos Pag. 387

62. F. (1921).- Anestesia Metamerica Rev Esp. Cirug., 3; 281-306

63. J. (1970).- Tratamiento Del Dolor Barcelona Ed. Salvat, 1343 Pp.

64. H. (1979).- Anestesia Local Barcelona, Ed. Salvat, 797 Pp.

65. P. (1979).- Anestesia Y Analgesia Peridurales Barcelona, Ed. Salvat, 164 Pp.

66. F. (1901).- Une Nouvelle Voie D'injection Rachidenne. Methode Des Injections Epidurales Par Le Procede Du Canal Sacré. Applications A L'homme. C.R.Soc. Biol, 53; 452-453

67. A.(1901).- Extradural Injection Of Medication By Way Of The Sacrococcygeal Canal C.R. Soc. Biol, 53; 396

68. A. J. (1981).- Punción Lumbar Y Analgesia Espinal Barcelona, Ed. Salvat 2a 232 Pp.

69. F. (1921).- Anestesia Metamerica Rev.. San. Mil ,3; 351-365; 385-396

70. A.M. (1931).- Un Prometende Metodo Di Anestesia Tronculare In Studio: La Rachianestesia Peridurale Segmentaria. Boll. Soc. Piemontese Di Chirurgie. Vol. I. Abril.

71. A.M. (1933).- A New Metod Of Block Anesthesia Segmental Peridural Spinal Anesthesia Amer. J. Sur 6, 20, 107

72. F. (1961).- Anestesia Metamérica Classical File. Survey Of Anesthesiology, 5; 326

73. K. (1978).- Achille Mario Dogliotti Orv. Hetil, 119; 343-344

74. P. (1967).- Physiology And Pharmacology Of Epidural Analgesia Anesthesiol, 28, 592

75. L. T. (1976).- A Medical Bibliography $3^{\mathrm{a}}$ Ed. Londres, Ed. Ebenezer Baylis And Son Ltd, $872 \mathrm{Pp}$

76. Catalogue.- Library Of The Surgeon General's Office (1972) $3^{\text {a }}$ Ed., Vol. Viii, Ed Johnson Reprint Corporation, New York: 337 Pp.

77. J.E.(1959).-MedicalDiscoveries Springfield,Ed.CharlesC.Thomas. Publisher, 555

78. L.S. Santander M.T. (1962).- Índice De Médicos Españoles Salamanca. Ed. Univ. Salamanca, $111 \mathrm{Pp}$.

79. J.A. (1979).- Arthur Edward James Barker (1850-1960). British Pioneer Of Regional Analgesia Anaesthesia, 34; 885-891. 
80. Ulla M. (1924).- Discursos Pronunciados En El Reciente Homenaje En Memoria De Pagés Revi. San. Mil, 5; 112-115

81. Julián J. (1924).- Discursos Pronunciados En El Reciente Homenaje En Memoria De Pagés Rev. San. Mil., 5; 109-112

82. Mata T.R. (1923) Et Al.- Fidel Pagés (1886-1923) Rev. Esp. Cirugía, 5

83. Fidel Pagés Miravé. Comandante Médico. Redactor Jefe De Esta Revista Rev. San. Mil. 1923, 13; 525-526

84. Sierra G. (1923).- ¡Pagés! Rev. San. Mil., 13; 527-528

85. Ulla M. (1923).- Homenaje A Un Héroe De La Ciencia ¡Pagés Ha Muerto! Rev. San. Mil., 13; 553-555.

86. F. (1923).- Los Homenajes Póstumos A Pagés. El Del Hospital Militar De San Sebastián. Rev. San. Mil., 13; 581-583

87. Dr. Pagés.- El Siglo Médico (1923) Rev. Clin., 72; 956

88. J. (1958).- La Analgesia Extradural Alta Rev. Esp. Anestesiol, 5; 241

89. Pagés Miravé.- Láminas Históricas (1985) Rev. Esp. Anestesiol 1985, 5; 322-325

90. C. (1991).- La Perenne Actualidad De Un Clásico: Fidel Pagés Y La Anestesia Epidural Rev. Esp. Anestesiol. Reanimación, 38; 317

91. Ma. Et Al (1992).- Fidel Pagés Miravé, Cirujano Descubridor De La Anestesia Epidural Cir. Esp., 51; 79-83

92. J.M. (1994).- Historia De La Sanidad Militar Española. Barcelona, Ed. PomaresCorredor Sa, Tomo Iii, Pags 396-397.

93. A. Et Al (1996).- En Memoria De Fidel Pagés Miravé (1886-1923) En El LXXV Aniversario De La Publicación De «Anestesia Metamérica» Rev. Esp. De Anestesiol. Y Reanim., 43; 59-66

94. A. Et Al (1965).- Foundations Of Anesthesiology Springfield, Charles C. Thomas; 927 Pp.

95. F. (1912).- La Lucha En Campaña Contra Las Enfermedades Infecciosas Rev. De San. Mil., 8; 502-506

96. F. Cirugía (1918).- La Teoría Y La Práctica Del Injerto Óseo Rev. San. Mil., 18; $541-554 ; 19,579-589$

97. F. (1919).- Sobre Un Caso De Estrangulación Retrógrada De Epiplón Rev. Esp. De Cirugía, $1 ; 1-11$

98. F. (1920).- Contribución Al Estudio De La Cirugía Plástica De La Mejilla Rev. De San. Mil., 3,4,5; 163-167 (201-205; 232-236; 267-303).

99. F. (1919).- El Tratamiento De Las Fracturas De Olécranon Por El Enclavijamiento Y La Extensión Continua. Rev. Esp. De Cirugía, 8;486-495

100. Pagés, F. (1921) Sobre Algunos Casos De Utilización De Las Fascias En Rev. De San. Mil., 2, 3, 33-43, 75-110

101. T. (1899).- L'analgesie Chirurgicale Par Voie Rachidenne Oeuvre Medicale Et Chirurgicale, 24

102. M. (1965).- La Pacificación De Marruecos Madrid. Serv. Geog. Ejercito, 655 Pp

103. Pagés, F. (1921).- Sobre La Existencia De Un Espacio Paravertebral Hipersonoro En Los Pneumotórax De Tensión Rev. Esp. De Cirugía, 12; 426-436

104. Pagés, F. (1922).- La Gastroenterostomía Con Collar Epiploico Rev. Esp. De Cirugía, $13 ; 1-6$

105. Pagés, F. (1922).- Heridas Abdominales De Guerra. Mi Experiencia Personal. Rev. Esp. De Cirugía, 10,11,12; 419-477

106. Haeger. K. (1993).- Historia De La Cirugía. Madrid, E. Raíces, 282 Pp. 107. F. (1989).- Historia De La Medicina Madrid, Ed. Norma, Tomo II, 1440 Pp. 108. J. (1985).- Historia, Medicina Y Sociedad Madrid, Ed. Pirámide, 439 Pp.

109. F. (1923).- Drenaje Transcerebral Rev. Esp. De Cirugía, 1; 1-15

110. F. (1923).- Aspecto Quirúrgico Del Estreñimiento Revista Española De Cirugía, $8 ; 363-382$

111. C. (1991).- Historia De España Barcelona, Instituto Gallach, Tomo V - 540 Pp.

112. De La Humanidad (1987) Barcelona, Ed. Plaza Y Janés, 1183 Pp.

113. Entralgo P. (1963).- Historia De La Medicina Moderna Y Contemporanea Barcelona Ed. Científico Médica. 773 Pp.

114. A. Et. Al (1996).- El Descubrimiento De La Anestesia Quirúrgica Y Su Llegada A Europa. A Propósito Del 150 Aniversario De La Introducción Clínica Del Éter. Rev. Esp. De. Anestesiol. Y Reanim., 43; 281-287

115. C. Et Al (1995).- Introducción Y Desarrollo De La Anestesia Local En España Rev. Esp. De Anestesiol. Y Reanim., 42; 58-66

116. Olivares J. (1847).- La Eterización En España Bol. Med. Cir. Farm, 81; 235-237; 82: $242-244$

117. Castillo R. (1884).- Del Empleo Del Clorhidrato De Cocaína En Oftalmología Andalucía Med., 9; 265-271; Andalucía Med. ,10; 1-5

118. Toro C. (1885).- El Clorhidrato De Cocaína Cron. Especial. Med Quir, 29-34 119. 11Miguel J. (1946).- Tratado De Anestesia Barcelona, Ed. Salvat S.A. 726 Pp.

120. R. D. (1988) - Anestesia Barcelona, Ed. Doymasa, Vol I, 744 Pp.
121. V. (1921).- L'anesthesie Regionale París, Ed. Gastón Doi, 349 Pp.

122. C. Et Al (1992).- Algunas Contribuciones Españolas A La Anestesiología De Finales Del Siglo XIX Rev. Esp. Anestesiol. Reanim. : 39; 301-305

123. O. (1893).-El Cloruro De Etilo Como Anestésico Local Siglo Med.: 40; 50-57

124. J.M. Et Al. (1991).- Orígenes De La Raquicocainización En España Rev. Esp. Anestesiol. Reanim. : 38; 38-40

125. J.J. (1987).- Reino Y Jefes De Estado Desde El 712 Madrid, Ed. Historipana, $287 \mathrm{Pp}$.

126. P. (1981).- Historia De España Barcelona, Ed. Grijalbo, 177 Pp.

127. De Lara M. Et Al (1981) Historia De España Barcelona, Ed. Labor, Tomo IX, 712 Pp.

128. R., Proust R., Jeanbrau E., Tixier L. (1925).- Tratado De Patología Quirúrgica Barcelona, Ed. Pubul, Tomo I, 1104 Pp.

129. T. (1901).- Analgesie Cocainique Par Voie Extradural. C.R. Soc. Biol. 53: 490

130. M. (1912).- Uber Leitunganaesthesie An Bauch, Brust, Arm Und Hals Durch Injektion Ans Foramen Intervertebrale. Munch. Med. Wschr. 59: 794-796

131. A. (1911).- Uber Extradulanästhesie Fur Chirurgische Operationen. Dtsch. Z. Chir. 108; 1

132. A. (1899) From Dtsch Z. Chir Tt. 51: 361

133. J.L. (1885).- Spinal Anaesthesia And Local Medication Of The Cord Ny. Med. J. $42: 483$

134. P.R. (1985).- Analgesia Epidural Barcelona, Ed. Salvat, 634 Pp.

135. A. (1932).-Anestesia Metamerica Epidural. Buenos Aires, Rev. Cirug., 11: 665-685

136. C. B. (1936) Epdidural Anesthesia Amer J. Surg. 34: 547

137. N. R. (1948) - Nossa Experiencia Con 1201 Casos De Anestesia Extradural Rev. Brasil De Cir, 17: 133

138. R.R. (1950).- Extradural Space Indicator Anaesthesia 5: 98

139. C.S. (1894).- On The Anatomical Constitution Of Nerves Of Skeletal Muscles; With Remarks On Recurrent Fibres In The Ventral Spinal Nerve-Root J. Physiol., $17: 211$

140.F. K. (1959).- Unexplaine Spread Of Epidural Anaesthesia. Brit. J. Anaesth, $31: 359$

141. J.W. (1960).- The Risk Of Epidural Block In Old People Brit. J. Anaesth, 32: 613

142. Garcia Et Al (1998).- Anestesia Intradural Con Aguja 27g De Sprotte Para La Cirugía De Artroscopia De La Rodilla En Los Pacientes Ambulatorios Menores De 40 Años Rev. Esp. Anestesiol. Reanim; 45:263-267

143. P.R. (1974).- Mechanism Of Action Of Extradural Analgesia Brit. J. Anaesth, 47:19

144. J.M. (1932).- Nuevo Procedimiento De Anestesia Lumbar Llamado Peridural Del Doctor Dogliotti Archiv. Med. Cir. Espec. 13: 165-168

145. Figueras J. (1932).- La Anestesia Peridural Segmentaria Por El Procedimiento De Dogliotti Barcelona Rev. Cirug., 4: 302-311

146. Figueras J. Oller C. De Sobregrau (1935).- La Anestesia Peridural Segmentaria De Pagés-Dogliotti. Barcelona, Rev. Cirug; 10: 336-345

147. C. (1992) Aproximación A La Obra Científica De Jaume Raventós (1905-1982) Rev. Esp. Anestesiol. Reanim; 39: 362-370

148. F. (1975).- L' Anesthesie Metamerique Cahiers D'anesthesiologie; 75-98

149. R., Proust, R., Jeanbrau E., Tixier, L. (1925).- Tmonografias Beechan Tratado De Patología Quirúrgica. Barcelona, Ed. Pubul, Tomo Iv, 1142 Pp.

150. R., Proust, R., Jeanbrau E., Tixier, L. (1925).- Tratado De Patología Quirúrgica. Barcelona, Ed. Pubul, Tomo III, 892 Pp.

151. A., Cebrián, V. (1897).- Enciclopedia Universal De Progresos Médicos. Madrid, Librería Del Heraldo, Vol. I, 746 Pp.

152.W.A. (1908) Remarks On The Results Of The Operative Treatment Of Chronic Obstipation.Br. Med. I.; 1: 126-130

153. R. (1910).- Revista De Medicina Y Cirugía Práctica. Madrid, Imp. Nicolás Moyá, Tomo LXXXVIII, 496 Pp.

154. R. (1979).- Patología Y Clínica Quirúrgica Del Tórax. Madrid, Ed. Marban, 375.

155. Jr. (1972).- Patología Quirúrgica Buenos Aires, Ed. Ateneo, 1136 Pp.

156. Ch. (1890).- Terapéutica De Las Enfermedades Infecciosas. Madrid, Ed. Librería, $530 \mathrm{Pp}$.

157. A. And Forestier J. (1921).- Radiographil Method For Exploration Of The Epidural Space Using Lipiodol Rev. Neurol. 28:1264.

158. A. And Forestier J. (1926).- Roentgenologic Exploration Of The Central Nervous System With Iodised Oil (Lipiodol) Arch Neurol. Psychiat, $16: 421$

159. F. (1955).- Anestesia Metamérica. Reproducción Con Comentarios. Hypnos De Anestesiología. 3; 182-201

160. R. (1976).- Tratado De Anestesiología, Reanimación Y Tratamiento Intensivo Barcelona, Ed. Salvat, 11 


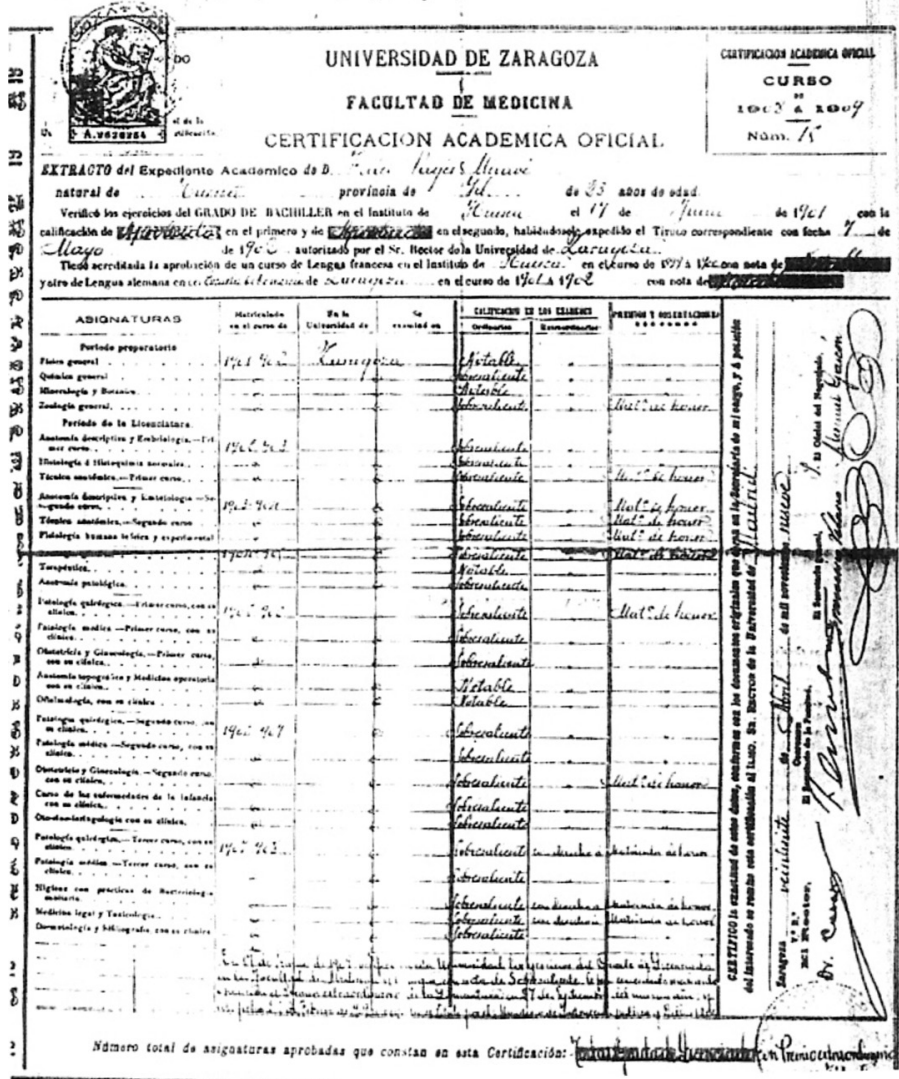

Figura 1. Certificación académica de la facultad de medicina de Zaragoza.

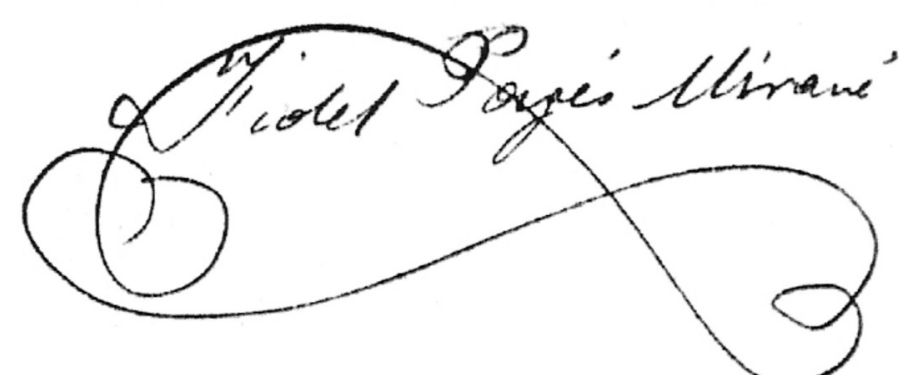

Figura 2. Firma de Pagés.

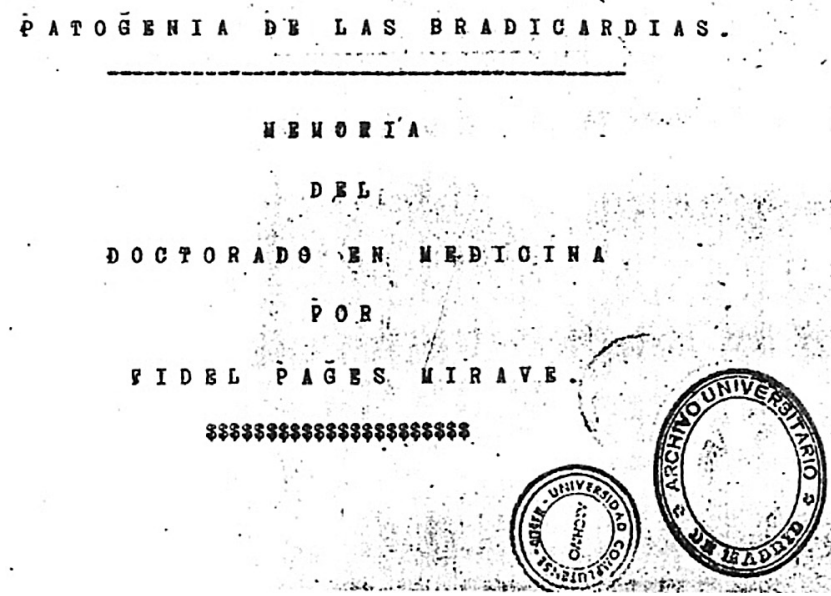

Figura 3. Portada de la tesis doctoral de Pagés.

\section{UNIVERSIDAD CENTRAL \\ ACTA DEL GRADO DE DOCTOR EN MEDICINA}

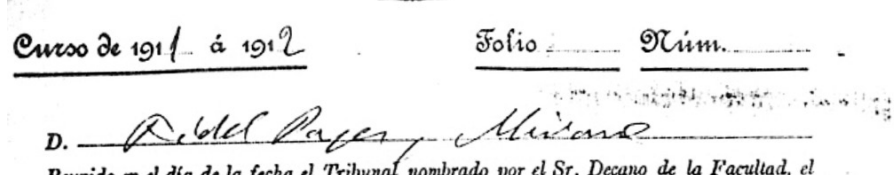

Reunido en el dia de la fecha el Tribural nombrado por el Sr. Decano de la Fggultad, el aspirante leyó un discurso sobre el siguiente tema, que libremente habia elegido: " a haceurh

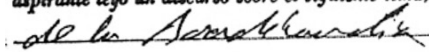

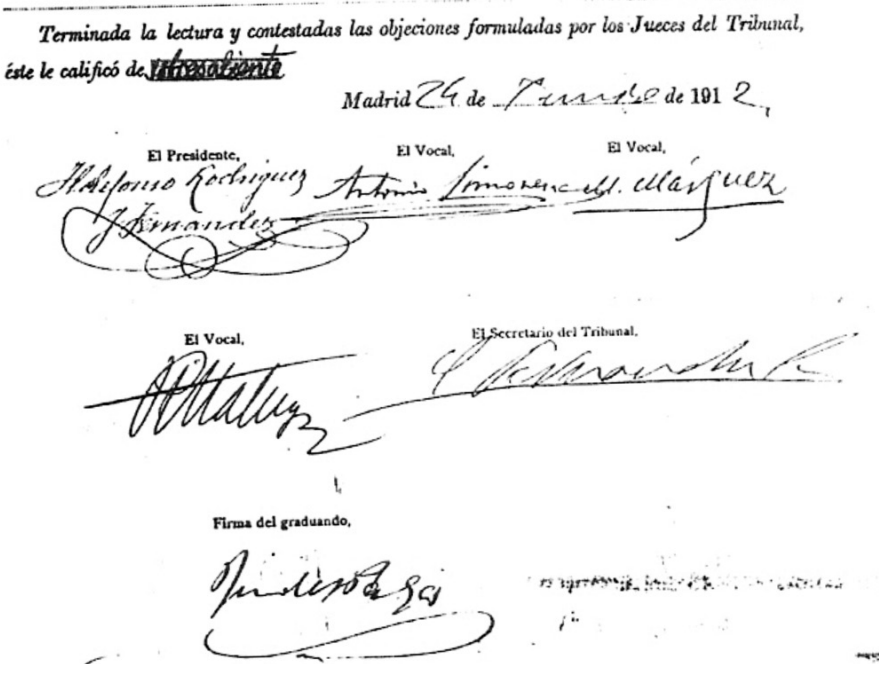

Figura 4. Acta de Grado del doctorado.

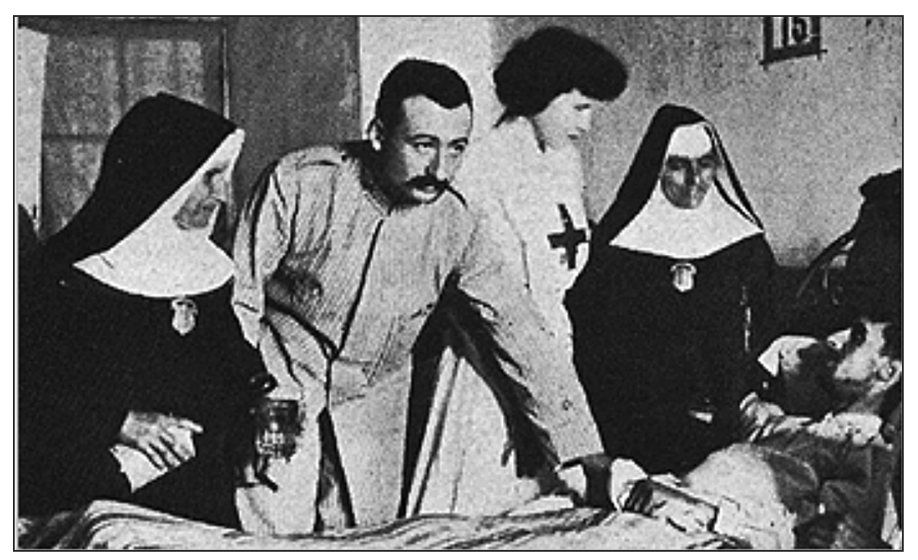

Figura 5.Pagés conAlejandraWolfen su primera estancia en Melilla.

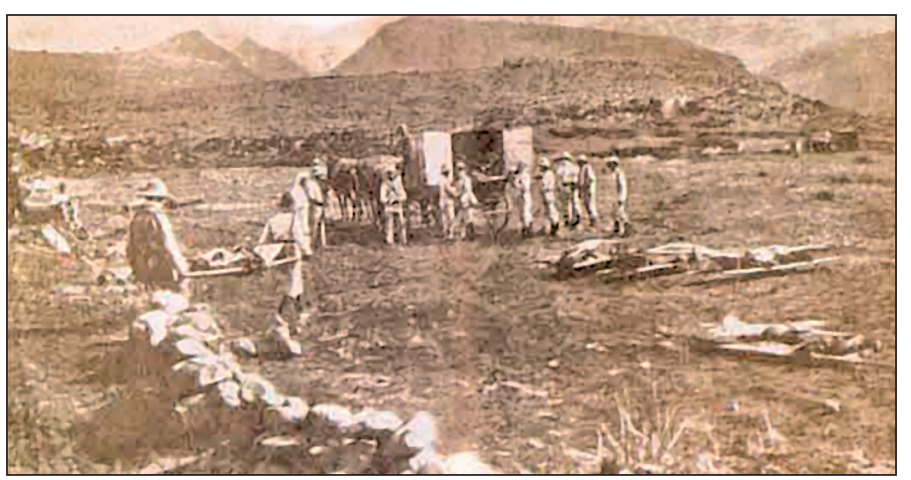

Figura 6. El barranco del lobo (1909). 


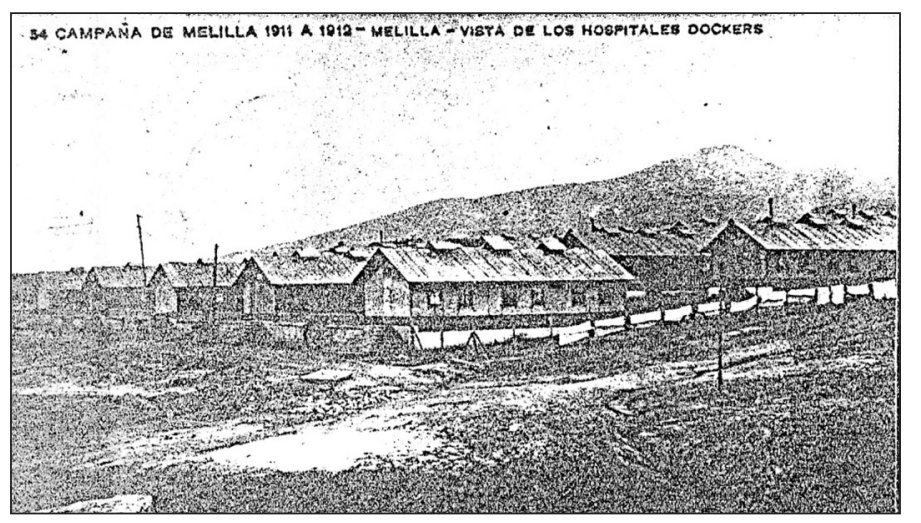

Figura 7. Hospital Docker 1912, posteriormente llevaría el nombre de capitán médico Fidel Pagés.
Figura 9. Quirófano del hospital Docker (1912).

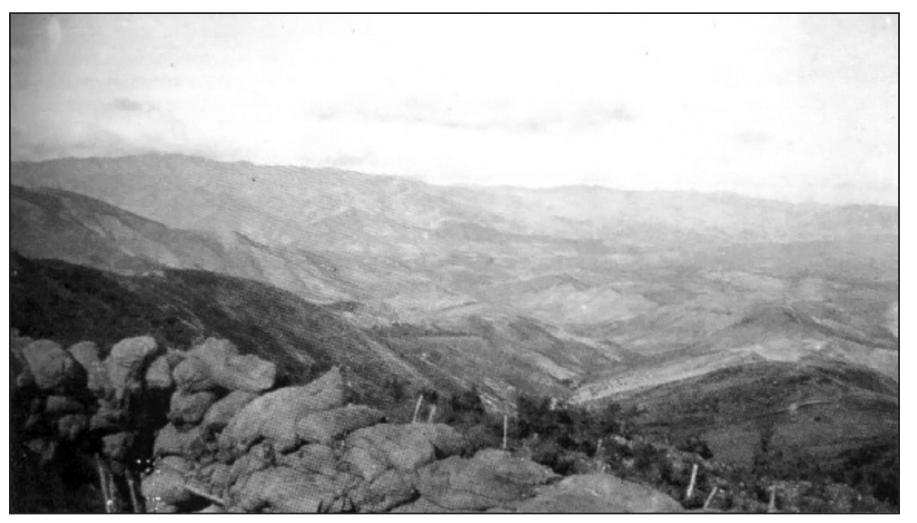

Figura 8. Valle del Kert (1912) conflicto que llevará a Pagés de nuevo a Melilla.


Figura 11. Portada del artículo de Pagés publicado en la Revista Española de Cirugía en 1921. 
Aproximación a la obra científica del Comandante médico Fidel Pagés Miravé



Figura 12. Foto de Pagés con uniforme de oficial médico.

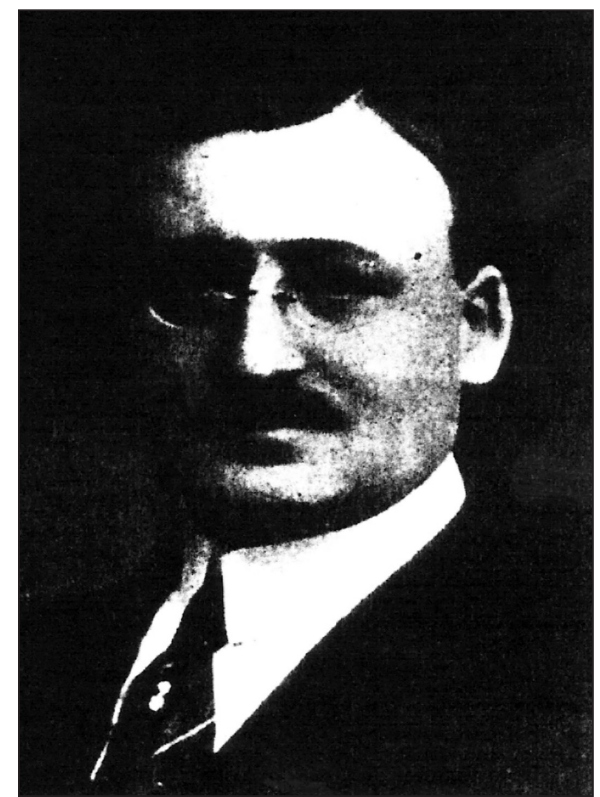

Figura 13. Foto de Pagés (a).

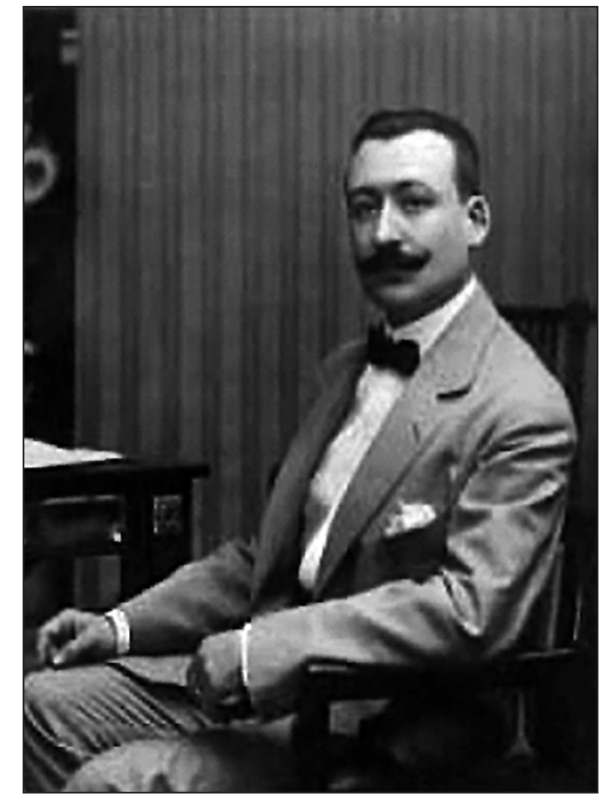

Figura 14. Foto de Pagés (b).

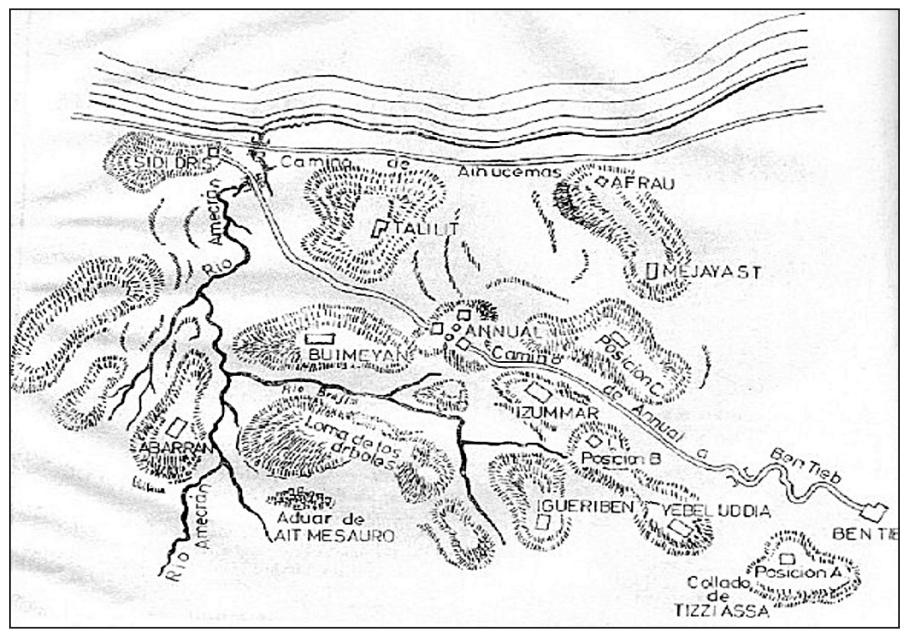

Foto 15. Croquis de la zona de Annual (1921).

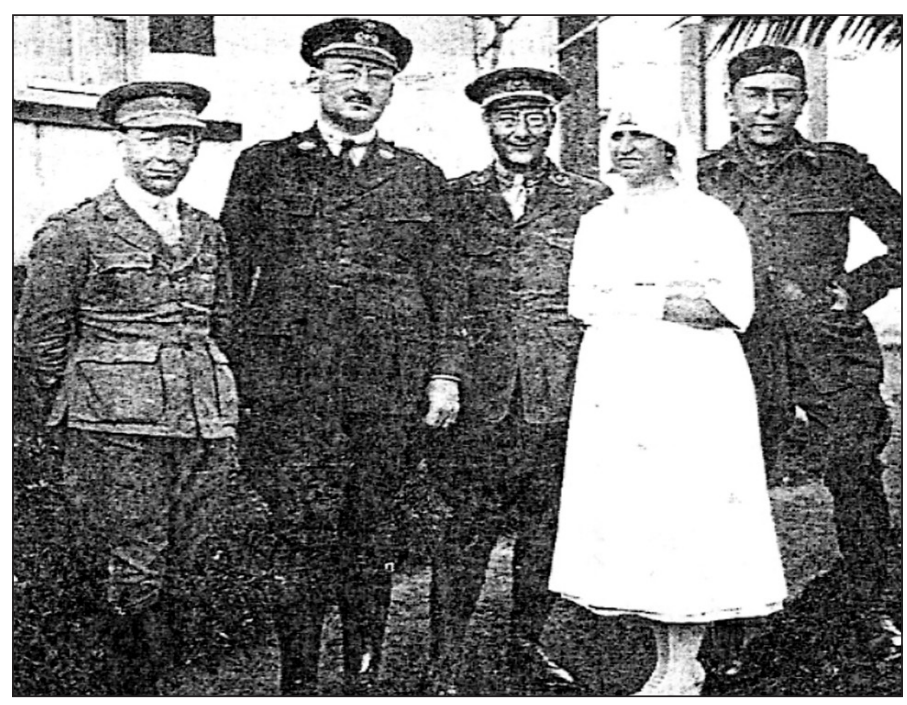

Figura 17. Pagés en el hospital Docker (Melilla 1921).

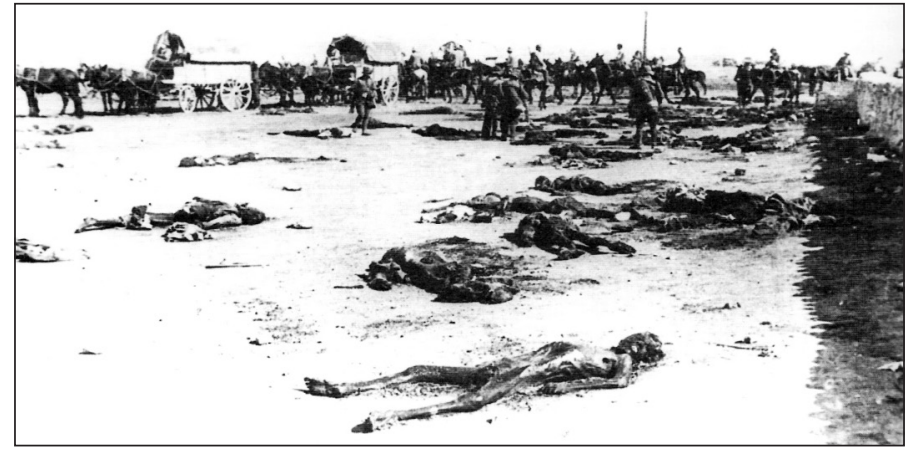

Figura 16. Imagen de Monte Arruit.

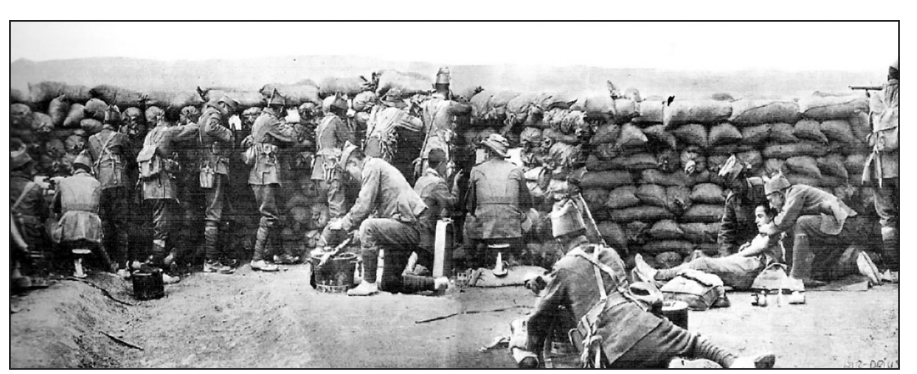

Figura 18. Tropas españolas parapetadas (1921).

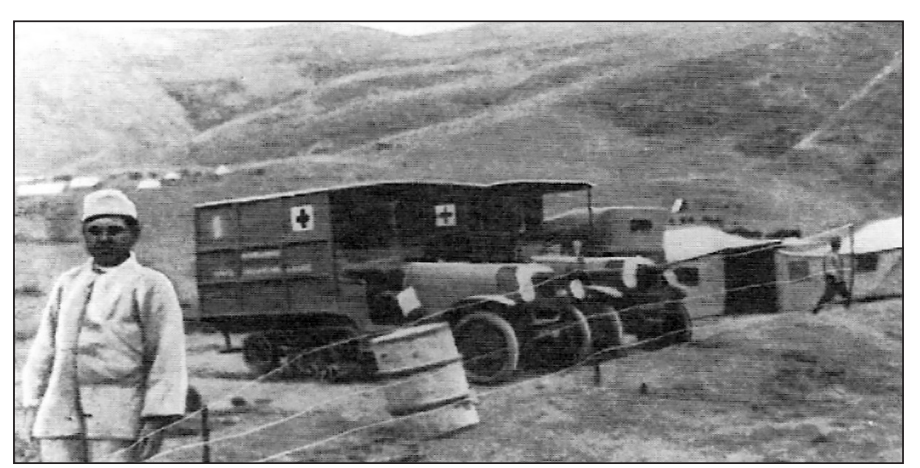

Figura 19. Ambulancias (1921). 


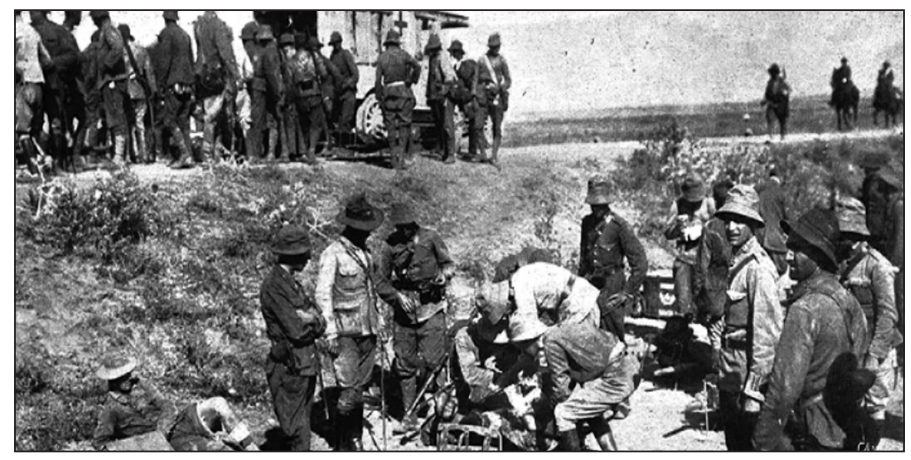

Figura 20. Evacuación sanitaria (1921).

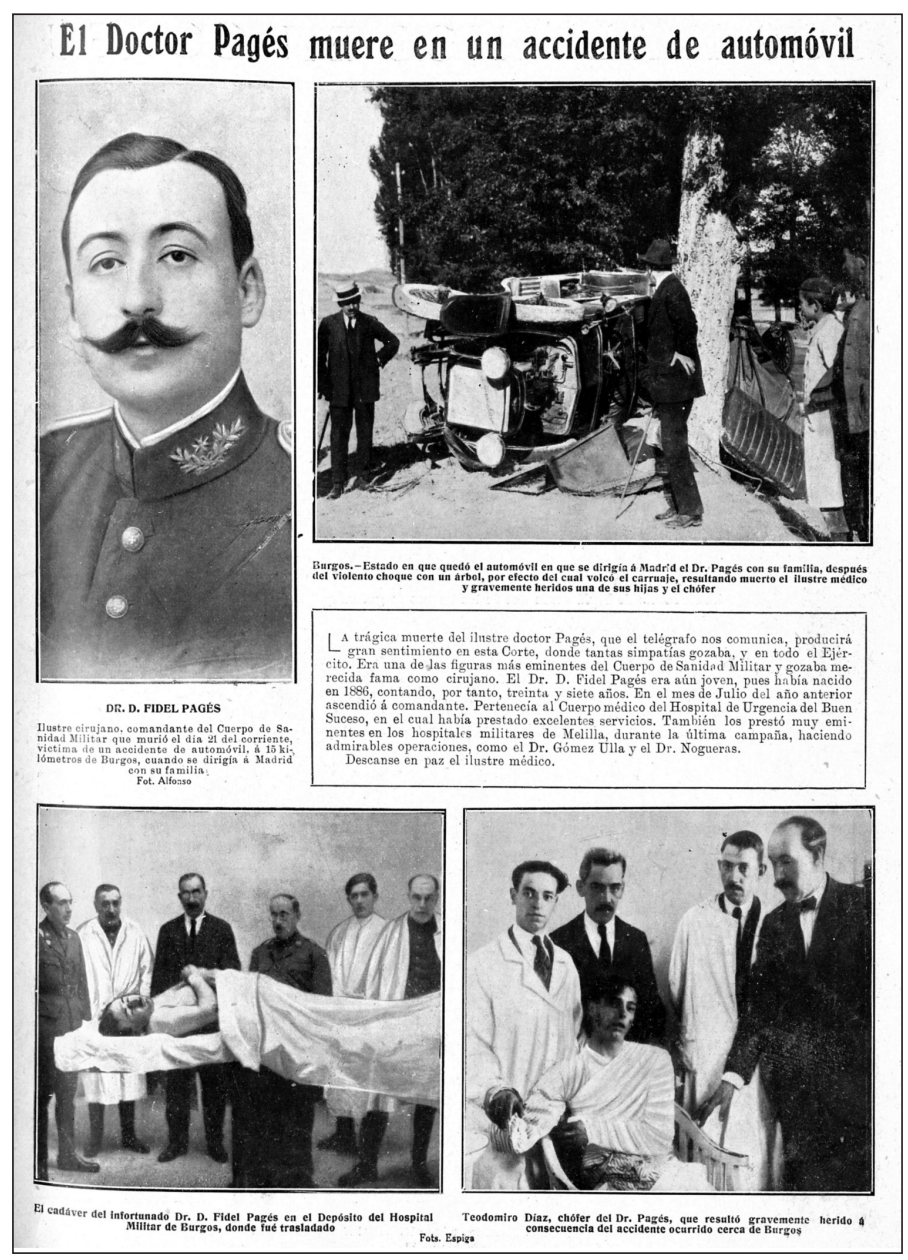

Figura 21. Mundo gráfico 26 septiembre de 1923.



Figura 22. Telegrama del Ministerio de la Guerra comunicando el fallecimiento de Pagés.

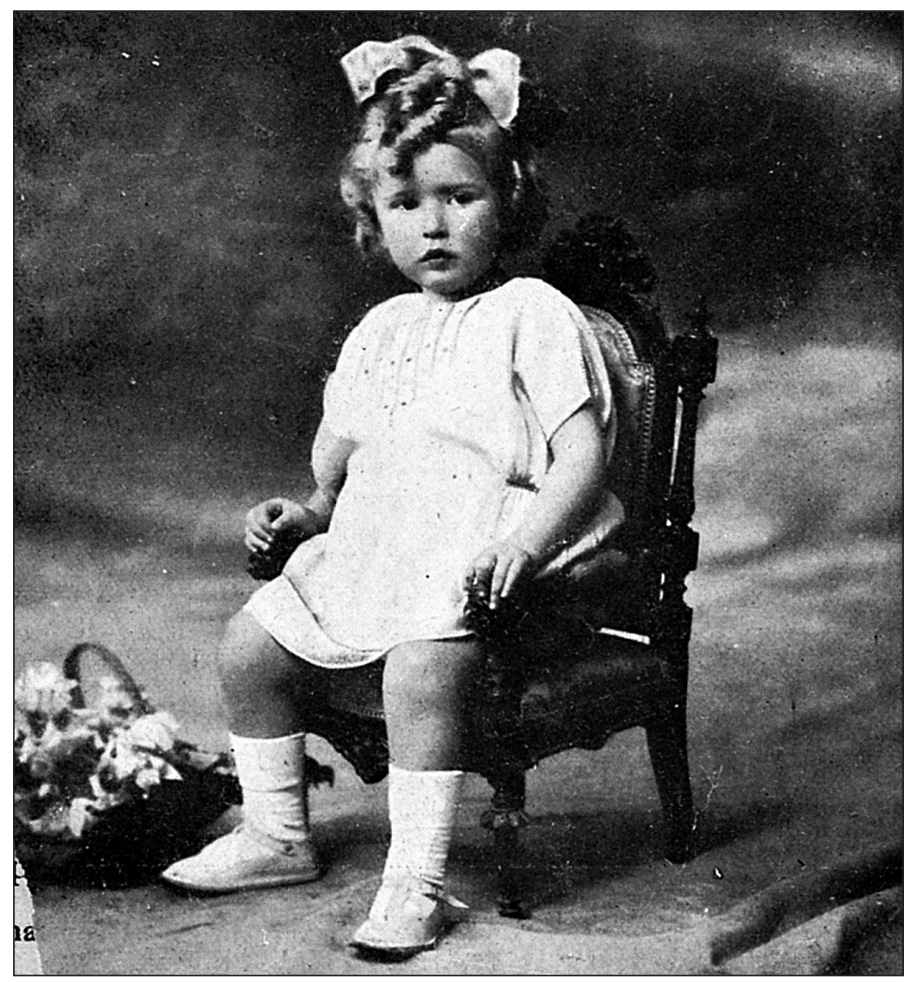

Figura 23. Foto de Asunción Pagés. En el accidente sufrió la amputación de la mano izquierda.

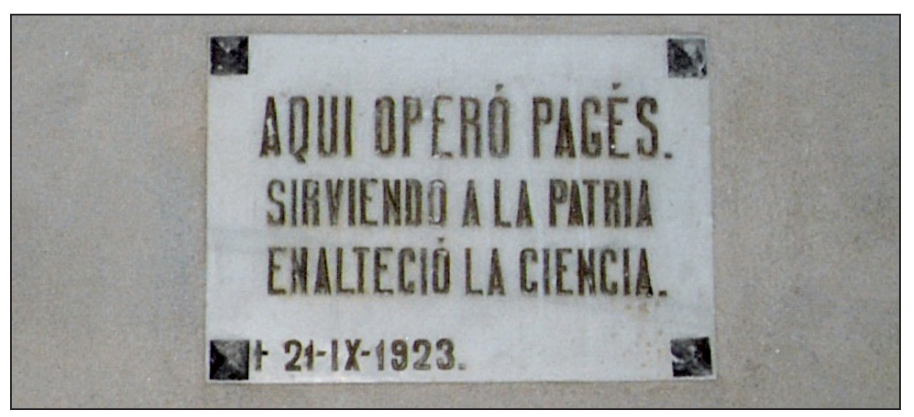

Figura 24. Placa conmemorativa colocada en el quirófano del hospital militar capitán médico Fidel Pagés.


Figura 25. Foto de Pagés (c). 